\title{
WestVirginiaUniversity
}

THE RESEARCH REPOSITORY @ WVU

Graduate Theses, Dissertations, and Problem Reports

1999

\section{Head impact characterization of generic A-pillar of an automobile}

Subramani Balasubramanyam

West Virginia University

Follow this and additional works at: https://researchrepository.wvu.edu/etd

\section{Recommended Citation}

Balasubramanyam, Subramani, "Head impact characterization of generic A-pillar of an automobile" (1999). Graduate Theses, Dissertations, and Problem Reports. 943.

https://researchrepository.wvu.edu/etd/943

This Thesis is protected by copyright and/or related rights. It has been brought to you by the The Research Repository @ WVU with permission from the rights-holder(s). You are free to use this Thesis in any way that is permitted by the copyright and related rights legislation that applies to your use. For other uses you must obtain permission from the rights-holder(s) directly, unless additional rights are indicated by a Creative Commons license in the record and/ or on the work itself. This Thesis has been accepted for inclusion in WVU Graduate Theses, Dissertations, and Problem Reports collection by an authorized administrator of The Research Repository @ WVU. For more information, please contact researchrepository@mail.wvu.edu. 


\title{
Head Impact Characterization Of
}

\section{Generic A-Pillar Of An Automobile}

\author{
Subramani Balasubramanyam
}

\begin{abstract}
Thesis submitted to the
College of Engineering and Mineral Resources

at West Virginia University

in partial fulfillment of the requirements
\end{abstract}

for the degree of

\author{
Master of Science \\ in \\ Mechanical Engineering \\ Kenneth H. Means, Ph.D. \\ Victor H. Mucino, Ph.D. \\ Nithiam T. Sivaneri, Ph.D., Chair \\ Department of Mechanical Engineering
}

Morgantown, West Virginia

1999

Keywords: hic(d),Trim Design, Mesh, Body in white(BIW)

Copyright 1999 Subramani Balasubramanyam 


\section{ABSTRACT \\ HEAD IMPACT CHARACTERIZATION \\ OF \\ GENERIC A-PILLAR OF AN AUTOMOBILE}

\section{Subramani Balasubramanyam}

The need to provide enhanced occupant protection for all impact conditions experienced in automobile crashes poses a great challenge. Several safety features such as seatbelts and airbags have been developed to reduce occupant injuries in the event of a crash. However, new studies have indicated that even with these safety features, head impact with the upper interior components have resulted in many injuries leading to fatalities in certain impact conditions such as side collision and rollover. Recent regulations imposed by NHTSA concerning head impact scenarios in automotive crashes are designed to provide maximum head impact protection against several locations on the upper interior components of the vehicle. To evaluate the head impact protection of the interior components, NHTSA introduced a performance criterion called as HIC(d) and specified it to not exceed 1000 as a result of the head impact.

Meeting these new head impact requirements while maintaining structural integrity of the vehicle necessitates a design methodology that can effectively be used in the design of safer automobiles. This research considers one of the main structural members of the vehicle that is required to provide head impact protection, viz., an A-Pillar. Using the finite element method, a generic cross-section of an A-Pillar is constructed and is used to investigate and compare the performances of aluminum and steel as structural material for meeting government head impact requirements.

For a given vehicle, estimation of stopping distance required to absorb the head impact energy is very useful during the early stages of vehicle design. This research also analyses three different types of trim designs for an A-Pillar at two different impact conditions and establishes a relationship between the stopping distance and the performance criteria, HIC(d). Further this research studies the use of plastic ribs as a countermeasure and develops a method for optimum plastic rib design. 


\section{ACKNOWLEDGEMENTS}

I would like to take this opportunity to thank my research advisor Dr. Nithi Sivaneri for all his help and guidance. His belief in my efforts and the motivation he has provided have been very inspiring to me.

I want to thank Dr. Means for being a member of my thesis committee. I would also like to thank Dr. Mucino for serving as my committee member and his help with the computer during my thesis defense.

I want to thank all the people at Hoff and Associates whom I am very proud to work with every day. I want to specifically thank Dr. Curtis J. Hoff and Mr. Joseph Formicola for their confidence and all the help they have provided to me.

I would like to extend my gratitude to Mr. Karl Luce and Lear Corporation without whose permission this research would not have been completed. I would like to also thank Dr. Dev Barpanda for his constant motivation, advice, and help that he provided in this research.

My appreciation to Mr. Andrew Blows of Jaguar Cars whose previous work was the motivation for the current research.

Finally I would like to thank my parents, my brothers, and, my wife for their motivation, support, and encouragement. 


\section{TABLE OF CONTENTS}

ABSTRACT

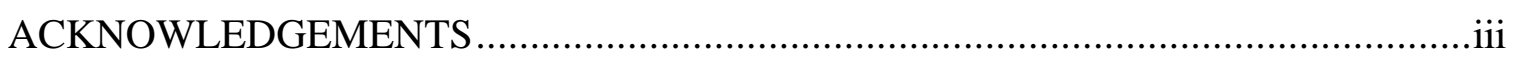

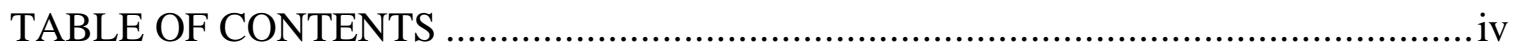

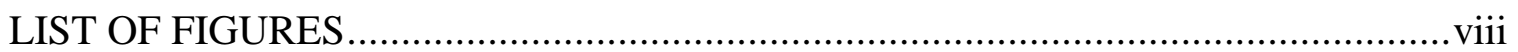

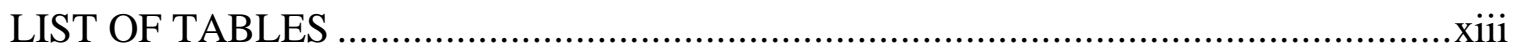

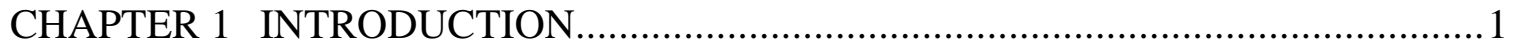

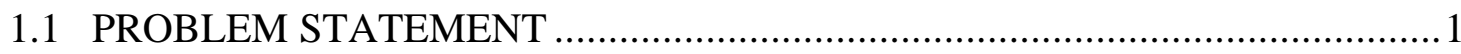

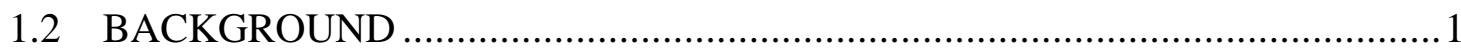

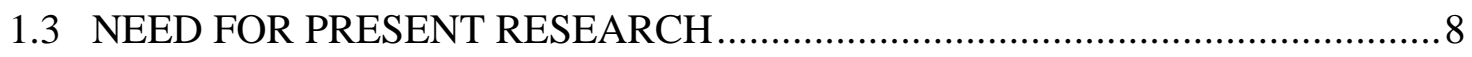

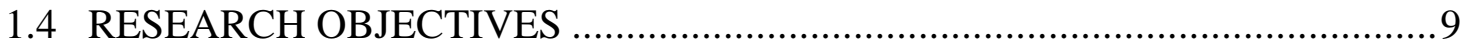

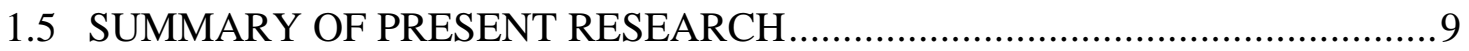

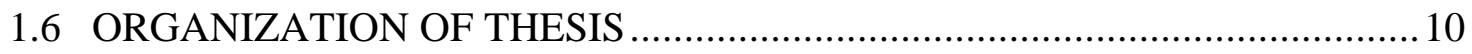

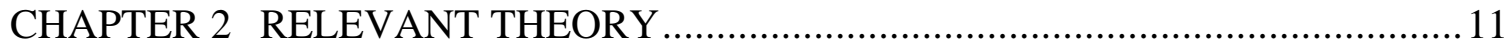

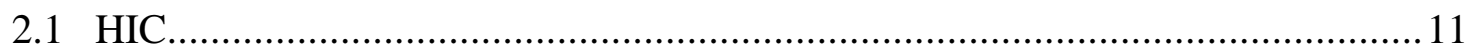

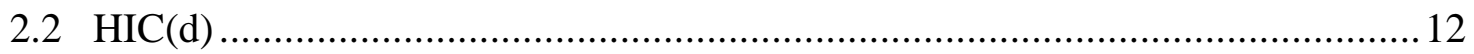

2.3 BASIC PRINCIPLES OF FINITE ELEMENT METHOD …................................13

2.3.1 EQUATION OF MOTION FOR A DYNAMIC SYSTEM ….........................13

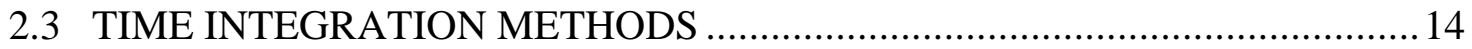

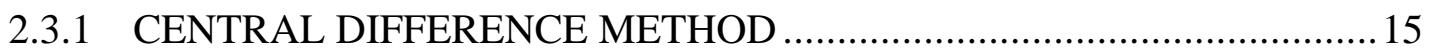

2.3.2 ADVANTAGES OF CENTRAL DIFFERENCE METHOD .......................17

2.3.3 DISADVANTAGES OF CENTRAL DIFFERENCE METHOD .................17 


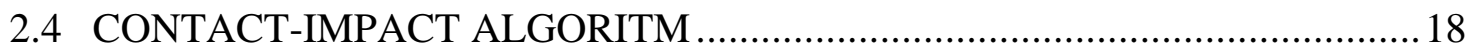

2.4.1 KINEMATIC CONSTRAINT METHOD ………...................................18

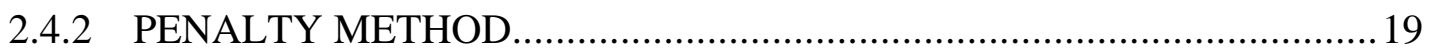

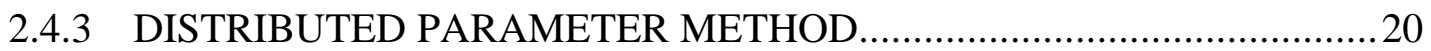

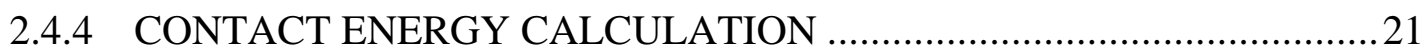

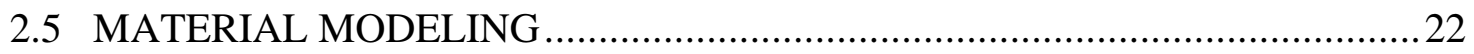

2.5.1 ELASTIC-LINEAR WORK-HARDENING MODEL …………..............22

2.5.2 DETERMINATION OF MATERIAL PROPERTIES FOR F.E.M ..............24

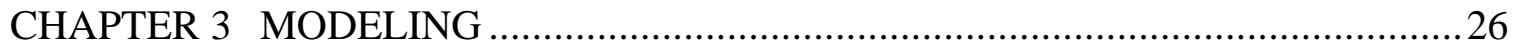

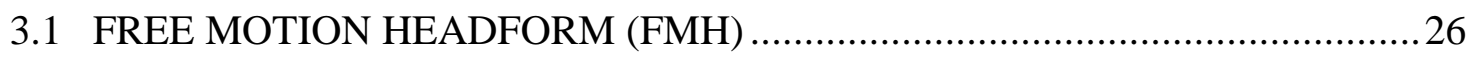

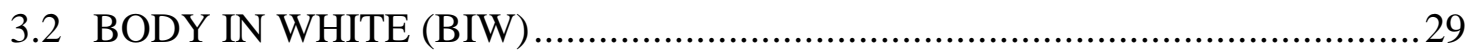

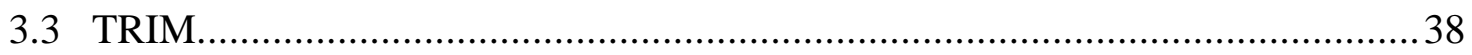

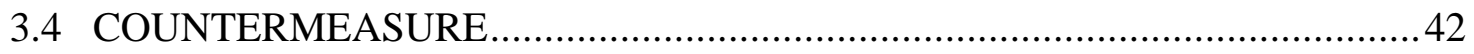

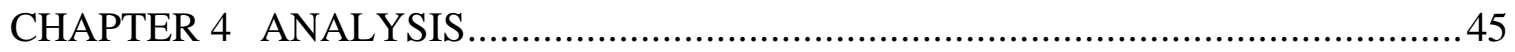

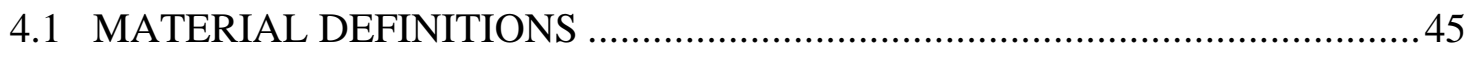

4.1.1 FREE MOTION HEADFORM (FMH) ………….................................45

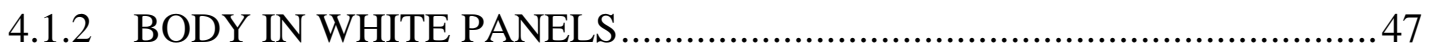

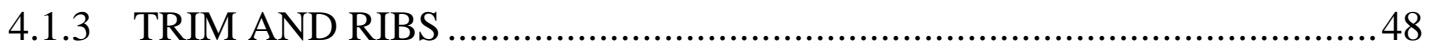

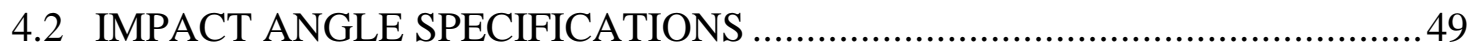

4.2.1 HORIZONTAL APPROACH ANGLE ...................................................49

4.2.2 VERTICAL APPROACH ANGLE .....................................................5

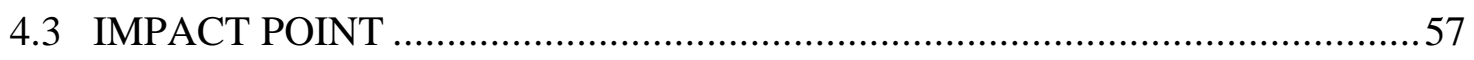

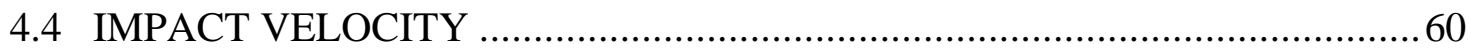




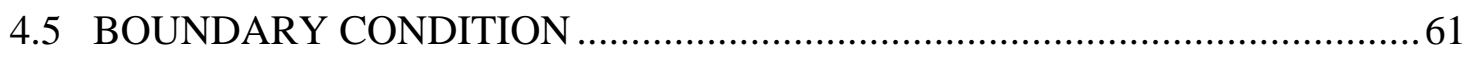

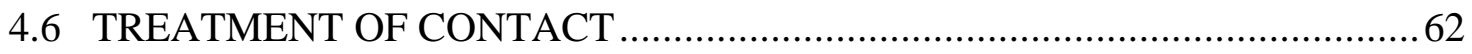

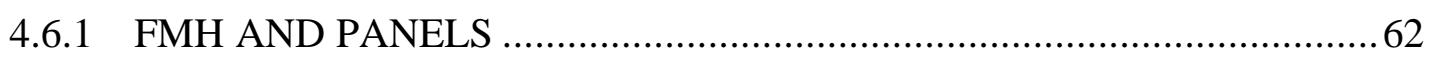

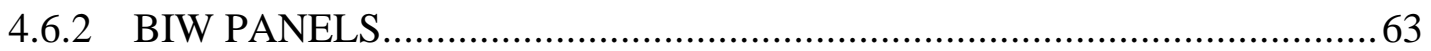

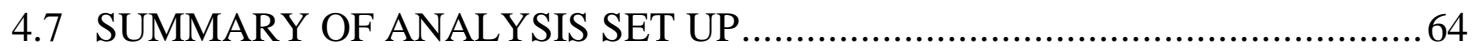

CHAPTER 5 RESULTS AND DISCUSSIONS ……………………………......65

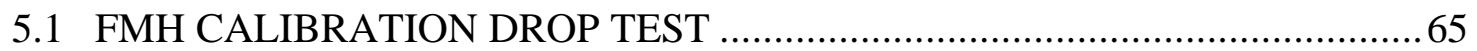

5.2 EFFECTS OF INNER PANEL MESH DENSITY ON HIC(d) ........................68

5.3 EVALUATION OF CONTACT ALGORITHMS ….........................................

5.4 BASELINE (NO TRIM) COMPARISON OF STEEL AND ALUMINUM FOR $30^{\circ}$ AND $60^{\circ}$ HORIZONTAL APPROACH ANGLE................................77

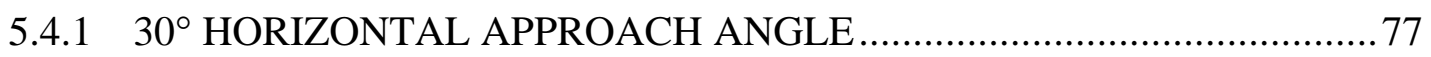

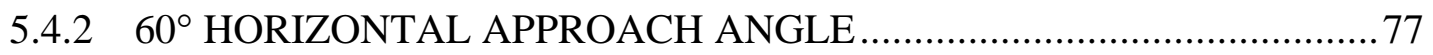

5.5 STEEL AND ALUMINUM USING TRIM DESIGN-1 (WITH AND

WITHOUT RIBS) AT $30^{\circ}$ HORIZONTAL APPROACH ANGLE....................81

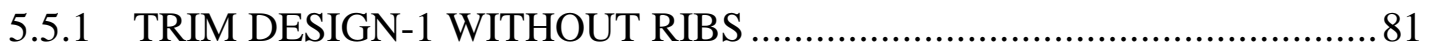

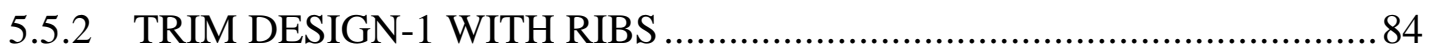

5.6 STEEL AND ALUMINUM USING TRIM DESIGN-2 (WITH AND

WITHOUT RIBS) AT $30^{\circ}$ HORIZONTAL APPROACH ANGLE....................86

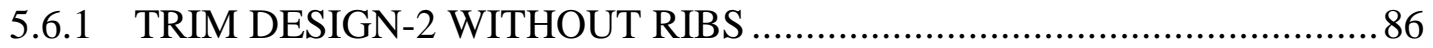

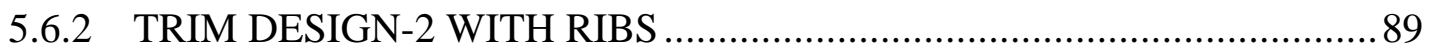

5.7 STEEL AND ALUMINUM USING TRIM DESIGN-3 (WITH 
AND WITHOUT RIBS) AT 30 HORIZONTAL APPROACH ANGLE...........91

5.7.1 TRIM DESIGN-3 WITHOUT RIBS ............................................... 91

5.7.2 TRIM DESIGN-3 WITH RIBS .................................................. 94

5.8 TRIM DESIGN-3 WITH AND WITHOUT RIBS USING ALUMINUM

AT $60^{\circ}$ HORIZONTAL IMPACT ANGLE...............................................99

5.9 OPTIMUM TRIM OFFSET ESTIMATION ............................................. 101

5.9.1 DEPENDENCE OF TRIM DESIGN VARIBLE 'A’ ON HIC(d) ............. 104

5.9.2 DEPENDENCE OF TRIM DESIGN VARIABLE 'B' ON HIC(d)........... 109

5.9.3 DEPENDENCE OF TRIM DESIGN VARIABLE 'C’ ON HIC(d)........... 113

5.10 DEPENDENCE OF RIB DESIGN VARIABLES ON HIC(d)................... 117

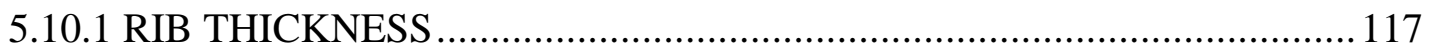

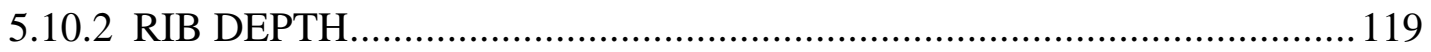

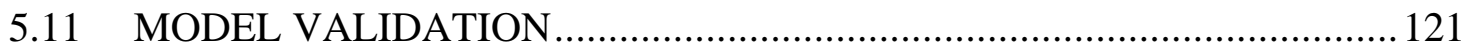

CHAPTER 6 CONCLUSIONS, CONTRIBUTIONS, and FUTURE WORK............. 122

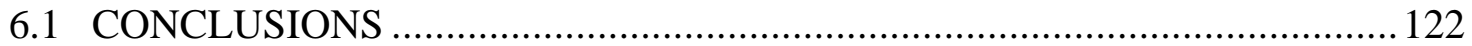

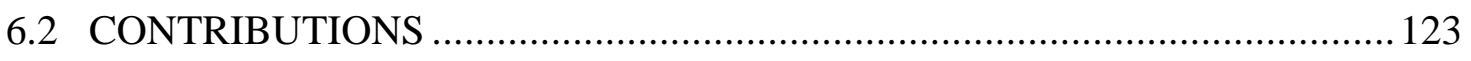

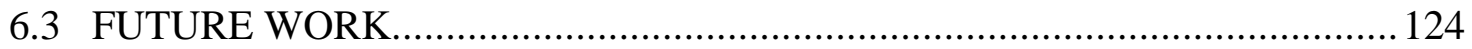

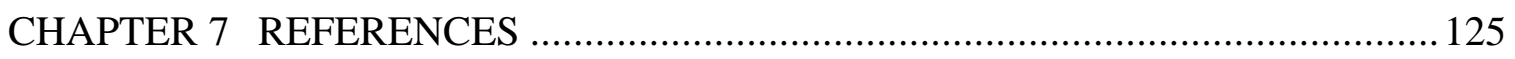

APPROVAL OF EXAMINING COMMITTEE ............................................... 128 


\section{LIST OF FIGURES}

Figure 1.1 Target locations and structural members identification ..............................

Figure 2.1 Central difference method representation ............................................ 16

Figure 2.2 Bilinear Elastic-Plastic Material Idealization ........................................23

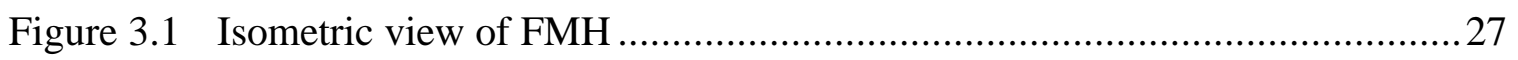

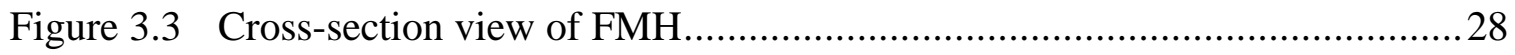

Figure 3.3 Target locations on the upper interior components of the vehicle................30

Figure 3.4 Cross section of BIW cut at AP3 target location (Section A-A) .................31

Figure 3.5a Dimensions of inner panel, thickness $=2 \mathrm{~mm}($ All dimensions in $\mathrm{mm}) \ldots \ldots . .32$

Figure 3.5b Dimensions of center panel, thickness $=1 \mathrm{~mm}($ All dimensions in $\mathrm{mm}) \ldots . .32$

Figure 3.5c Dimensions of outer panel, thickness $=1 \mathrm{~mm}($ All dimensions in $\mathrm{mm}) \ldots \ldots .32$

Figure 3.6 a) Coarse mesh of inner panel $\quad$ b) Finer mesh of inner panel ..................34

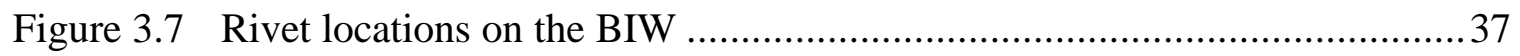

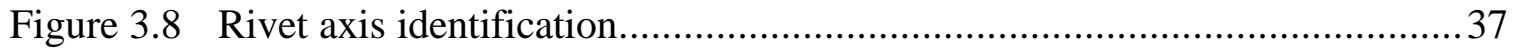

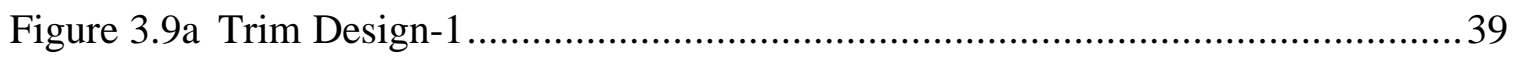

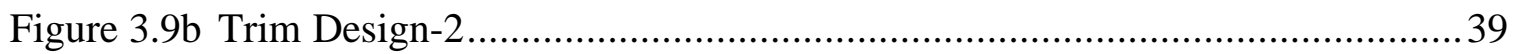

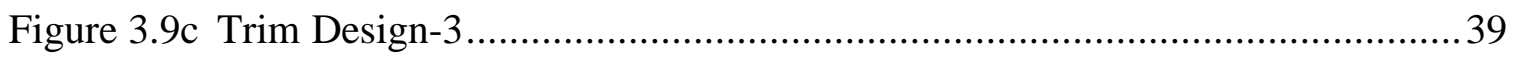

Figure 3.10 Isometric view of trim design to show clips and clip housing ..................41

Figure 3.11 Side view of Trim Design-1 showing impact point on trim .....................41

Figure 3.12 Trim Design-1 with ribs as a countermeasure .....................................43

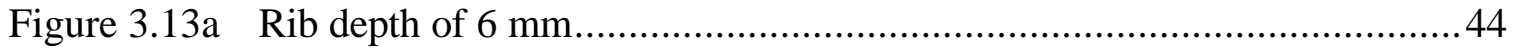

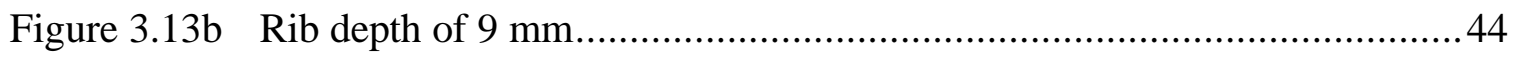




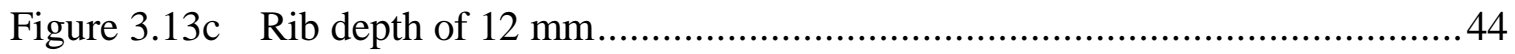

Figure 4.1 Determination of horizontal approach angles for an A-Pillar .....................50

Figure4.2a $30^{0}$ Horizontal approach angle set up ...............................................52

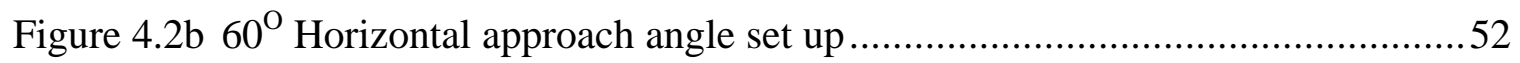

Figure4.3a $30^{0}$ Horizontal approach angle set up for Trim Design-1 ........................53

Figure 4.3b $30^{\circ}$ Horizontal approach angle set up for Trim Design-2 .........................53

Figure4.3c $30^{0}$ Horizontal Approach Angle Set Up for Trim Design-3.......................53

Figure 4.4 Determination of vertical approach angle for an A-Pillar ...........................55

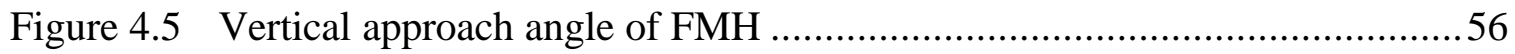

Figure 4.6 Determination of target point for AP3 on the A-Pillar............................58

Figure 4.7 Target point used in current research ...........................................5

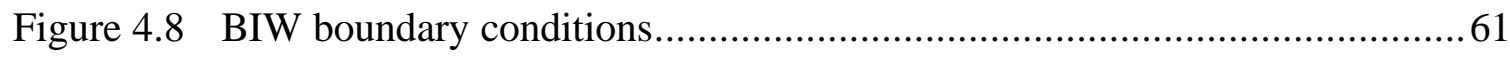

Figure 4.9 Flow chart of analyses setup for both steel and aluminum ......................... 64

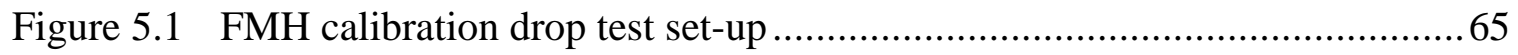

Figure 5.2 Peak resultant acceleration of FMH for calibration drop test....................67

Figure 5.3 Coarse vs fine mesh of inner panel for $30^{\circ}$ horizontal angle .....................69

Figure 5.4a Deformation plot at $3.5 \mathrm{~ms}$ using coarse mesh on the inner panel ..............70

Figure 5.4b Deformation plot at $3.5 \mathrm{~ms}$ using fine mesh on the inner panel ..................70

Figure 5.5 Sectional plane at point of first contact .......................................... 72

Figure 5.6 Baseline impact at $30^{\circ}$ horizontal approach angle ................................. 73

Figure 5.7 Effects of thickness consideration in contact algorithm........................... 75

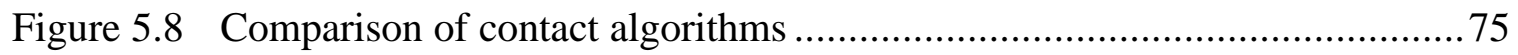


Figure 5.9 Steel vs aluminum for $30^{\circ}$ horizontal approach angle .78

Figure 5.10 Steel vs aluminum for $60^{\circ}$ horizontal approach angle ............................ 78

Figure 5.11 Transient plot for $60^{\circ}$ horizontal approach angle ................................ 80

Figure 5.12 Steel and aluminum using Trim Design-1 (without ribs) at

$30^{\circ}$ horizontal Angle................................................................. 82

Figure 5.13 Transient plots of steel using Trim Design-1 (without ribs) at

$30^{\circ}$ horizontal approach angle.

Figure 5.14 Steel and aluminum using Trim Design-1 (with Ribs) at

$30^{\circ}$ horizontal approach angle..

Figure 5.15 Steel and aluminum using Trim Design-2 (without ribs) at

$30^{\circ}$ horizontal approach angle 87

Figure 5.16 Transient plots of steel using Trim Design-2 (without ribs) at $30^{\circ}$ horizontal approach angle .88

Figure 5.17 Steel and aluminum using Trim Design-2 (with ribs) at $30^{\circ}$ horizontal approach angle .90

Figure 5.18 Steel and aluminum using Trim Design-3 (without ribs) at $30^{\circ}$ horizontal approach Angle 92

Figure 5.19 Transient plots of steel using Trim Design-3 (without ribs) at $30^{\circ}$ horizontal approach angle

Figure 5.20 Steel and aluminum using Trim Design-3 (with ribs) at $30^{\circ}$ Horizontal approach angle 95 
Figure 5.21 Trim Design-1, 2, and 3 (without ribs) using aluminum at $30^{\circ}$ horizontal approach angle

Figure 5.22 Trim Design-1, 2, and 3 (without ribs) using steel at $30^{\circ}$ horizontal approach angle

Figure 5.23 Trim Design-1, 2, and 3 (with ribs) using aluminum at $30^{\circ}$ horizontal approach angle 98

Figure 5.24 Trim Design-1, 2, and 3 (with Ribs) using steel at $30^{\circ}$ horizontal approach angle .98

Figure 5.25 Transient plots of Trim Design-3 using aluminum at $60^{\circ}$ horizontal approach angle 100

Figure 5.26 Trim design variables definitions 102

Figure 5.27 $\mathrm{HIC}(\mathrm{d})$ vs design variable 'A' using steel at $30^{\circ}$ horizontal approach angle (without ribs)

Figure $5.28 \mathrm{HIC}(\mathrm{d})$ vs design variable 'A' using aluminum at $30^{\circ}$ horizontal approach angle (without ribs). 106

Figure 5.29 Percentage reduction in $\mathrm{HIC}(\mathrm{d})$ vs design variable ' $\mathrm{A}$ ' using steel at $30^{\circ}$ horizontal approach angle (without ribs) 106

Figure 5.30 Percentage reduction in $\mathrm{HIC}(\mathrm{d})$ vs design variable 'A' using aluminum at $30^{\circ}$ horizontal approach angle (without ribs) 107

Figure 5.31 Percentage reduction in $\mathrm{HIC}(\mathrm{d})$ vs design variable 'A' using aluminum at $30^{\circ}$ horizontal approach angle (with ribs) 108 
Figure 5.32 Percentage reduction in $\mathrm{HIC}(\mathrm{d})$ vs design variable 'A' using aluminum at $30^{\circ}$ horizontal approach angle (with ribs) 108

Figure 5.33 Percentage reduction in $\mathrm{HIC}(\mathrm{d})$ vs design variable ' $\mathrm{B}$ ' using steel at $30^{\circ}$ horizontal approach angle (wthout ribs)

Figure 5.34 Percentage reduction in $\mathrm{HIC}(\mathrm{d})$ vs design variable 'B' using aluminum at $30^{\circ}$ horizontal approach angle (without ribs)

Figure 5.35 Percentage reduction in $\mathrm{HIC}(\mathrm{d})$ vs design variable ' $\mathrm{B}$ ' using steel at $30^{\circ}$ horizontal approach angle (with ribs)

Figure 5.36 Percentage reduction in $\mathrm{HIC}(\mathrm{d})$ vs design variable ' $\mathrm{B}$ ' using aluminum at $30^{\circ}$ horizontal approach angle (with ribs)

Figure 5.37 Percentage reduction in $\mathrm{HIC}(\mathrm{d})$ vs design variable ' $\mathrm{C}$ ' using steel at $30^{\circ}$ horizontal approach angle (without ribs)

Figure 5.38 Percentage reduction in $\mathrm{HIC}(\mathrm{d})$ vs design variable ' $\mathrm{C}$ ' using steel at $30^{\circ}$ horizontal approach angle (with ribs) 115

Figure 5.39 Percentage reduction in $\mathrm{HIC}(\mathrm{d})$ vs design variable 'C' using aluminum at $30^{\circ}$ horizontal approach angle (without ribs) 116

Figure 5.40 Percentage reduction in $\mathrm{HIC}(\mathrm{d})$ vs design variable 'C' using aluminum at $30^{\circ}$ horizontal approach angle (without ribs) 116

Figure 5.41 Rib thickness vs $\mathrm{HIC}(\mathrm{d})$ for $60^{\circ}$ horizontal approach angle 118

Figure 5.42 Rib thickness vs HIC(d) for $30^{\circ}$ horizontal approach angle 118

Figure 5.43 Rib depth vs HIC(d) for $60^{\circ}$ horizontal approach angle 120

Figure 5.44 Rib depth vs HIC(d) for $30^{\circ}$ horizontal approach angle 120 


\section{LIST OF TABLES}

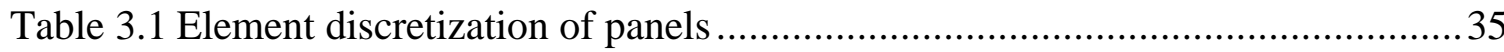

Table 4.1 Material properties of rigid inner skull of FMH [FTSS (1998)] ......................45

Table 4.2 Rubber skin material properties of FMH [FTSS (1998)]..............................46

Table 4.3 Material properties of steel and aluminum..............................................4

Table 4.4 Properties of PC/ABS [Sherman et al. (1995)] ...............................................48

Table 5.1 Trim design variable 'A' and corresponding $\mathrm{HIC}(\mathrm{d})$ for steel at $30^{\circ}$

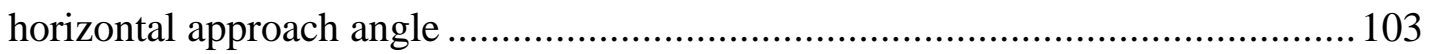

Table 5.2 Trim design variable 'A' and corresponding HIC(d) for aluminum at $30^{\circ}$ horizontal approach angle 103

Table 5.3 Trim design variable ' $\mathrm{B}$ ' and corresponding $\mathrm{HIC}(\mathrm{d})$ for steel at $30^{\circ}$ horizontal approach angle 110

Table 5.4 Trim design variable ' $\mathrm{B}$ ' and corresponding HIC(d) for aluminum at $30^{\circ}$ horizontal approach angle 110

Table 5.5 Trim design variable ' $\mathrm{C}$ ' and corresponding $\mathrm{HIC}(\mathrm{d})$ for steel at $30^{\circ}$ horizontal approach angle 114

Table 5.6 Trim design variable ' $\mathrm{C}$ ' and corresponding $\mathrm{HIC}(\mathrm{d})$ for aluminum at $30^{\circ}$ horizontal approach angle 114 


\section{CHAPTER 1 INTRODUCTION}

\subsection{PROBLEM STATEMENT}

Head injuries caused due to occupant's head striking the upper interior structures of the vehicle is a major concern in the automotive industry. Studies have shown that even with several safety standards, head impact related injuries during a crash are responsible for several fatalities. To address this concern, the National Highway Traffic Safety Administration (NHTSA) introduced a regulation that focuses on providing head impact protection in relation to all the upper interior components. Designing upper interior components to meet the regulation requires efficient design of these components while maintaining structural integrity of the vehicle. A general methodology is needed to effectively design the upper interior components to meet the head impact safety standards.

\subsection{BACKGROUND}

In August 1995, NHTSA estimated that even with seat belts and air bags installed in all cars and Light Transport Vehicles (LTV's), head impact with the pillars, roof side rails, windshield header, and rear header resulted in an average of 1,591 annual passenger car occupant fatalities and 575 annual LTV occupant fatalities [Kanianthra (1995)]. In addition to these estimates NTHSA believes that such head impact also results in nearly 13,600 moderate to critical (but non-fatal) passenger car occupant injuries and more than 5,200 serious LTV occupant injuries. 
Federal Motor Vehicle Safety Standard (FMVSS) 201 focuses on the requirement related to head impacts against the interior components of the automobile during a crash. Earlier head impact requirements were focused on providing protection for a few crash events where the head would impact the instrument panel, steering wheel and the rear of the seat. To meet these requirements, seat belts and other protection systems such as airbags were introduced to provide occupant protection in cases such as full-frontal and rearward impact conditions. However, head injuries were still caused due the occupant head striking the upper interior components during side impacts and rollover conditions. Amendments to FMVSS 201 in August 1995 final rule now requires impact protection of the occupant's head against the upper interior components such as side rail, pillars, front and rear headers, for all vehicles weighing 10,000 pounds or less [NHTSA, Standard No 201 (1995)]. This amendment significantly expands the scope of standard 201 and adds new procedures and performance requirements for a new vehicle component test.

Target points specified on the upper interior components of the vehicle and some of the main components such as A-Pillar, B-Pillar, Rear Header, Front Header, and Side Rails are shown in Figure 1.1. To completely identify these members is a vehicle, NHTSA has defined each of the components as follows: The term A-Pillar is used for any pillar that is entirely forward of a transverse vertical plane passing though the seating reference point of the driver's seat. B-Pillar is the pillar that is just rearward to the APillar and rearward to the seating reference point of the driver's seat. Front header is the structural member that connects the A-Pillars. Rear header is the structural member that connects the rearmost pillars of the vehicle. Side rail connects the A-Pillar and B-Pillar and any other pillar rearward to B-Pillar along one side of the vehicle. The term 'trim' is 
used for the components that conceal the body in white (BIW) pillars. The clearance provided between the trim and the BIW pillar is referred as trim-offset. An upper interior

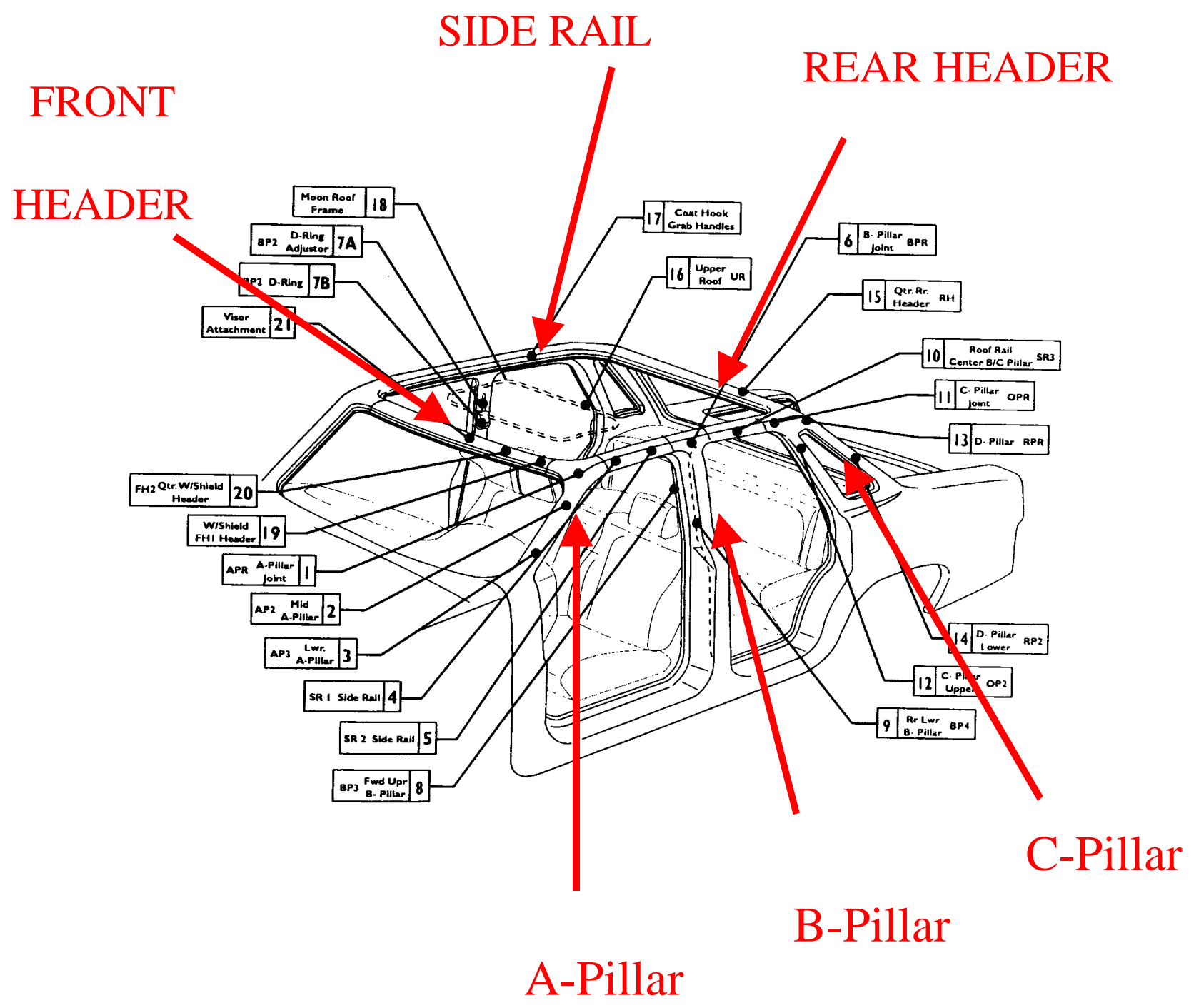

Figure 1.1 Target locations and structural members identification 
having a greater trim-offset will provide greater stopping distance for the impact thereby reducing the peak acceleration for head impact resulting in lower HIC(d). However the need to increase interior space for the passengers induces the interior component designers to determine the optimum trim offset, which meets head impact requirements and provides maximum interior space.

The need to test the vehicle at the NHTSA specified target locations for head impact protection requires the use of a head model that would accurately represent the human head in an impact. Biofidelity is defined as a measure of how well a test device duplicates the responses of a human being in an impact. In a drop testing procedure to evaluate the biofidelity of the test device, the response of Free Motion Headform (FMH), head of a Hybrid III dummy, showed similar behavior when compared with human body. FMH is now recognized by NHTSA as a test device that can be used to test the interior components of the vehicle to evaluate the head injury criterion (HIC).

HIC is a mathematical expression that defines the severity of impact to the head. It is a function of resultant acceleration of the dummy and any two-time points in the acceleration curve between which the maximum value of HIC is determined. Since only the FMH is used during the testing process, HIC needs to be converted to a dummy equivalent value called as HIC (d). NHTSA specifies that the HIC(d) of the FMH should not exceed 1000 for the vehicle upper interior to be considered as providing head impact protection under FMVSS 201.

The resultant acceleration pulse of the FMH, and likewise the HIC(d) value, are affected by the impact velocity, available headform stopping distance (S), and the BIW 
deformation [Lim et al. (1995)]. The impact velocity of FMH specified by NHTSA is either $12 \mathrm{mph}$ or $15 \mathrm{mph}$, depending on the target location on the upper interior. The head impact requirement includes approximately 30 target points on the upper interior components that need to provide head impact protection. Some auto manufacturers have included side airbags in the vehicles that are designed to deploy in case of a side impact or rollover impact conditions. If the target location specified by NHTSA is within the airbag covering area in its fully deployed state, the vehicle is tested at $12 \mathrm{mph}$ and all other target locations are tested at $15 \mathrm{mph}$.

The stopping distance, $S$, is governed by the design of the upper interior components and local deformation at the impact area. Main factors causing local deformation are BIW sheet metal deformation, countermeasures (foam padding and plastic ribs) and plastic trim deformations. In an effort to achieve a lower HIC(d) value, a number of thermoplastics for the interior components are being used. Some of the thermoplastics are: Polypropylene (PP), Acrylonitrile/ Butadiene/ Styrene terpolymer (ABS), Thermoplastic Olefin (TPO), Polycarbonate (PC), PC/ABS blends, PP/PS blends and Styrene/Maleic Anhydride (SMA) copolymers. In a recent paper [Traugott and Maurer (1998)], a new ductile, heat resistant ABS resin for energy management applications was presented that not only had good impact characteristics but also showed good improvement in appearance and manufacturing capability.

To provide maximum interior space while providing head impact protection, a relationship between $\mathrm{HIC}(\mathrm{d})$ and the FMH stopping distance $(S)$ needs to be established so as to determine the optimum clearance between the trim and BIW. Chou and Nyquist [(1974)] conducted a numerical study on HIC and found that acceleration of the FMH is 
same at the two time limits between which the maximum value of HIC is calculated. For a given maximum acceleration, they calculated HIC for idealized acceleration pulses such as half sine, triangular, trapezoidal, and square pulses and estimated the required stopping distance for the given acceleration pulse. Continuing the effort of establishing practical relationship between HIC and stopping distance [Lim et al. (1995)], detailed method of determining the waveform efficiency for a given pulse and estimated HIC for generic pulses such as square and haversine waveforms. They developed a generic waveform concept to estimate the stopping distance by determining the pulse characteristic constants and waveform efficiency of a given acceleration pulse. This was concluded to be applicable to most perpendicular impacts $\left(90^{\circ}\right)$, which would result in a haversine response of the FMH. In most head impact conditions, the acceleration pulses of the FMH does not follow generic pulses and are highly nonlinear depending of the target point specified by NHTSA. Therefore these methodologies developed based on generic pulses cannot be applied in real world head impact conditions. This creates a need to develop an efficient design methodology that can be used to estimate the required stopping distance that is based on vehicle dependent acceleration pulses of the FMH. The present research will focus on one of the main components, viz., A-Pillar and will establish the relationship between the HIC(d) and the stopping distance which can be used to estimated the trim offset based on the required HIC(d).

Inclusion of countermeasures in establishing relationship between the performance criteria $\mathrm{HIC}(\mathrm{d})$ and stopping distance, $S$, is very important to estimate the trim offset that incorporates a particular type of countermeasure as a design solution. In a paper by Rychlewski [(1998)], a matrix listing several possible countermeasures 
applicable to specific region of impact on the upper interior components of a vehicle has been presented. For an A-Pillar it presents a general approach which is to either build an integrated trim piece that provides suitable impact properties or to use a trim that is backed by some other energy absorbing mechanism (countermeasure). Among countermeasures, foam padding and innovative designs of plastic rib structures are used to complement the trim design. Use of the advance plastics and different types of countermeasures have been employed to aid the trim designs [Gandhi, Lorenzo and Noritake, (1997)] and are solely directed towards 'softening' the impact for achieving a lesser severity blow to the head.

Material properties of thermoplastics are strongly influenced by both the strain rate and the temperature of the specimen [Walley and Field (1994)]. As a result of this, there has been increasing need to obtain high strain rate properties of plastics that can be used in numerical material models. Sawas and Brar [(1998)] of University of Dayton Research Institute (UDRI) presented a testing method that utilizes an all polymeric split Hopkinson bar to achieve dynamic characterization of compliant materials. This method was found to be an improved technique over other methods to characterize high strain rate mechanical behavior of wide range of plastics. A study on energy absorbing mechanism of plastic ribs [Arimoto et al. (1998)] was performed by including high strain rate material properties of the trim material at different strain rates. Using high strain rate material properties, simulation involving the energy absorption of plastic ribs was found to correlate well with the test results. 


\subsection{NEED FOR PRESENT RESEARCH}

For the BIW of the vehicle, steel has been the material of choice for many years. However the percentage of non-steel components in an automobile has been increasing in recent years to meet the Corporate Average Fuel Economy (CAFÉ) standards. Failure of automotive companies to meet these standards would result in high fines $(\$ 0.50$ per vehicle sold per mile per gallon over the imposed standard) [Crandall and Graham (1989)]. Aluminum has been replacing steel for lighter and more fuel-efficient automobiles. Aluminum exhibits good ductility behavior that enables it to be designed to absorb energy in a controlled manner in the plastic range. When compared to commonly used mild steel, the advantage of using aluminum is that the mass density is only onethird of that of steel and the yield stress can be quite close to that of steel. Previous work has been performed in designing aluminum made energy absorbing rails that met the target load-deflection and crush characteristics when compared to steel [Lakshminarayanan et al. (1995)]. All the existing work compares the performance of aluminum and steel for impact conditions not involving head impacts. This proposed research would establish a comparison between these two materials under FMVSS 201 conditions.

The methodologies developed so far do not consider the inclusion of countermeasures, which are normally used to enhance the energy absorption capacity of trim components. Efficient utilization of countermeasures could result in lower HIC(d) resulting in a reduced trim offset requirement and providing maximum interior space for the passengers. This present research will consider plastic ribs as a countermeasure and 
will establish the required trim offset for a given $\mathrm{HIC}(\mathrm{d})$. In addition to this, a relationship between rib design variables and $\mathrm{HIC}(\mathrm{d})$ will be determined for optimum design of plastic ribs in conjunction with the trim.

\subsection{RESEARCH OBJECTIVES}

This research investigates and compares the performance of aluminum with steel as BIW material for FMVSS 201 impact conditions. An attempt will also be made to develop a general methodology to design and analyze interior components using the finite element analysis. The objectives of this research are

(i) Develop a generic A-Pillar BIW cross section.

(ii) Analyze an A-Pillar BIW cross section under FMH impact conditions based on generic steel and aluminum properties and quantify HIC(d) response

(iii) Develop, analyze and compare three different A-Pillar trim designs.

(iv) Develop, analyze and study the effects of ribs as a counter-measure.

\subsection{SUMMARY OF PRESENT RESEARCH}

In this research, head impact performance of aluminum is evaluated against steel. After this baseline (no trim) performance is determined, three different trim designs are evaluated to develop a relationship between trim design variables and the corresponding performance criteria, HIC(d). This is intended to enable estimation of trim offsets for a given vehicle BIW. Further, this research studies the dependence of HIC(d) on ribs as a countermeasure and on rib design variables such as rib depth and rib thickness. 


\subsection{ORGANIZATION OF THESIS}

In Chapter 2, a brief discussion of the significance of HIC and HIC(d) is included to understand the performance criteria for FMVSS 201. Also basic principles of finite element method used in the present research is discussed.

In Chapter 3, the finite element model of the FMH, generic A-Pillar BIW crosssection, three different trim designs, and plastic ribs are described.

In Chapter 4, analysis set up of FMVSS 201 used in the present research along the material properties of BIW and trim is detailed.

In Chapter 5, results of the various analysis performed are described in detail.

In Chapter 6, conclusions obtained from the present research along with the design methodology established to estimate the trim offset is discussed. Brief listing of future work is also included. 


\section{CHAPTER 2 RELEVANT THEORY}

\subsection{HIC}

The head injury criterion (HIC) is an analytical tool that is currently recognized by the U.S. Department of Transportation to determine if the blow to the head exceeds the maximum tolerable severity threshold. It is an acceleration-profile-based criterion that requires the time history of the magnitude of the linear acceleration of the center of gravity of the head for the duration of impact.

HIC evolved from a weighted impulse criterion called as the Gadd Severity Index (GSI) [Gadd (1966)]. GSI was basically developed to enable a quantitative method of comparing head impacts to biomechanical tolerance data provided in a literature called as the Wayne Tolerance Curve [Patrick, Lissner, and Gurkjian, (1963)]. GSI is defined by the equation,

$$
G S I=\int_{t_{\text {begin }}}^{t_{\text {end }}} a(t)^{2.5} d t
$$

where:

$a(t)=$ acceleration magnitude, g's

$t \quad=\quad$ time, seconds

and the limits of integration $t_{\text {begin }}$ and $t_{\text {end }}$ are the times at the onset and end of the impact respectively. Since the acceleration is weighted by the exponent 2.5 , high accelerations 
for short time duration will contribute more to the integral than low accelerations for extended time duration.

From this criterion, HIC has evolved and is defined mathematically by the expression,

$$
H I C=\left(t_{2}-t_{1}\right)\left[\frac{1}{t_{2}-t_{1}} \int_{t_{1}}^{t_{2}} a(t) d t\right]^{2.5} \mid \max \text { imum }
$$

where:

$a(t)=$ magnitude of resultant acceleration at head center of gravity in g's

$t_{1}$ and $t_{2}=\quad$ two points in time measured in seconds during the impact which maximizes HIC.

HIC is based on the acceleration of the head center of gravity when the complete dummy is considered in the tests. However in evaluating head impact protection, only the FMH (head model of hybrid III dummy) is used and therefore a new method of determining a dummy equivalent criterion, $\mathrm{HIC}(\mathrm{d})$, for the FMH was developed. This is discussed in the next section.

\section{$2.2 \quad \mathrm{HIC}(\mathrm{d})$}

HIC(d) was basically developed to relate the HIC obtained using only a FMH to a dummy equivalent number. This dummy equivalent number, $\mathrm{HIC}(\mathrm{d})$ is expressed in terms of HIC by the following equation [Amori et al. (1995)]. 


$$
\mathrm{HIC}(\mathrm{d})=166.4+0.75466(\mathrm{HIC})
$$

As it can be seen only about $75 \%$ of HIC is considered and a constant, 166.4 , is added to get the dummy equivalent number. NHTSA specifies that the HIC(d) value should not exceed 1000 when the FMH is used to evaluate the head impact protection of the upper interior components.

\subsection{BASIC PRINCIPLES OF FINITE ELEMENT METHOD}

The Finite element method is a numerical procedure for analyzing structures and continua. The Finite element method involves discretizing differential equations into simultaneous algebraic equations. The advances made in the computational efficiency of digital computers have increased the use of the finite element method as an analysis tool since large number of the equations generated by the finite element method can be solved very efficiently. Initial developments made in the finite element method involved analysis of problems related to structural mechanics. This was later applied to various other fields like heat transfer, fluid flow, lubrication, electric and magnetic fields. The analysis tool used in the present research is LSDYNA [Hallquist (1998)]. The Basic principles of finite element techniques used in this code are described below:

\subsubsection{EQUATION OF MOTION FOR A DYNAMIC SYSTEM}

The dynamical equation of motion for a single d.o.f system is

$$
m \ddot{u}+c \dot{u}+k u=p(t)
$$


The closed form solution of the above dynamic equation subjected to a harmonic loading is given by [Collatz (1950)]:

$$
u(t)=\underbrace{u_{0} \cos \omega t+\frac{u_{o}}{\omega} \sin \omega t}_{\text {hom ogenous solution }}+\underbrace{\frac{p_{O}}{k\left(1-\beta^{2}\right)}(\sin \bar{\omega} t-\beta \sin \omega t)}_{\text {particular solution }}
$$

where,

$$
\begin{aligned}
& u_{O}=\text { initial displacement } \\
& \dot{u}_{O}=\text { initial velocity } \\
& \frac{p_{O}}{k}=\text { static displacement }
\end{aligned}
$$

Some of the terms are defined as follows:

Harmonic Loading:

$$
p(t)=p_{O} \sin \bar{\omega} t
$$

Natural Frequency:

$$
\omega=\sqrt{\frac{k}{m}}
$$

Damping ratio:

$$
\xi=\frac{c}{c_{c r}}=\frac{c}{2 m \omega}
$$

Applied load frequency: $\quad \beta=\frac{\bar{\omega}}{\omega}$

\subsection{TIME INTEGRATION METHODS}

The equation of equilibrium for a nonlinear finite element system in motion is a nonlinear ordinary differential equation for which numerical solutions much easier to obtain, in general, than analytical solutions. The procedure used to solve the equations of 
equilibrium can be divided into two methods: direct integration and mode superposition.

In direct integration, the equations of equilibrium are integrated using a numerical step-by-step procedure. The term 'direct' is used because the equations of equilibrium are not transformed into any other form before the integration process is carried out. Some of the few commonly used direct integration methods are the central difference method, Houbolt method, Wilson - $\theta$ method, and Newmark method.

LSDYNA is based on central difference method of direction integration. Therefore the description of the direct integration method is limited to only central difference method.

\subsubsection{CENTRAL DIFFERENCE METHOD}

Consider a dynamical system, represented mathematically by a system of ordinary differential equation with constant coefficients. The central difference method is an effective solution scheme for such a system of equations.

The velocity and acceleration are approximated (see Figure 2.1) as follows:

$$
\begin{aligned}
& \dot{u}_{n}=\frac{1}{2 \Delta t}\left(u_{n+1}-u_{n-1}\right) \\
& \ddot{u}_{n}=\frac{1}{(\Delta t)^{2}}\left(u_{n+1}-2 u_{n}+u_{n-1}\right)
\end{aligned}
$$

Substituting the approximate equations for the velocity and acceleration from the central difference scheme in the equations of equilibrium, we get 


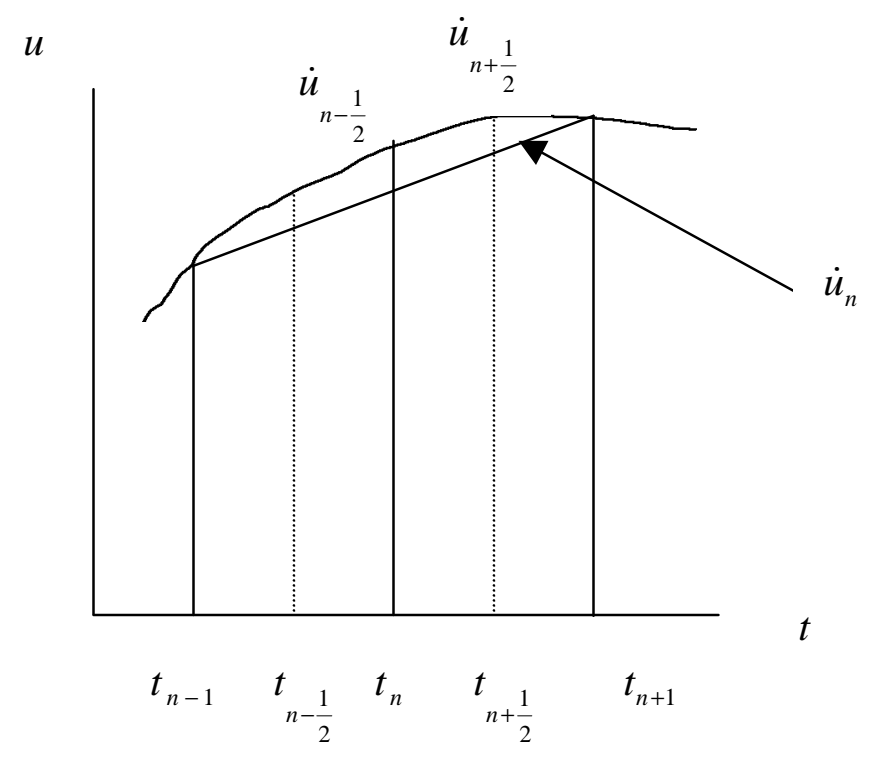

Figure 2.1 Central difference method representation

$$
\left(m+\frac{1}{2} \Delta t c\right) u_{n+1}=\Delta t^{2} P_{n}-\left(\Delta t^{2} k-2 m\right) u_{n}-\left(m-\frac{\Delta t}{2} c\right) u_{n-1}
$$

From the above equation, where $P_{n}$ is the external body force loads, the solution for $u_{n+1}$ can be determined. Since the solution for $u_{n+1}$ is based on conditions at time $t_{n-1}$ and $t_{n}$, the central difference integration procedure is called as explicit integration method. Also this method does not require the factorization of effective stiffness matrix in the step-by-step solution. On the other hand, the Houbolt, Wilson, and Newmark methods involve conditions at time $t_{n+1}$ also and hence are called implicit integration methods. 


\subsubsection{ADVANTAGES OF CENTRAL DIFFERENCE METHOD}

The main advantage of central difference method is that no stiffness and mass matrices of the complete element assemblage are calculated [Bathe and Wilson (1976)]. The solution can be essentially carried out on an element level and relatively very little storage is required. The method becomes more effective if the element stiffness and mass matrices of subsequent elements are the same, since it is only necessary to calculate or read from back-up storage the matrices corresponding to the first element in the series. This is why systems of very large order can be solved very effectively using the central difference scheme. The effectiveness of the central difference procedure depends on the use of a diagonal mass matrix and the neglect of general velocity-dependent damping forces. The benefits of performing the solution at the element level are preserved only if the diagonal damping matrix is included.

\subsubsection{DISADVANTAGES OF CENTRAL DIFFERENCE METHOD}

The central difference methods as well as other explicit methods are conditionally stable. If the time step, $\Delta t$, is too large for a given element size $L$, the method fails and if $\Delta t$ is smaller than required the solution time becomes very expensive losing the effectiveness of the method. Therefore it is necessary to determine the critical time for the given problem. For central difference method, critical $\Delta t$ is governed by the following equation

$$
\Delta t=\frac{L}{C}
$$

where, 


$$
c=\text { wave speed }=\sqrt{\frac{E}{\rho}}, \quad E=\text { Material Youngs Modulus, } \rho=\text { Material Density }
$$

The above equation is called the CFL condition after Courant, Friedrichs, and Lewy [Bathe and Wilson (1976)]. The physical interpretation of the condition is that the time step, $\Delta t$, must be small enough that the information does not propagate across more than one element per time step. In some structural analysis, depending on the material properties and the dimensions of the geometry, the time step required could be very small resulting in a longer computational time.

\subsection{CONTACT-IMPACT ALGORITM}

Treatment of sliding and impact along interfaces are very critical in simulation the correct load transfer between components in an analysis. Contact forces generated influence the acceleration of a body. Contact algorithms employed in finite element codes divides the nodes of bodies involved in contact into slave and master nodes. After the initial division, each slave node is checked for penetration against master nodes that for an element face. Therefore using a robust contact algorithm that can efficiently track and generate appropriate forces to the slave nodes without generating spurious results is very important. Three different methods such as the kinematic constraint method, the penalty

method and the distributed method are implemented in LSDYNA. A brief discussion of the three methods with merits and demerits follows.

\subsubsection{KINEMATIC CONSTRAINT METHOD}

This method uses the impact and release conditions of Hughes et al. [1976]. 
Constraints are imposed on the global equations by a transformation of the nodal displacement components of the slave nodes along the contact interface. This transformation has the effect of eliminating the normal degree of freedom of nodes. Since computational efficiency of the explicit time integration needs to be preserved, the mass is lumped to the extent that only the global degrees of freedom of each master node are coupled. Impact and release conditions are imposed to insure momentum conservation. This method is advantageous to use when two materials in contact have very different material properties. The nodes are constrained to stay on or very close to the surface without causing penetrations due to the difference in the stiffness. However problems arise when the master surface zoning is finer that the slave surface zoning. Certain master nodes can penetrate through the slave surface without resistant and create a kink in the slide line.

\subsubsection{PENALTY METHOD}

This method consists of placing normal interface springs between all penetration nodes and the contact surface. With the exception of the spring stiffness matrix, which must be assembled in the global stiffness matrix, the implicit and explicit methods are similar. Momentum is conserved without the necessity of impact and release conditions.

The equations involving the stiffness of the contact springs are as follows:

$$
\begin{aligned}
& k=\frac{f_{s} \times \text { Area }^{2} \times K}{\text { Minimum Diagonal Length }} \text { for shell elements } \\
& k=\frac{f_{s} \times \text { Area }^{2} \times K}{\text { Volume }} \quad \text { for solid elements }
\end{aligned}
$$


where,

$$
\begin{array}{ll}
\text { Area } & =\quad \text { Area of the contact segment } \\
\mathrm{K} & =\quad \text { Bulk Modulus of contacted element } \\
f_{s} & =\quad \text { penalty factor }(0.1 \text { by default })
\end{array}
$$

The interface stiffness $k$ is chosen to be approximately the same order of magnitude as the stiffness of the interface element normal to the interface. Consequently the computed time step size is unaffected by the existence of the interfaces. However, if interface pressures become large, unacceptable penetration may occur. By scaling up the stiffness $f_{s}$ and scaling down the time step size $\Delta t$, this may be overcome. $\mathrm{K}$ for a contact segment is calculated based on the material properties of the component involved in the contact. If two different materials with varying stiffness such as foam and steel come in contact, the stiffness of the lesser magnitude is taken as the contact stiffness. This causes penetration problems as the force generated by foam is small compared to the force generated by steel. This is overcome by scaling $f_{s}$ until the forces generated by the two materials are in equilibrium. Determining the appropriate value of $f_{s}$ is important so that the forces generated are in equilibrium.

\subsubsection{DISTRIBUTED PARAMETER METHOD}

This method is derived from TENSOR [Burton (1982)] and HEMP [Wilkins (1964)] programs, which displaced fewer mesh instabilities compared to the nodal constraint algorithm. In this method, one half the slave element mass of each element in contact is distributed to the covered master surface area. Also, the internal stress in each element determines a pressure distribution for the master surface area that receives that 
mass. After the distribution of mass and pressure the acceleration of the master surface is updated.

\subsubsection{CONTACT ENERGY CALCULATION}

The contact energy, $E_{\text {contact }}$, is incrementally updated from time n to $\mathrm{n}+1$ for each contact interface. $E_{\text {contact }}$ is determined using the following equation,

$$
E_{\text {contact }}^{n+1}=E_{\text {contact }}^{n}+\left[\sum_{i=1}^{n s n} \Delta F_{i}^{\text {slave }} \times \Delta \text { dist }_{i}^{\text {slave }}+\sum_{i=1}^{n m n} \Delta F_{i}^{\text {master }} \times \Delta \text { dist }_{i}^{\text {master }}\right]^{n+\frac{1}{2}}
$$

Where,

$$
\begin{aligned}
& n s n=\quad \text { number of slave nodes } \\
& m s n=\quad \text { number of master nodes } \\
& \Delta F_{i}^{\text {slave }}=\quad \text { interface force between the } i \text { th slave node and the } \\
& \text { contact segment } \\
& \Delta F_{i}^{\text {master }}=\quad \text { interface force between the } i \text { th master node and the } \\
& \Delta \text { dist }_{i}^{\text {slave }}=\quad \text { is the incremental distance the } i \text { th slave node has } \\
&
\end{aligned}
$$

$\Delta$ dist $_{i}^{\text {master }}=$ is the incremental distance the $i$ th master node has moved during the current time step.

Monitoring the contact energy calculated is very important to ensure proper 
calculation made by the contact algorithm. In the absence of friction, the slave and master side energies should be close in magnitude but opposite in sign. The sum, $E_{\text {contact }}$, should equal the stored energy. Large negative contact energy is a sign of undetected nodal penetrations.

\subsection{MATERIAL MODELING}

The engineering design of structures is based on determining the forces acting on the body and understanding the response of the material to the external force field. In the finite element analysis the response of the structural material is dependent on the representation of the elastic and plastic behavior of the material. In some instances, the material would not go into the plastic region therefore a simple elastic material model would be sufficient would be appropriate to study the response thereby reducing a significant about the computational time. However in the field of crash analysis, some of the main automobile structures are designed to absorb the energy in a controlled manner and they usually are in the plastic region. Therefore it becomes necessary to idealize the stress-strain behavior of the material to include plasticity. There are several idealized models incorporated in LSDYNA. One of the models extensively used in this work is described in the next section.

\subsubsection{ELASTIC-LINEAR WORK-HARDENING MODEL}

This modeling technique basically represents a continuous stress-strain curve of the material by two straight lines as shown in Figure 2.2. The first linear line represents the elastic portion of the curve while the second linear line (whose slope is always less 
than the elastic linear line) represent the plastic portion of the stress-strain curve. The smooth transition curve is represented by a sharp breaking point, which is the yield point, $\sigma_{y}$. The stress-strain relation has the form,

$$
\begin{aligned}
& \varepsilon=\frac{\sigma}{E} \quad \text { for } \quad \sigma \leq \sigma_{y} \\
& \varepsilon=\frac{\sigma}{E}+\frac{\left(\sigma-\sigma_{y}\right)}{E_{t}} \quad \text { for } \quad \sigma>\sigma_{O}
\end{aligned}
$$

where $E$ is Young's modulus, and $E_{t}$ is the tangent modulus.

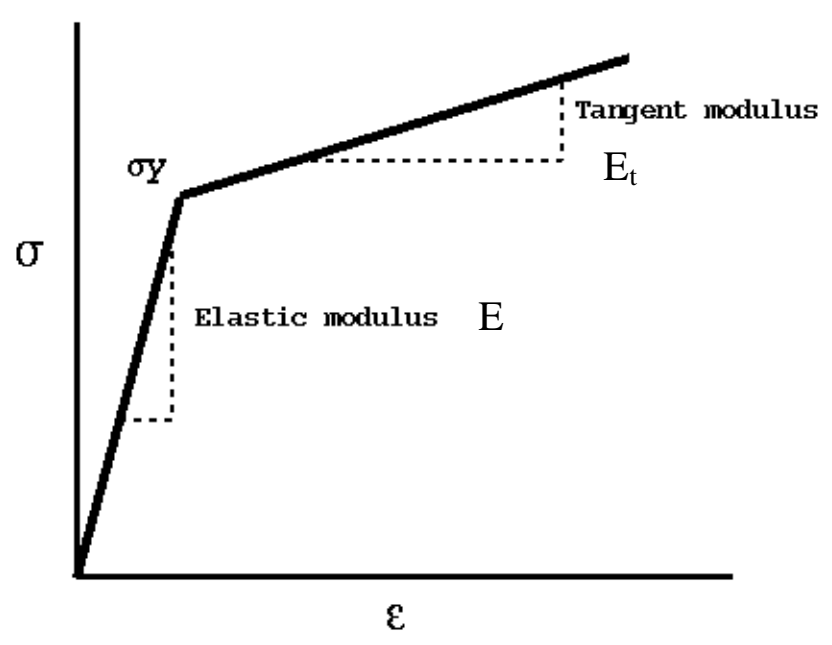

Figure 2.2 Bilinear Elastic-Plastic Material Idealization 


\subsubsection{DETERMINATION OF MATERIAL PROPERTIES FOR F.E.M}

Accurate representation of the material depends on the determination of the material properties from the tensile-test specified by ASTM. Materials models in some finite element curves require the input of true stress and true strain value to define plastic portion of the curve. Inputting engineering stress-strain values will be inappropriate for that material model. Therefore understanding the material model requirements and meeting those requirements is essential. Following procedure outlines the mathematics involved in handling raw test data.

- Conversion of force deflection data into engineering stress and engineering strain

$$
\sigma_{e}=\frac{F}{A_{o}}, \varepsilon_{e}=\frac{D}{L_{o}}
$$

where

$$
\begin{aligned}
& \sigma_{e}=\text { engineering stress } \\
& F=\text { force } \\
& A_{o}=\text { original cross sectional area of test specimen } \\
& \varepsilon_{e}=\text { engineering strain } \\
& D=\text { displacement measured on the test specimen } \\
& L_{o}=\text { Original length of specimen }
\end{aligned}
$$

- The above stress strain calculations are based on original cross-section and original length. This would hold good until a certain point in the stress strain curve, where the cross-sectional reduction is insignificant. However the necking phenomenon causes large reduction in the cross-section area of the 
specimen, which needs to be taken into account. The true values of stress and strain takes into account the cross-sectional change beyond the necking region. The equations for converting the engineering values to true values are written below:

$$
\begin{aligned}
& \sigma_{t}=\sigma_{e}\left(1+\varepsilon_{e}\right) \\
& \varepsilon_{t}=\ln \left(1+\varepsilon_{e}\right)
\end{aligned}
$$

where,

$$
\begin{aligned}
& \sigma_{t}=\text { true stress } \\
& \varepsilon_{t}=\text { true strain }
\end{aligned}
$$




\section{CHAPTER 3 MODELING}

\subsection{FREE MOTION HEADFORM (FMH)}

Free motion headform (FMH) is the head model of a Hybrid III dummy which is recognized by NHTSA for evaluating head impact protection against vehicle interior components. The nose and other features of the hybrid III dummy head are removed to prevent their interference with the trim component during testing. Physical model of free motion headform (FMH) mainly consists of an outer rubber skin attached firmly over an inner aluminum skull. At the center of gravity of FMH, accelerometers are placed to record the acceleration used to calculate the HIC(d). To accurately simulate the behavior of FMH using the finite element method, the following key features need to be incorporated:

- accurate geometric representation of the headform

- appropriate material models to characterize the rubber skin material

- identical mass and inertia properties of FMH thereby matching the center of gravity of the physical FMH

- accurate modeling of contact

A finite element model of a featureless FMH developed by a commercial software vender is used in this project [FTSS (1998)]. Figure 3.1 shows an isometric view of the model indicating the impact zone as defined by NHTSA. It can be observed form the figure that the impact zone on FMH has been finely discretized. This is done to improve the contact force distribution thus providing smoother acceleration responses. 


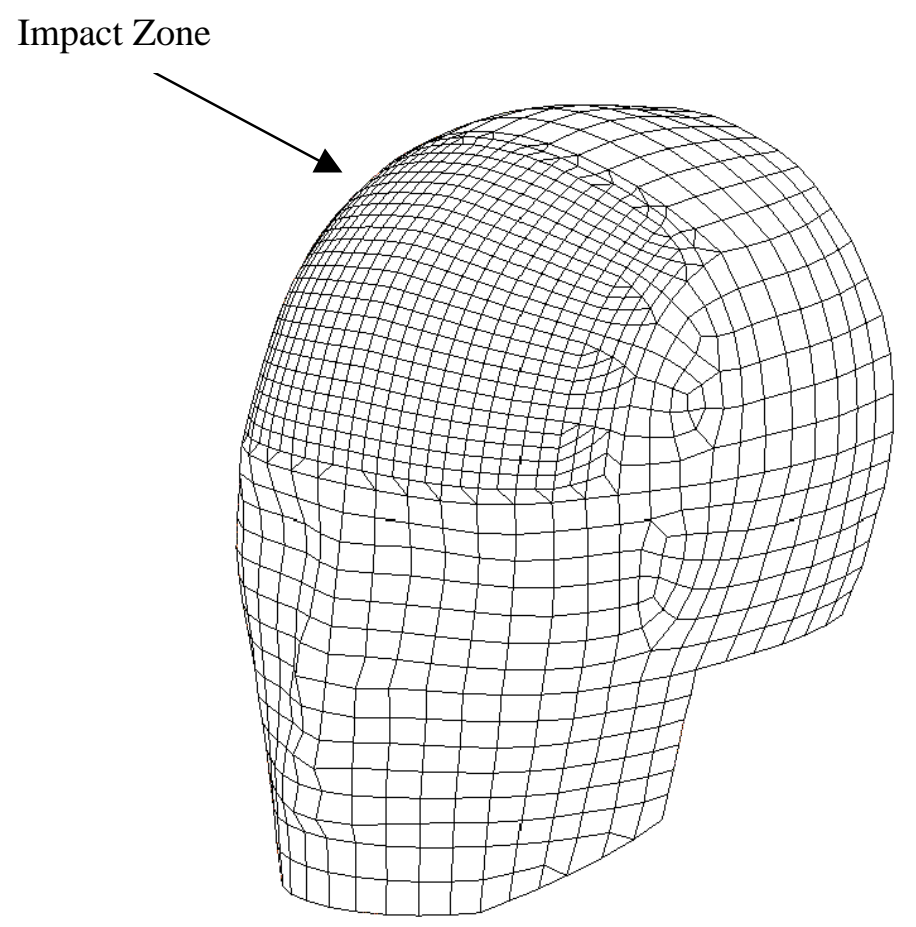

Figure 3.1 Isometric view of FMH

The inner aluminum skull is modeled using shell elements and is defined as a rigid member. Figure 3.2 shows a cross sectional view of the headform. The rubber skin is modeled using two layers of solid elements. Assuming no sliding takes place between the rubber skin and the skull, the outer nodes of the rigid skull and the corresponding nodes of the rubber skin are constrained to the same displacement, thus preventing 
sliding. To account for the overall mass and the inertia properties of the physical headform, additional mass elements connected by beam elements are defined as extra nodes to the rigid inner skull. A local coordinate system defined at the head center of gravity is used to record the acceleration in local axes of FMH.

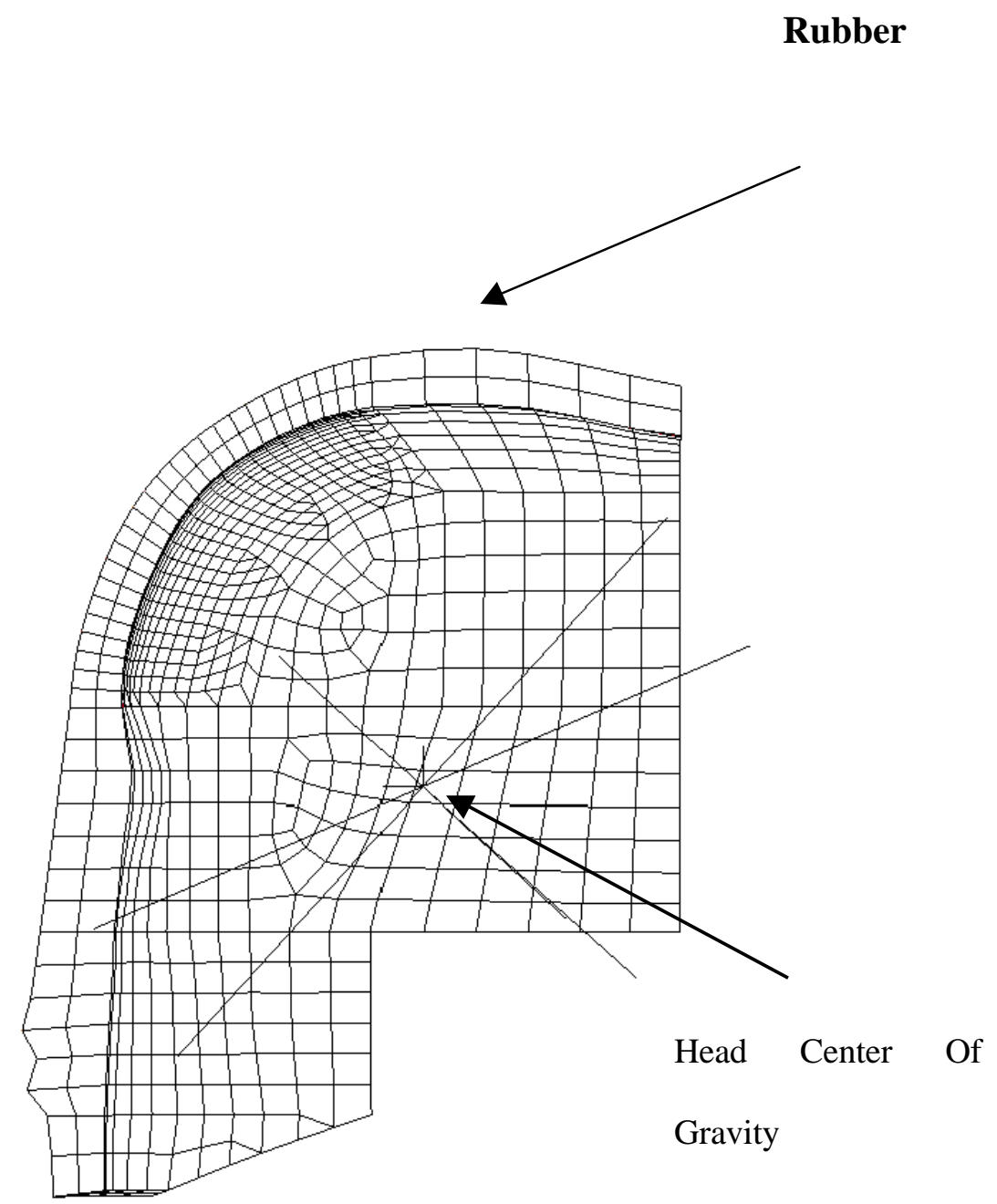

\section{Figure 3.2 Cross-section view of FMH}




\subsection{BODY IN WHITE (BIW)}

A typical BIW cross section of the A-Pillar consists of inner, center, and an outer panel. Figure 3.3 shows several target locations on the upper interior components of a vehicle. A cross section cut of an A-Pillar is shown in Figure 3.4. This figure shows a generic cross section of an A-Pillar cut at AP3 target location (section A-A) of Figure 3.3. Component nomenclature is based on their relative position to the interior of the vehicle. By this definition, inner and outer panels are the component facing the interior and exterior of the vehicle, while the center panel is the component that is in between the two panels. All the three components are usually a one-piece sheet metal stamped panel providing basic structural integrity to the automobile. Depending on the structural requirements of the vehicle, the components are either welded, riveted, glued (using an adhesive), or a combination of the three. The thickness of these components generally ranges from $0.5 \mathrm{~mm}$ to $2.5 \mathrm{~mm}$. 


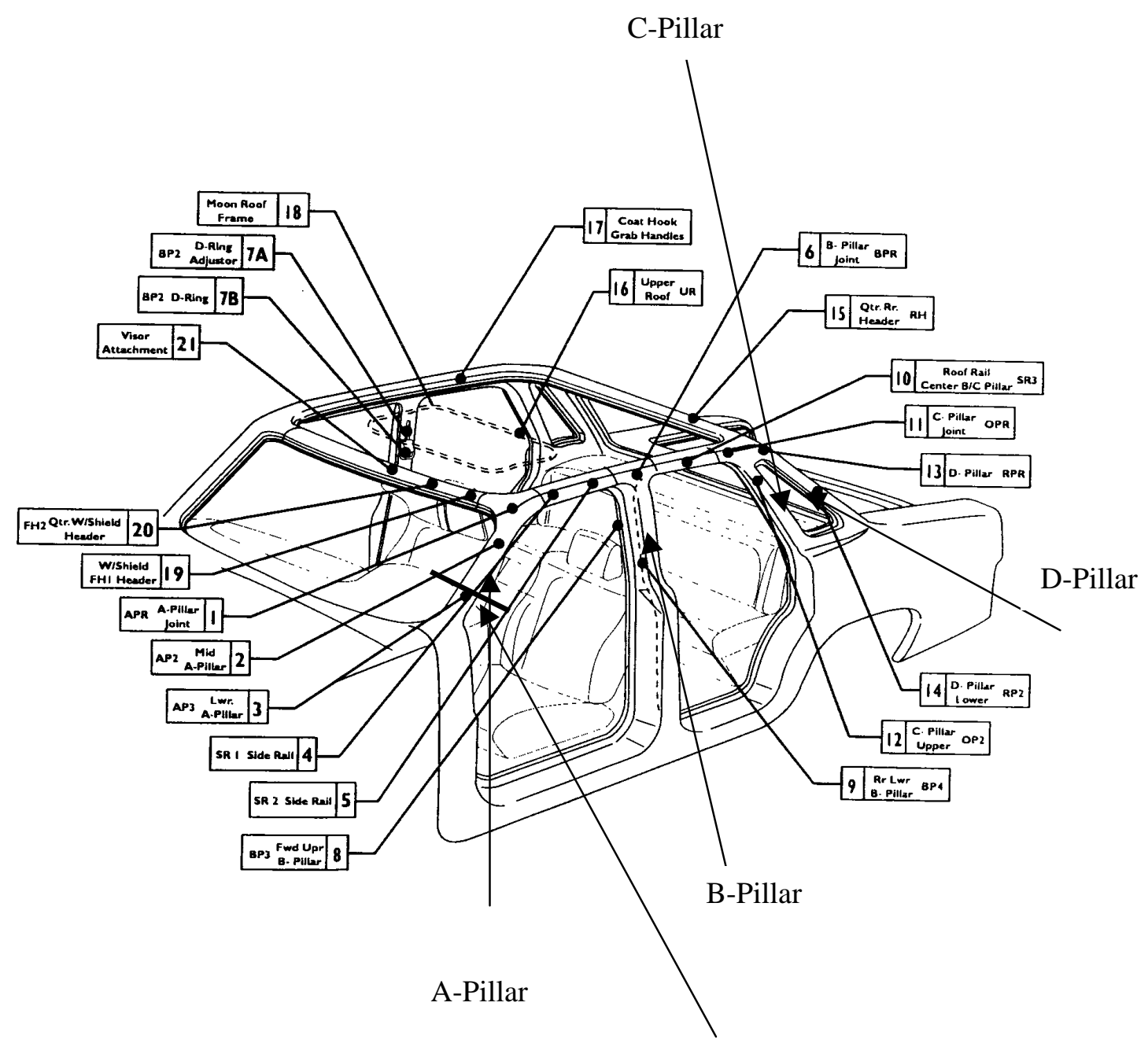

Section A-A of A-Pillar at AP3 target point

Figure 3.3 Target locations on the upper interior components of the vehicle 


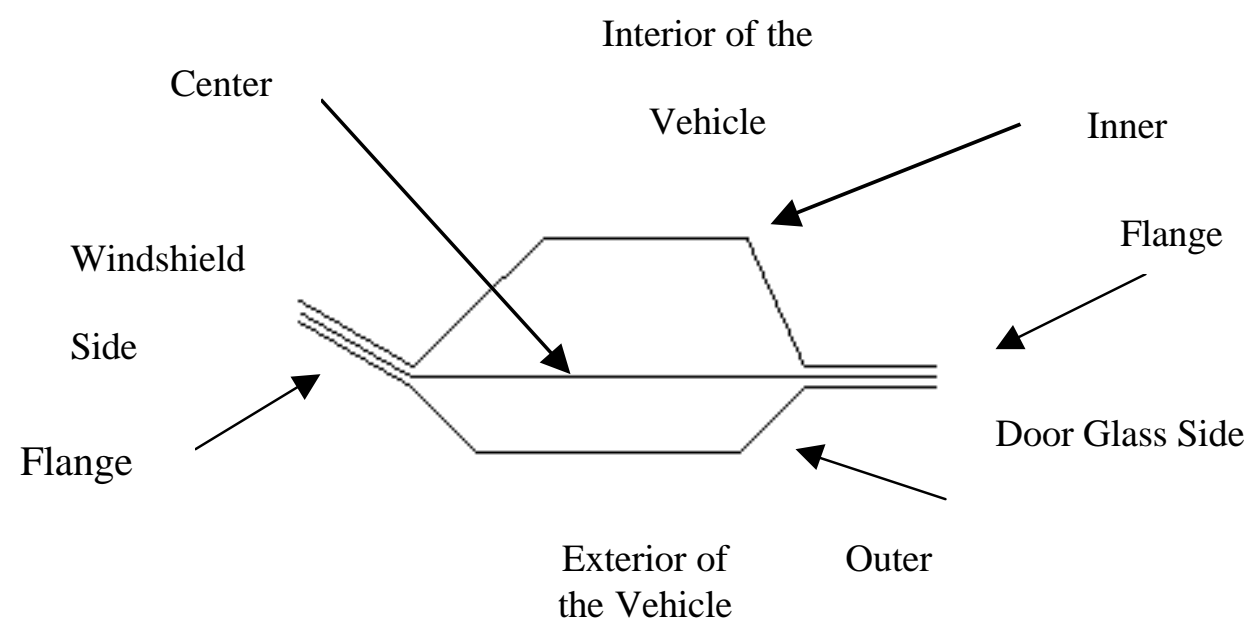

\section{Figure 3.4 Cross section of BIW cut at AP3 target location (Section A-A)}

A generic cross section of an A-Pillar was developed by establishing points starting from the tip of the flange on the front door side and proceeding to the tip of the flange on the windshield side. A line was then drawn to connect these discrete points resulting in the two-dimensional geometry of the panels. This line represents the mid plane of the panel and therefore appropriate clearances need to be incorporated between the panels. Individual dimensions of the panels are shown in Figures 3.5a, 3.5b, and 3.5c. These two-dimensional lines are then extruded to a total length of $500 \mathrm{~mm}$ in the out of plane direction to form the surfaces of the panels.

Surfaces representing the mid plane of the planes were meshed using four noded shell elements. A thickness of $2 \mathrm{~mm}, 1 \mathrm{~mm}$, and $1 \mathrm{~mm}$, was assigned to inner, outer, and center panels respectively. 


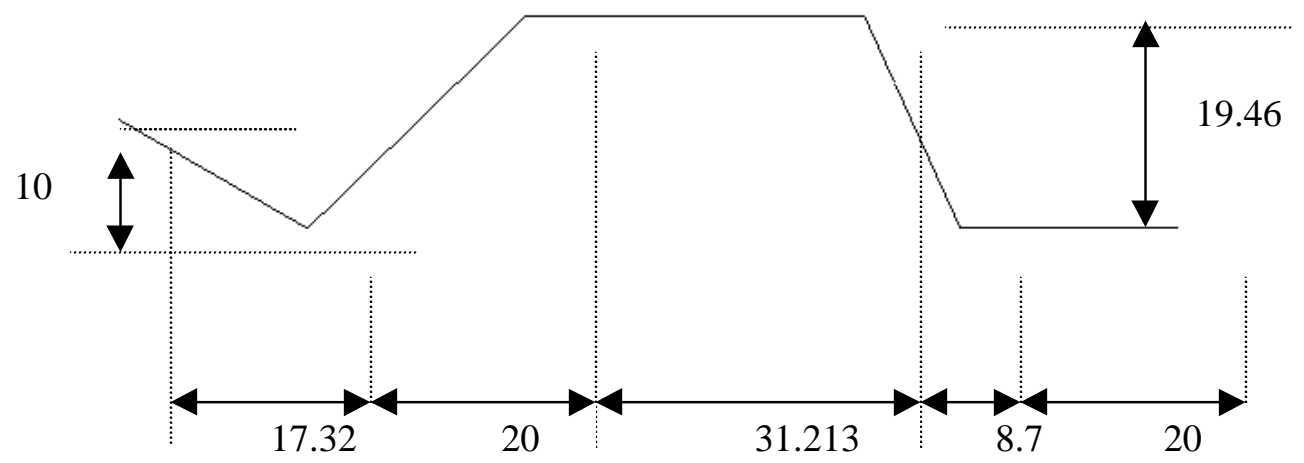

Figure 3.5a Dimensions of inner panel, thickness $=2 \mathrm{~mm}$ (all dimensions in $\mathbf{m m})$

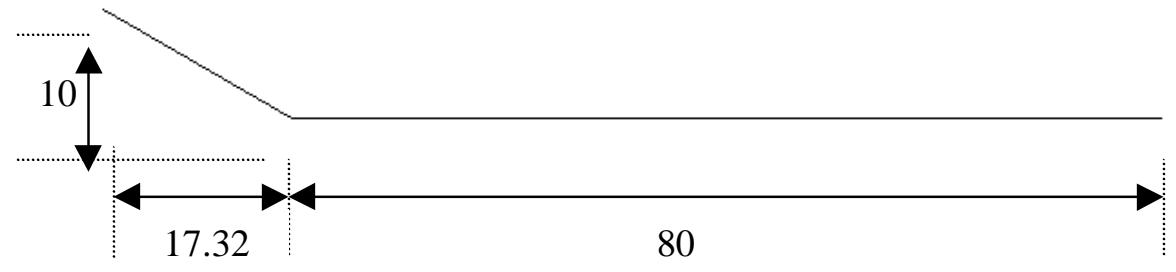

Figure 3.5b Dimensions of center panel, thickness $=1 \mathrm{~mm}($ all dimensions in $\mathrm{mm})$

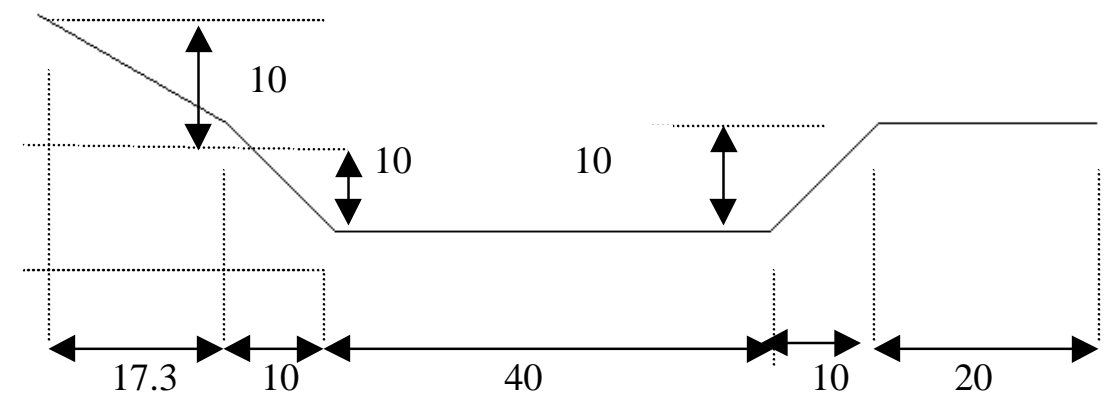

Figure 3.5c Dimensions of outer panel, thickness $=1 \mathrm{~mm}($ all dimensions in $\mathbf{m m})$ 
To account for thickness while assembling the panels, a clearance $1.5 \mathrm{~mm}$ (half the sum of the thickness of two components) was established between the inner and center panels while a clearance of $1 \mathrm{~mm}$ was considered between the center and outer panels. The shell element formulation is based on Belytschko-Lin-Tsay formulation with reduced integration available in LSDYNA. This element is generally considered as computationally efficient and accurate.

To study the effects of mesh densities on contact forces generated due to impact between FMH and inner of BIW, two cases of mesh densities were evaluated for the baseline (no trim) analyses. In case I, the mesh density along the extruded length of the cross section is maintained the same in all the three components as shown in Figure 3.6a.

In case II, the mesh density on only the inner panel is increased to approximately twice near the impact zone as shown in Figure 3.6b. In this case, an element length of $2 \mathrm{~mm}$ was maintained near the impact zone. This element length is approximately equal to the size of the rubber solid elements used to discretize the forehead impact zone of FMH.

Table 3.1 shows the number of elements used in cases I and II. 

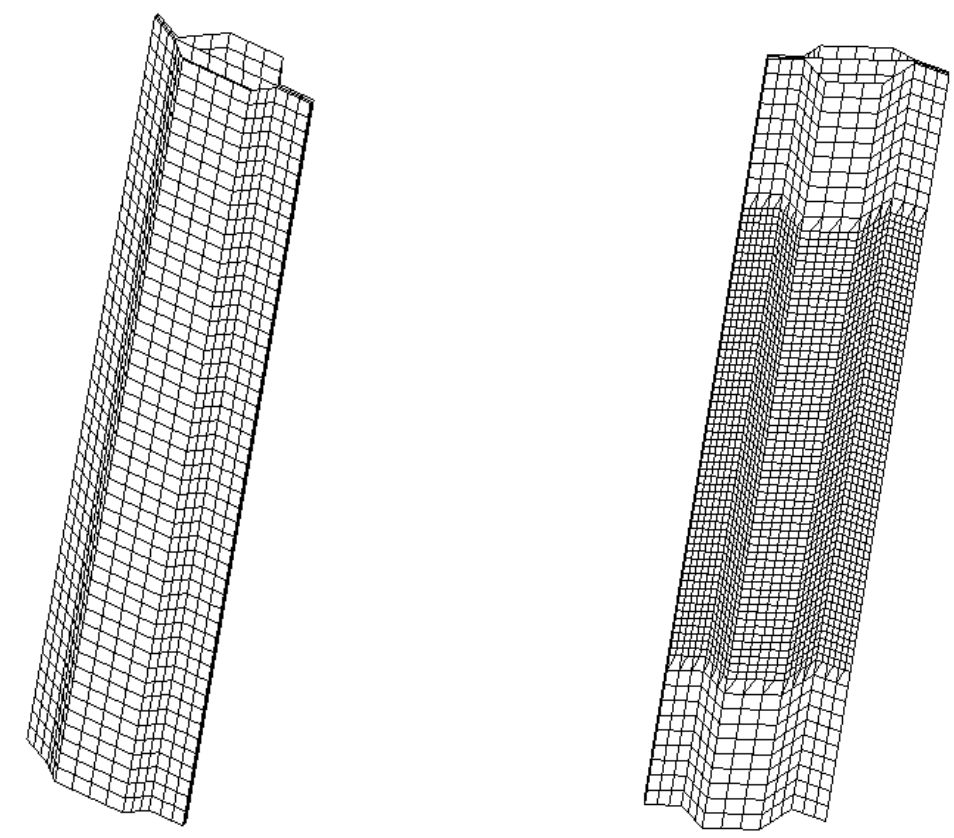

Figure 3.6 a) Coarse mesh of inner panel

b) Finer mesh of inner panel 


\begin{tabular}{|c|c|c|}
\hline \multirow{2}{*}{ Panels } & \multicolumn{2}{|c|}{ Number Of Elements } \\
\cline { 2 - 3 } & Coarse & Fine \\
\hline Inner & 748 & 2122 \\
\hline Center & 800 & 800 (Not Modified) \\
\hline Outer & 600 & 600 (Not Modified) \\
\hline
\end{tabular}

Table 3.1 Element discretization of panels 
Modeling of the rivets that connect the BIW panels is based on defining the nodes lying on the axis of the rivet (one each on inner, center, and outer) as a rigid body. This option in LSDYNA is called as *CONSTRAINED_NODAL_RIGID_BODY and does not consider failure of the rivets, if any, during the impact. Riveted locations on the panels are as shown in Figure 3.7. Figure 3.8 shows a top view highlighting the axis of the rivets through the three panels. 
Riveted Points

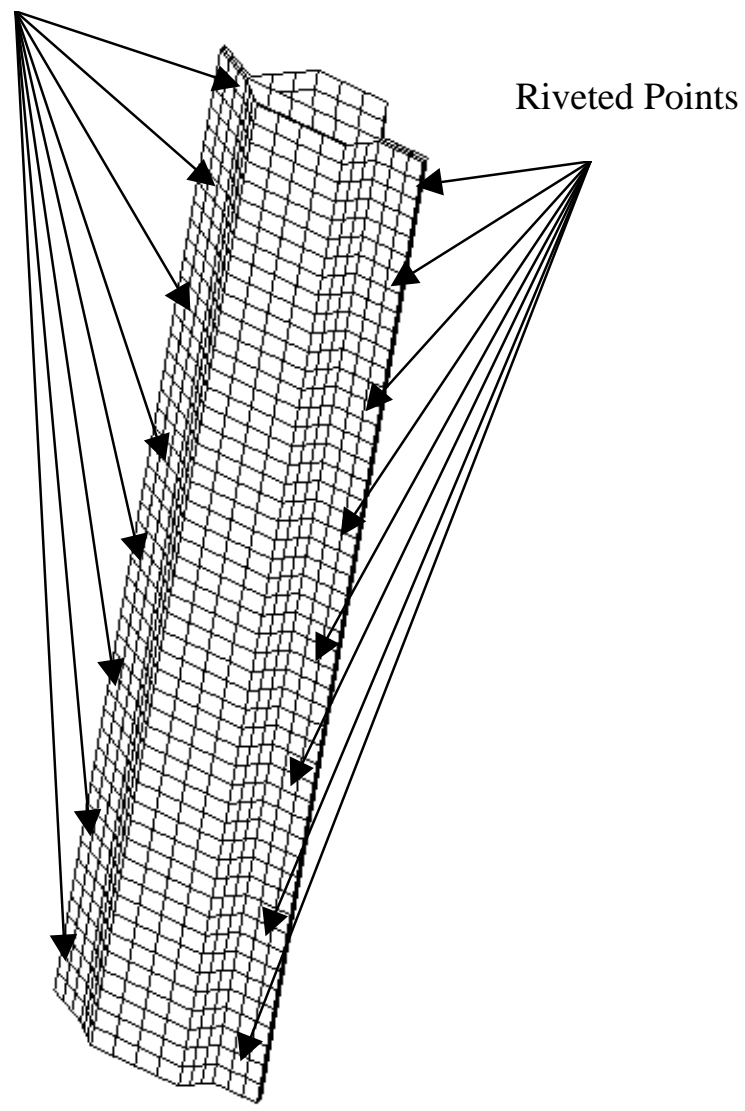

Figure 3.7 Rivet locations on the BIW

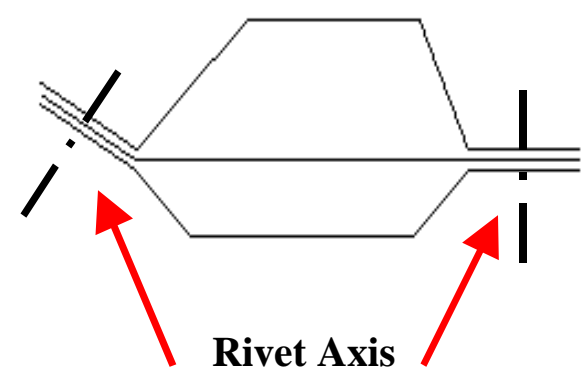

Figure 3.8 Rivet axis identification 


\subsection{TRIM}

The term trim is used for a component that encloses the BIW. It is used to satisfy both the aesthetic as well as impact protection requirements. The trim has a smooth outer surface visible to the occupant while the inner surface has attachment features such as clip housing and clip. The function of the clips is to enable fixing of the trim on to the BIW components. The clip-housings provide the necessary clearance between the BIW and the inner surface of the trim.

In this work, three different trim designs, namely Trim Design-1, Trim Design-2, and Trim Design-3 are considered for evaluation under impact conditions. All three trim designs are meshed using shell elements with default element formulation available in LSDYNA.

Trim design- 1 is a simple semi-circular cross section enclosing the BIW as shown in Figure 3.9a with the center of the semi-circle being closer to the door area to aid more stopping distance along the impact direction. A uniform thickness of $2 \mathrm{~mm}$ is used for the trim, clip housing, and clip. In Trim Design-2 and Trim Design-3, the stopping distance is increased relative to the inner as shown in Figure 3.9b and Figure 3.9c. 


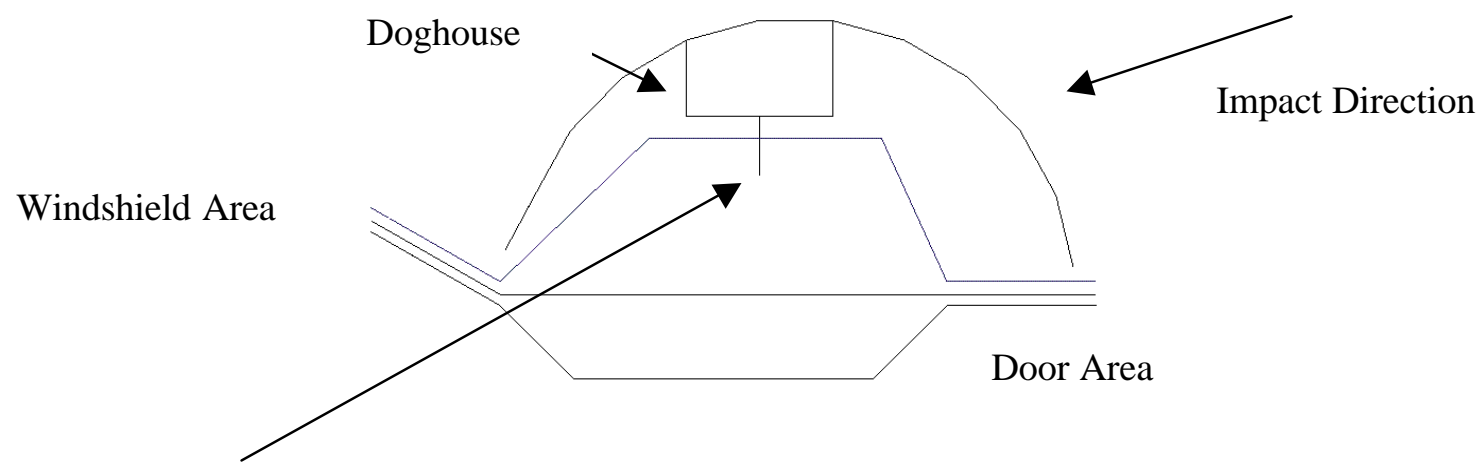

Clip

Figure 3.9a Trim Design-1

Increased Clearance Compared

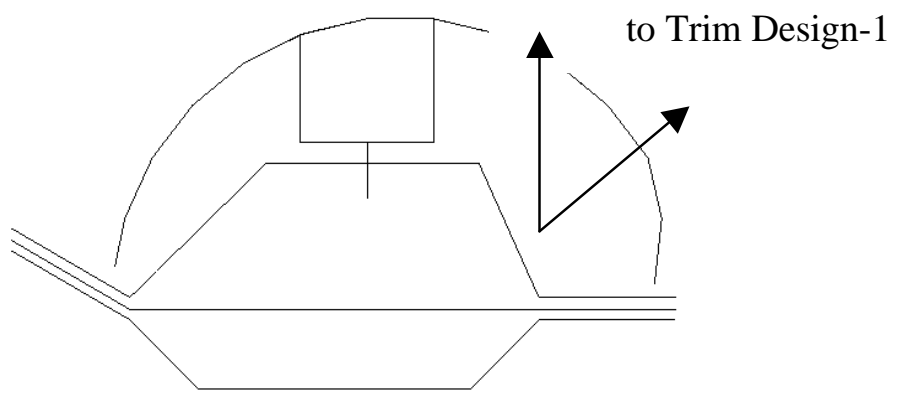

Figure 3.9b Trim Design-2

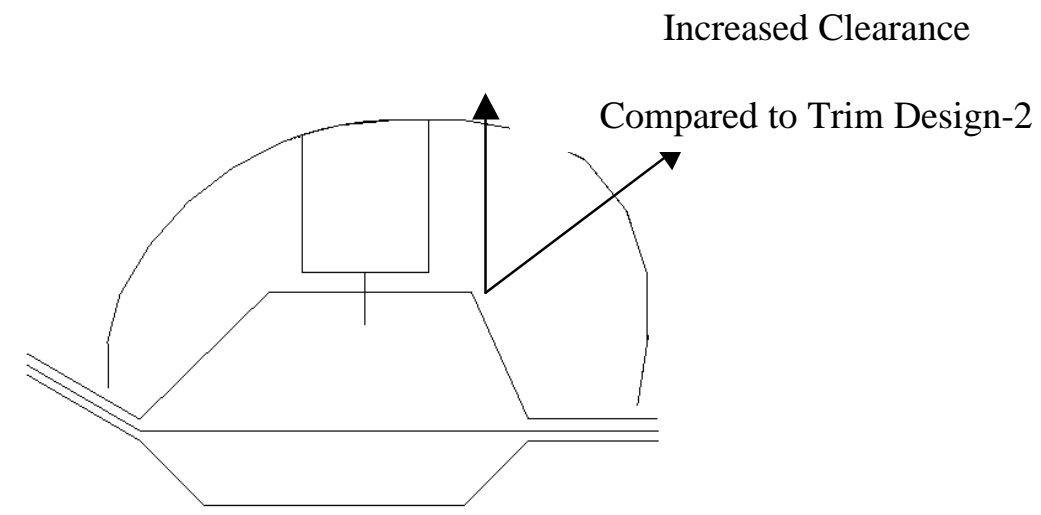

Figure 3.9c Trim Design-3 
Two clips, one on each end of the trim, are modeled in all three trim designs to attach the trim to BIW. Figure 3.10 shows an isometric view of Trim Design-1 identifying the two clips and clip-housings. Attachment between the clips and inner is modeled by rigidly attaching the clip to the slot provided on the inner panel using CONSTRAINED_NODAL_RIGID_BODY card available in LSDYNA. The total length of the trim cross section is $250 \mathrm{~mm}$ (half of BIW) and is centered along the cross sectional length of BIW as shown in Figure 3.11. 


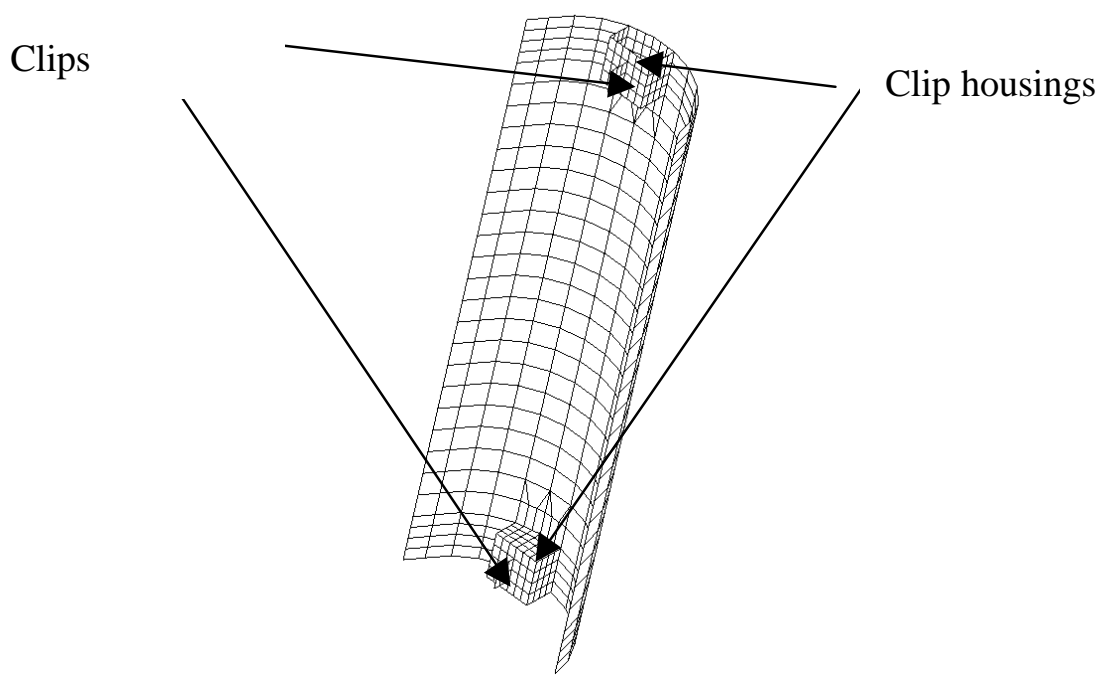

Figure 3.10 Isometric view of trim design to show clips and clip housing

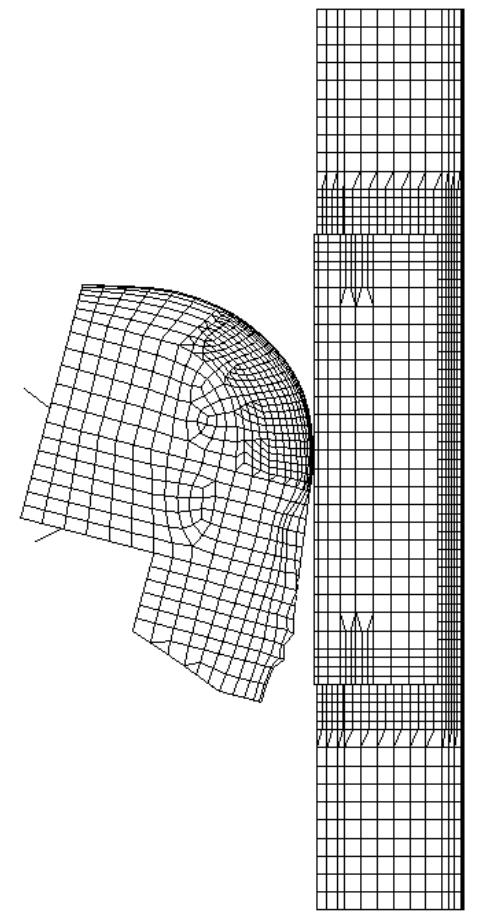

Figure 3.11 Side view of Trim Design-1 showing impact point on trim 


\subsection{COUNTERMEASURE}

Countermeasure is a general term used for components that work in conjunction with interior trim to influence the HIC(d). In this work, ribs integrated on the inside of the trim are evaluated as a countermeasure. Figure 3.12 shows Trim Design- 1 with ribs built on the inner surface of trim. The ribs were meshed with shell elements with a minimum of three elements across the depth to capture appropriate bending during impact. A uniform thickness of $1 \mathrm{~mm}$ (50\% of trim thickness) is used for the ribs.

To study the influence of two design variables, namely rib thickness and rib depth, on HIC(d), six models were generated to account for three rib thickness and three rib depths. The three rib thickness used were $0.5 \mathrm{~mm}, 1.0 \mathrm{~mm}$, and $1.5 \mathrm{~mm}$. The three rib depths used were 6 mm, 9 mm, and $12 \mathrm{~mm}$ as shown in Figures 3.13a, b, and c.

During impact, large forces are transmitted from the ribs to the inner panel over a small area of the edge of the ribs. To improve the force distribution, a finer mesh is preferred on the ribs. To avoid an overall increase in the number of elements in the model by trying to match the mesh densities on both the ribs and trim, the feature *CONTACT_TIED_SHELL_EDGE_TO_SURFACE in LSDYNA is used. This interface ties all degrees of motion of the slave node to the master segment simulating a tied interface. This enables to have finer mesh densities on the ribs while having a coarser mesh density on the trim thereby improving computational efficiency. 


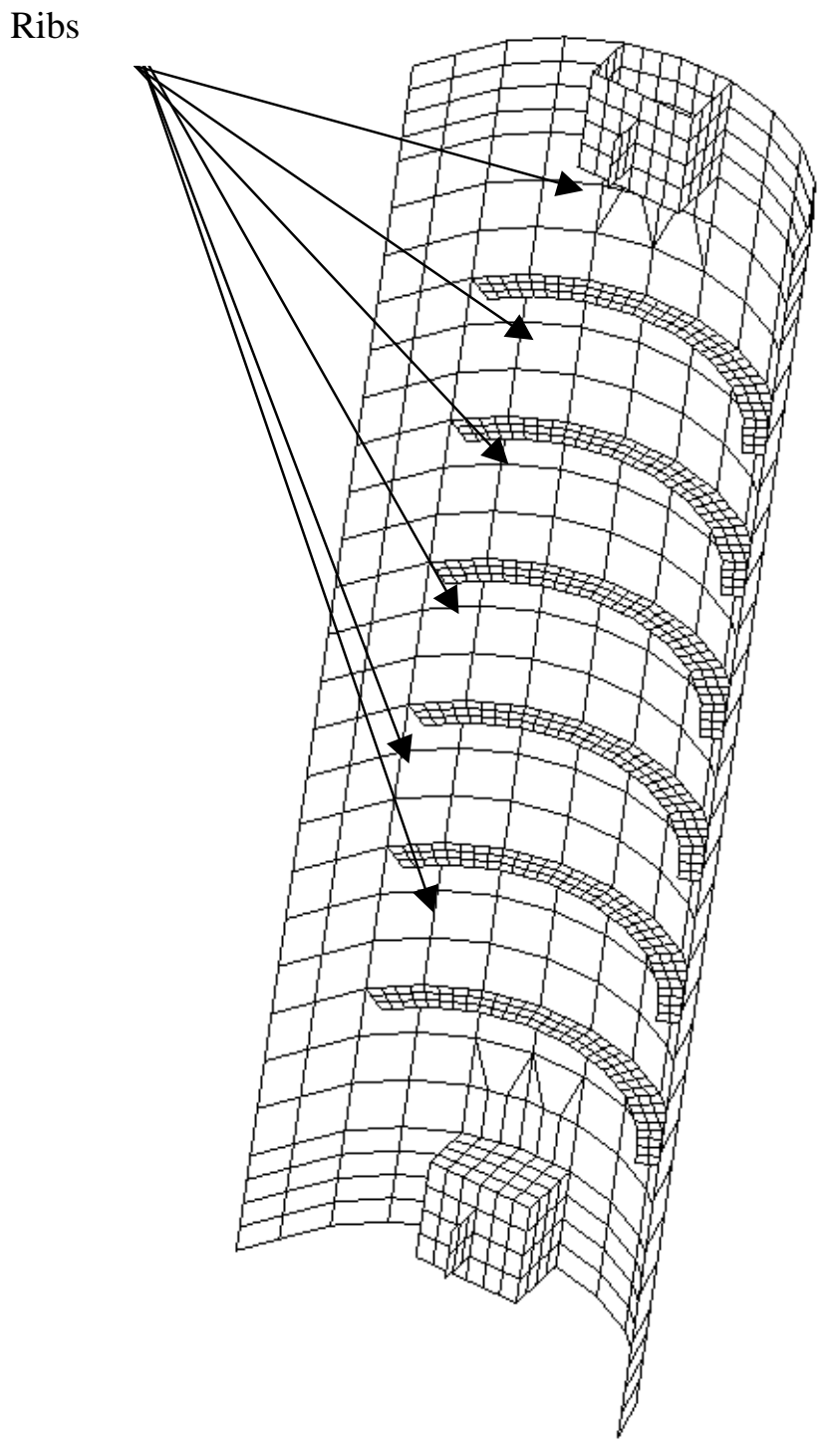

Figure 3.12 Trim Design-1 with ribs as a countermeasure 


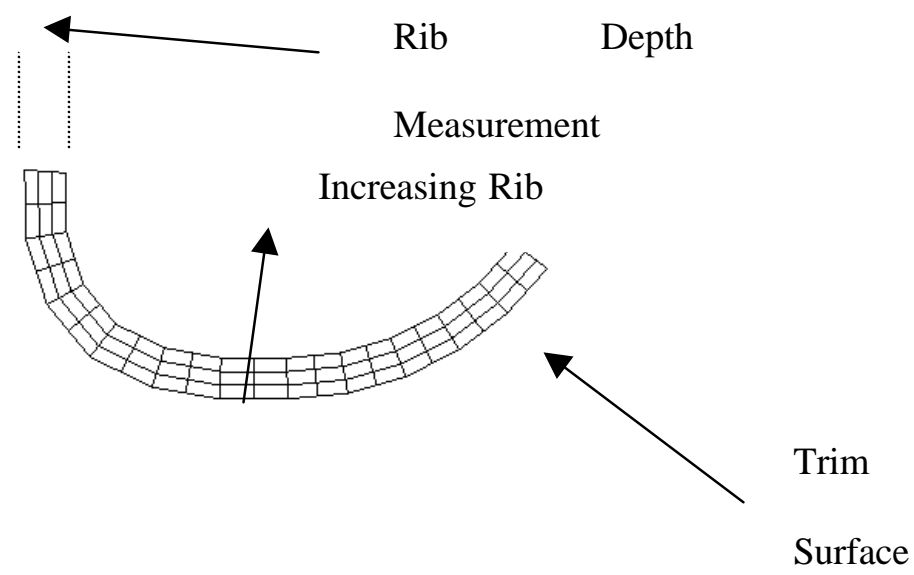

Figure 3.13a Rib depth of $6 \mathbf{m m}$

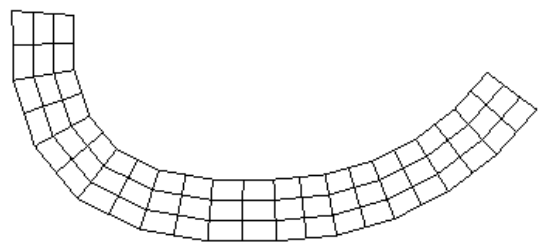

Figure 3.13b Rib depth of $9 \mathrm{~mm}$

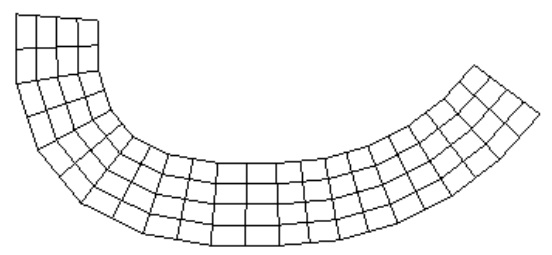

Figure 3.13c Rib depth of $12 \mathrm{~mm}$ 


\section{CHAPTER 4 ANALYSIS}

\subsection{MATERIAL DEFINITIONS}

\subsubsection{FREE MOTION HEADFORM (FMH)}

Material properties of aluminum are used to define the rigid inner skull. Although the skull is defined as a rigid body, assigning appropriate aluminum properties is important to account for proper distribution of mass on the skull. To represent the rubber skin material, viscoelastic material model based on Ogden rubber formulation is used. Rubber is generally considered to be fully incompressible since the bulk modulus greatly exceeds the shear modulus. Table 4.1 and Table 4.2 detail the material properties of aluminum and Ogden rubber, respectively, used in the finite element model of FMH.

\begin{tabular}{|c|c|}
\hline \multicolumn{2}{|c|}{ Aluminum Material Properties } \\
\hline $\mathrm{E}, \mathrm{MPa}$ & 950 \\
\hline$\rho, \mathrm{Mgm} / \mathrm{mm}^{3}$ & $2.71 \mathrm{E}-9$ \\
\hline$\gamma$ & 0.33 \\
\hline
\end{tabular}

Table 4.1 Material properties of rigid inner skull of FMH [FTSS (1998)] 


\begin{tabular}{|c|c|}
\hline \multicolumn{2}{|c|}{ Rubber Properties } \\
\hline$\rho, \mathrm{Mgm} / \mathrm{mm}^{3}$ & $1.433 \mathrm{E}-9$ \\
\hline Shear Modulus1, MPa & -0.032 \\
\hline Shear Modulus 2, MPa & 0.0838 \\
\hline Exponent 1 & -8.384 \\
\hline Exponent 2 & 3.064 \\
\hline Shear Relaxation \\
Modulus, MPa
\end{tabular}

Table 4.2 Rubber skin material properties of FMH [FTSS (1998)] 


\subsubsection{BODY IN WHITE PANELS}

BIW panels form the basis for the structural integrity of the vehicle. Two different materials, steel and aluminum were used as the BIW material. Table 4.3 compares the material properties of steel with aluminum.

\begin{tabular}{|c|c|c|c|}
\hline Properties & Units & 1010 Steel & $\begin{array}{c}\text { 5052 H34 Aluminum } \\
\text { [Kenamond, 1994] }\end{array}$ \\
\hline $\mathrm{E}$ & $\mathrm{MPa}$ & 200000 & 69640 \\
\hline$\rho$ & $\mathrm{Mgm} / \mathrm{mm}^{3}$ & $7.82 \mathrm{E}-9$ & $2.71 \mathrm{E}-9$ \\
\hline$\gamma$ & - & 0.3 & 0.33 \\
\hline$\sigma_{\mathrm{y}}$ & $\mathrm{MPa}$ & 200 & 165.5 \\
\hline $\mathrm{E}_{\mathrm{tan}}$ & $\mathrm{MPa}$ & 1000 & 388.2 \\
\hline
\end{tabular}

Table 4.3 Material properties of steel and aluminum. 


\subsubsection{TRIM AND RIBS}

Trim material, $\mathrm{PC} / \mathrm{ABS}$, is modeled as being perfectly plastic using *MAT_PIECEWISE_ELASTIC_PLASTIC (MAT 24) material model in LSDYNA. In this material model, discrete points representing the plastic portion of the material are defined using a load curve definition option such as *DEFINE_CURVE. To model a perfectly plastic behavior, the slope between the yield point and the ultimate point is given a very small number. Material model,*MAT_PIECEWISE_ELASTIC_PLASTIC, allows user to specify a plastic strain based failure of the material. This option is used to model the fracture of clip from clip housing during the impact and the fracture of the ribs. A plastic failure strain of $50 \%$ is used. Table 4.4 shows the material properties of PC/ABS used in this work.

\begin{tabular}{|c|c|}
\hline \multicolumn{2}{|c|}{ PC/ABS properties } \\
\hline $\mathrm{E}, \mathrm{MPa}$ & 2350 \\
\hline$\rho, \mathrm{Mgm} / \mathrm{mm}^{3}$ & $1.05 \mathrm{E}-9$ \\
\hline$\gamma$ & 0.33 \\
\hline$\sigma_{\mathrm{y}, \mathrm{MPa}}$ & 70.3 \\
\hline$\sigma_{\mathrm{u}, \mathrm{MPa}}$ & 71.0 \\
\hline
\end{tabular}

Table 4.4 Properties of PC/ABS [Sherman et al. (1995)] 


\subsection{IMPACT ANGLE SPECIFICATIONS}

Before designing the trim to meet head impact protection, it is important to fully understand the impact conditions specified by NHTSA. Several procedures outlined in FMVSS 201 standards uniquely describe the targeting and impact methodology for each specific target point. Knowledge of this procedure will help understand the significance of design variables that can later be used in designing the interior components to provide head impact protection. Some of the basic definitions and procedures are briefly enumerated below.

\subsubsection{HORIZONTAL APPROACH ANGLE}

As an initial step in establishing the target points, the occupant head's center of gravity location in the vehicle coordinate system is determined based on the seating reference point. This information needs to be identified for all the occupants in the vehicle such as driver, passenger, and other occupants in the rear.

Determination of minimum and maximum horizontal approach angles for a given trim design is shown in Figure 4.1. The figure shows the top view of the two occupants, driver and passenger, and the cross section of the A-pillar. The line forming the shortest distance between the driver head's center of gravity point and the trim design is called as the minimum horizontal angle measured from the negative $\mathrm{x}$-axis in the counter clockwise direction. The maximum horizontal approach angle is determined by establishing the shortest distance to the A-pillar trim from the passenger head's center of gravity. 


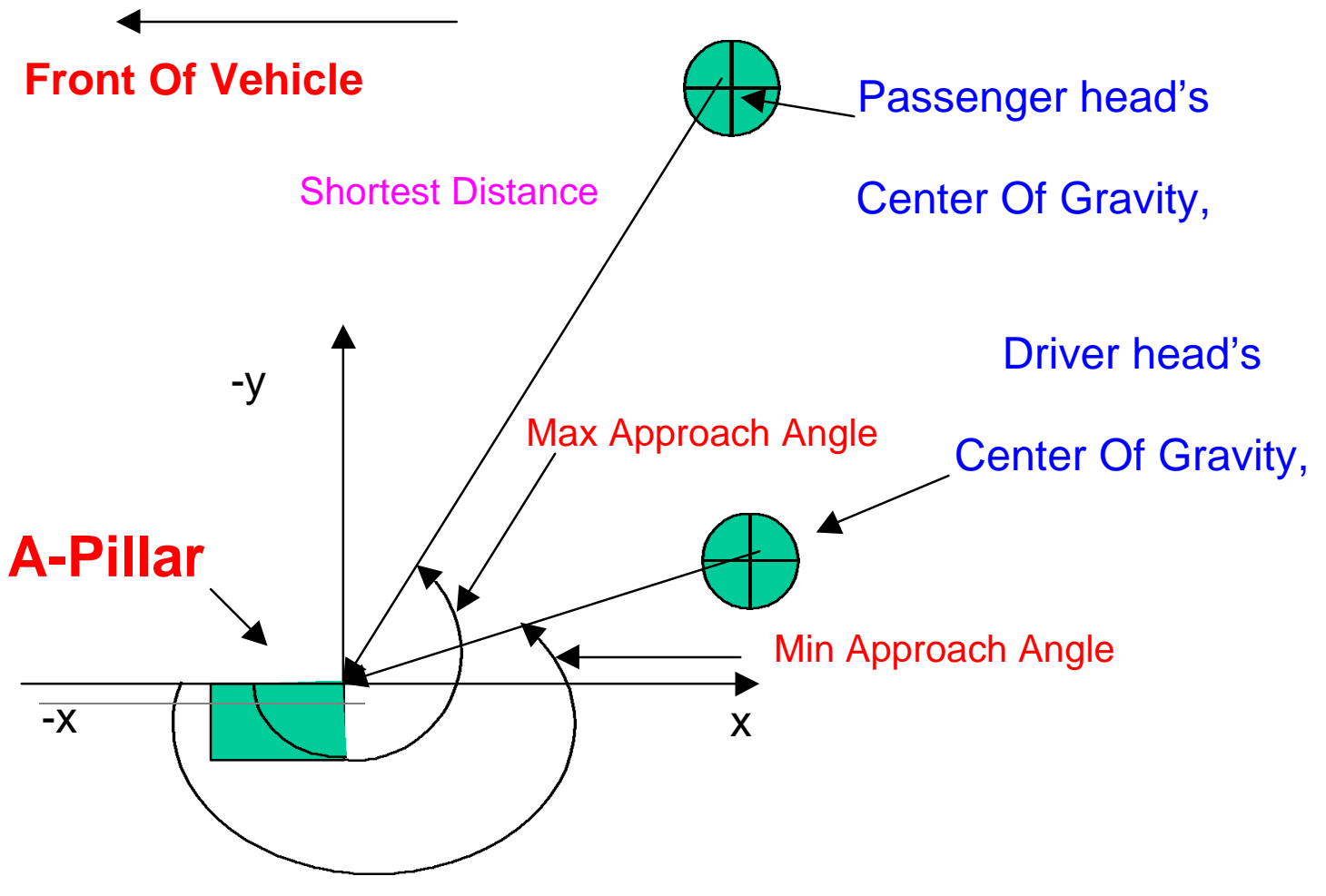

Figure 4.1 Determination of horizontal approach angles for an A-Pillar 
These angles are dependent on the interior trim design and on the occupant head's center of gravity relative to the trim. FMH is then launched along the horizontal angle that may be in between the minimum and maximum values including the extreme angles.

In this work, the horizontal approach angle is referenced from the flange of the inner panel rather than the negative $\mathrm{x}$-axis as shown in Figure 4.1. This is done as a matter of convenience so as to state the FMH impact angle off the flange of the inner panel. Therefore a sum of $180^{\circ}$ needs to be added to this angle to state the horizontal approach angle as per NHTSA specifications. In this research, the analyses are performed at two different horizontal approach angles measured from the flange of the inner panel. These two angles are $30^{\circ}$ (minimum) and $60^{\circ}$ (maximum) (if stated as per NHTSA definitions, these angles would be $210^{\circ}$ and $240^{\circ}$ respectively). The $30^{\circ}$ horizontal impact angle shown in Figure 4.2a, represents the impact vector passing through the driver side occupant head's center of gravity and forms a worst case since the headform directly impacts the flange of the BIW. The $60^{\circ}$ horizontal impact angle as shown in Figure $4.2 \mathrm{~b}$, represents the impact vector passing through the passenger side occupant head's center of gravity. Figures $4.3 \mathrm{a}, 4.3 \mathrm{~b}$, and $4.3 \mathrm{c}$, show the $30^{\circ}$ horizontal approach angle setup for the three different trim designs. 


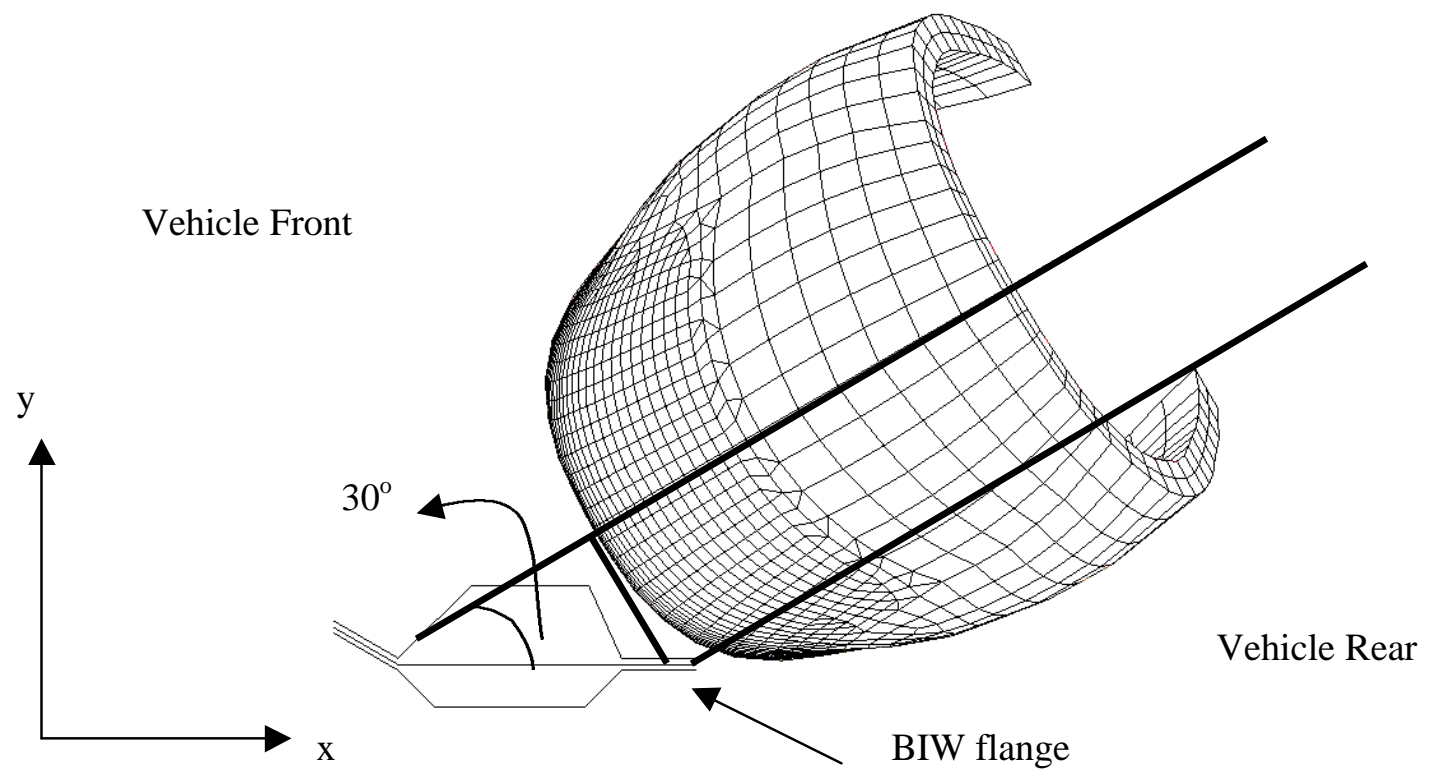

Figure4.2a Modified $30^{\circ}$ Horizontal approach angle set up

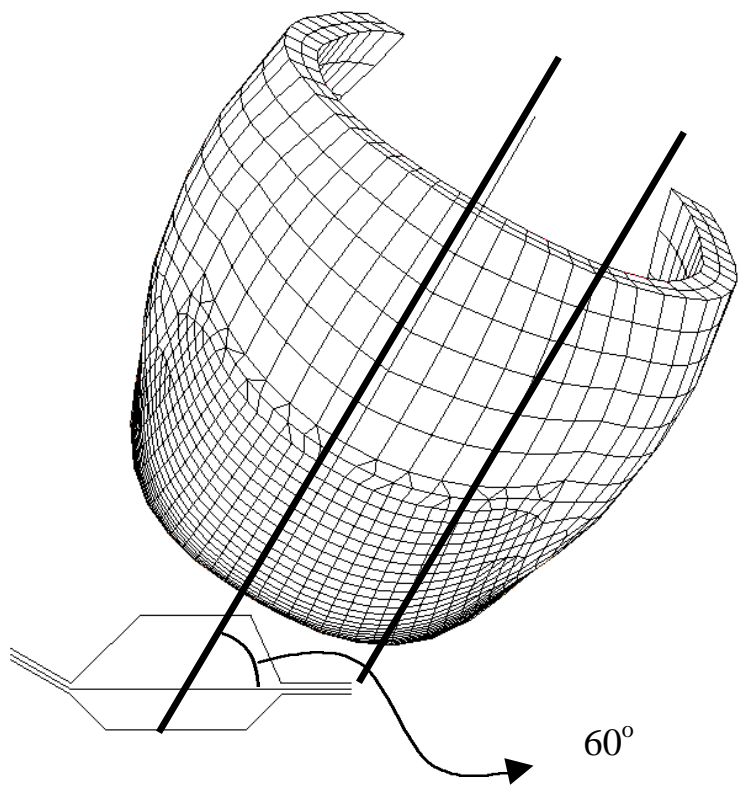

Figure 4.2b Modified $60^{\circ}$ Horizontal approach angle set up 


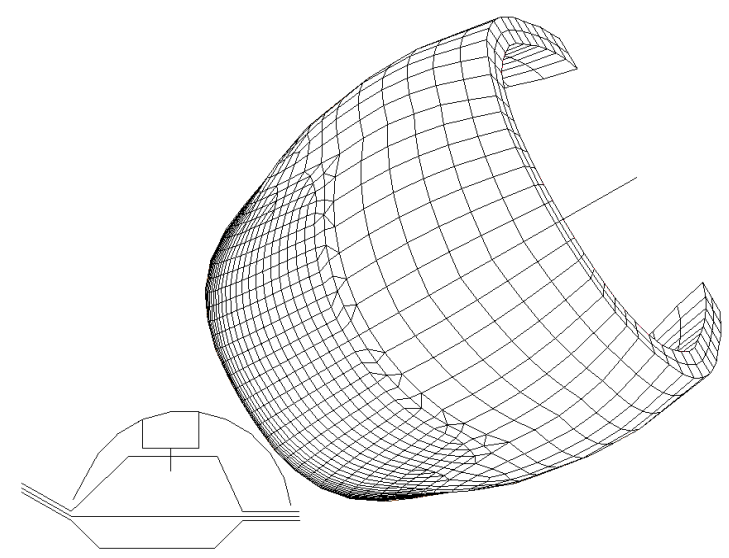

Figure4.3a $\quad 30^{0}$ Horizontal approach angle set up for Trim Design-1

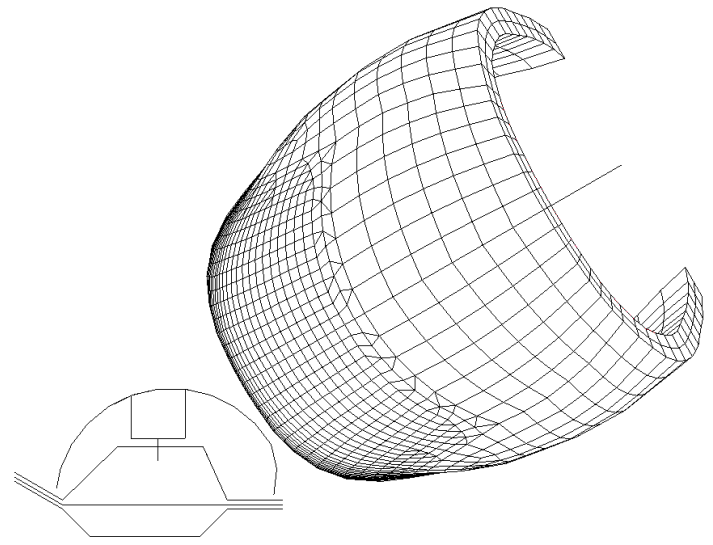

Figure4.3b $\quad 3^{0}$ Horizontal approach angle set up for Trim Design-2

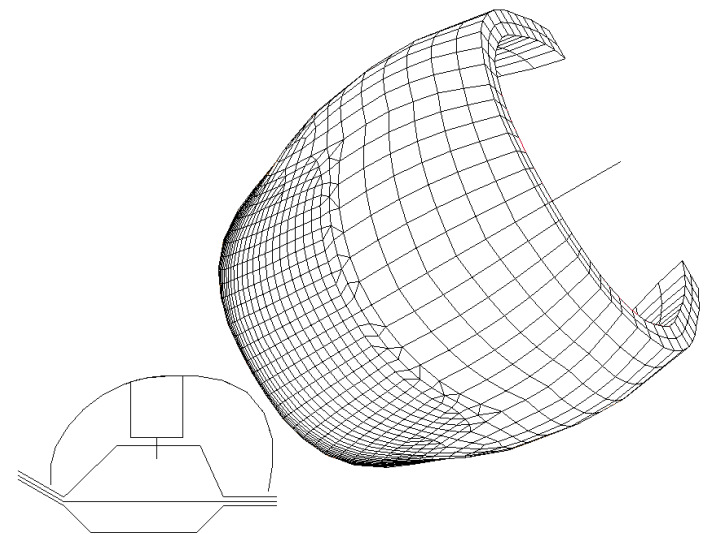

Figure4.3c $\quad 3^{0}$ Horizontal Approach Angle Set Up for Trim Design-3 


\subsubsection{VERTICAL APPROACH ANGLE}

Vertical approach angle is defined as the angle that the centerline of FMH makes with $x-y$ plane of the vehicle. Vertical approach angle is dependent on the target point and a particular value of the horizontal approach angle. Figure 4.4 shows the three steps needed to determine the vertical approach angle of the headform for a given target point and horizontal angle for an A-Pillar. After identifying a particular target point on the interior trim, the headform is first placed corresponding to any desired horizontal approach angle as shown in step 1. The headform is then rotated about the xy-plane towards the interior trim surface until the chin of the headform touches the trim as shown in step 2. As a final step, the headform is rotated back $5^{\circ}$ to achieve the vertical approach angle.

In this research, a vertical approach angle of $15^{\circ}$ is used for all the analyses as shown in Figure 4.5. 


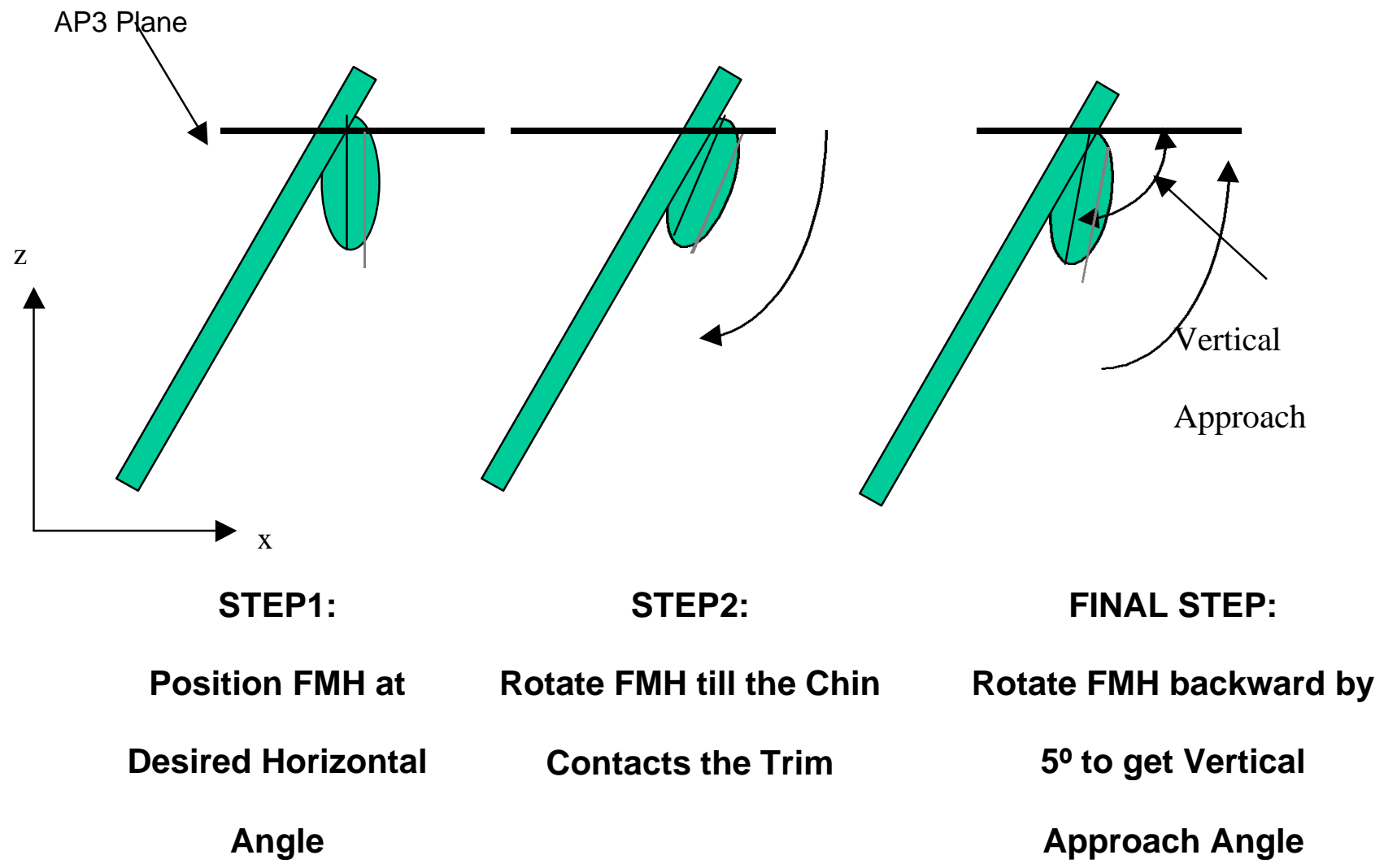

Figure 4.4 Determination of vertical approach angle for an A-Pillar 


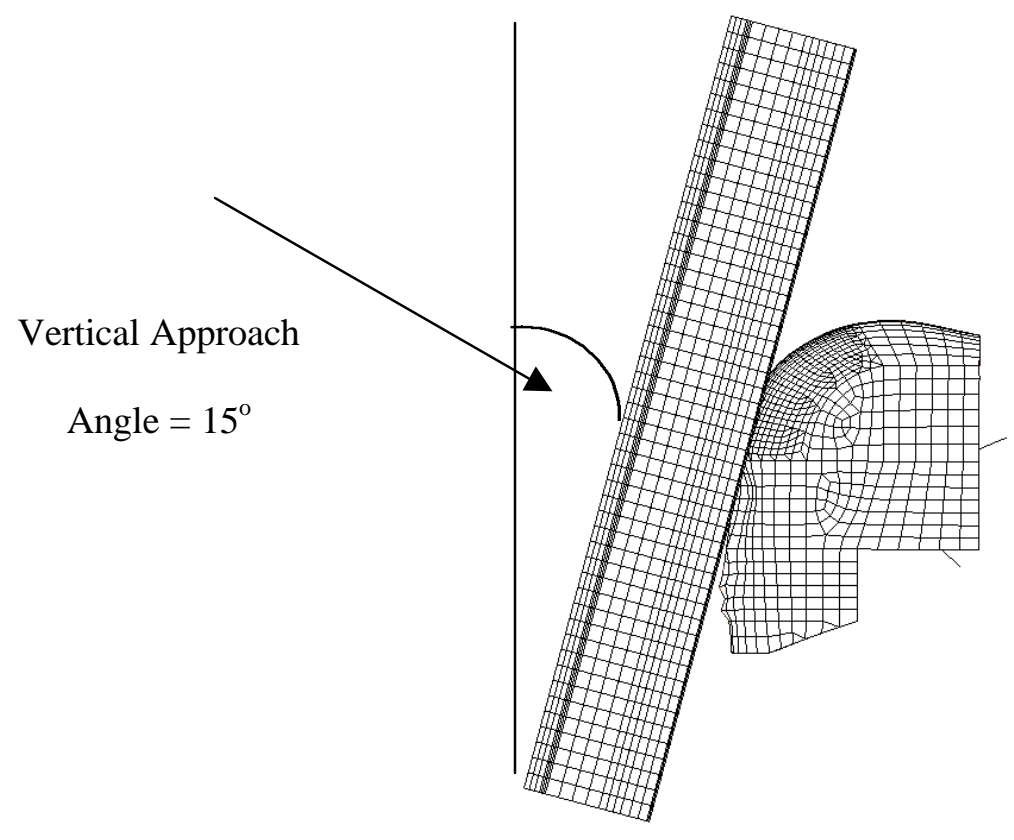

Figure 4.5 Vertical approach angle of FMH 


\subsection{IMPACT POINT}

Impact locations are determined based on NHTSA test procedures to identify specific points in the vehicle and then determining the target planes on the pillars. These measurements are unique to each vehicle model and require precise calculations relative to the vehicle including the exact length and width of the interior roof area, height of the pillars, and contour line measurements.

For an A-Pillar, there are three points (AP1, AP2, and AP3) that need to provide head impact protection. The AP3 target point is a point on the AP3 cross-sectional plane that gives the shortest distance between the driver side occupant head' center of gravity (in the forward most seating position) and the cross-section at AP3 as shown in Figure 4.6.

In this work the target point is measured at $45 \mathrm{~mm}$ from the edge of the flange normal to the horizontal approach angle as shown in Figure 4.7. 


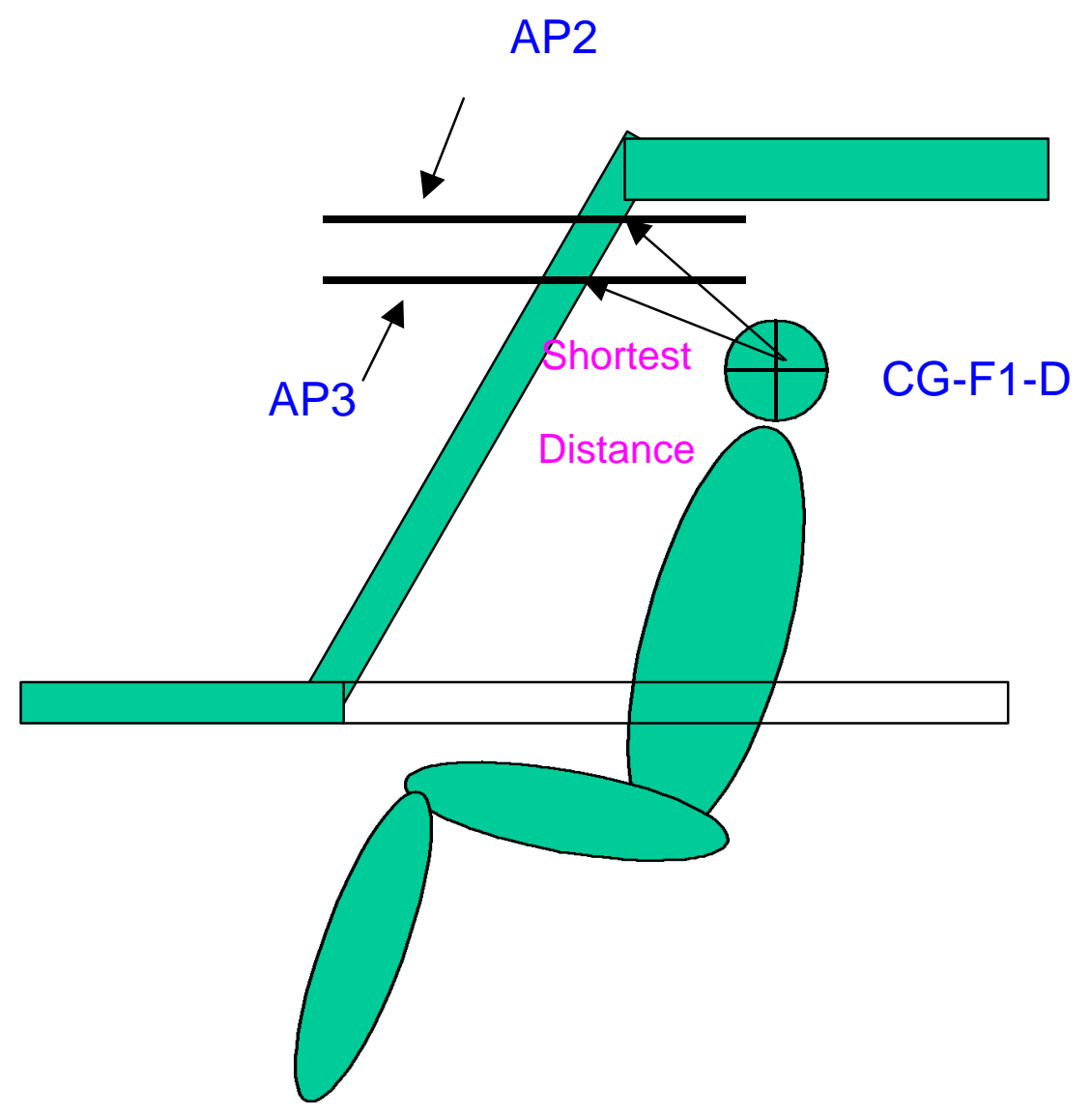

Figure 4.6 Determination of target point for AP3 on the A-Pillar 


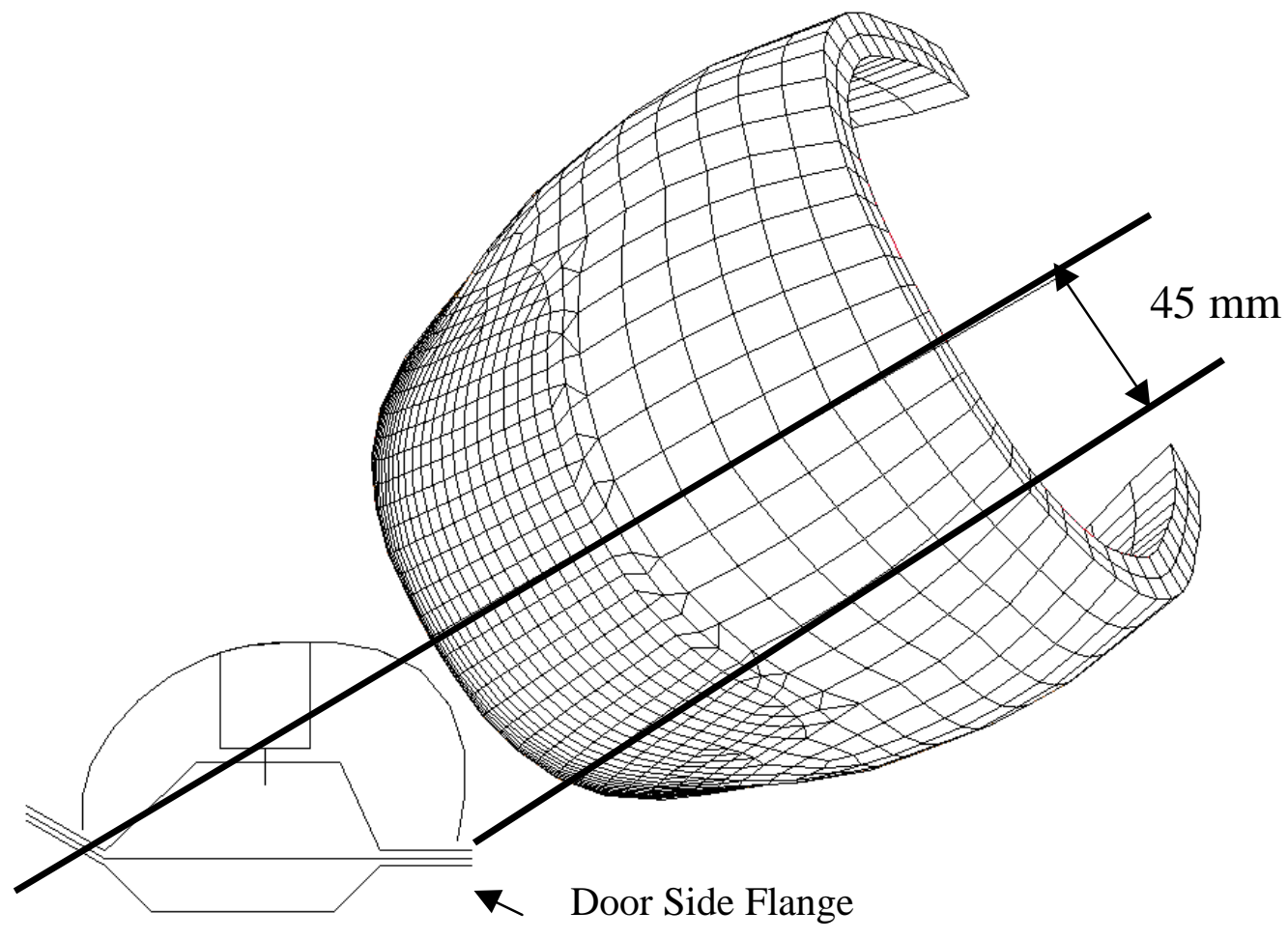

Figure 4.7 Target point used in current research 


\subsection{IMPACT VELOCITY}

Impact velocity is determined based on the presence of dynamic systems such as air curtains embedded inside the side rail designed to deploy in an event of a side or rollover impact condition. Based on FMVSS 201 regulations, target points that fall with in the deployed state of dynamic systems, should provide impact protection at a FMH impact velocity of $12 \mathrm{mph}$ while the remaining target points should be tested at $15 \mathrm{mph}$. For vehicles without dynamic systems, all target locations should provide head impact protection at $15 \mathrm{mph}$. In this work, all the analyses are performed at $15 \mathrm{mph}$ as this forms the worst case. 


\subsection{BOUNDARY CONDITION}

Four points, two at each ends of BIW, are constrained in all degrees of freedom to simulate a fully anchored condition. Nodes at these four points as shown in Figure 4.8 are fixed using *BOUNDARY_SPC option is LSDYNA.

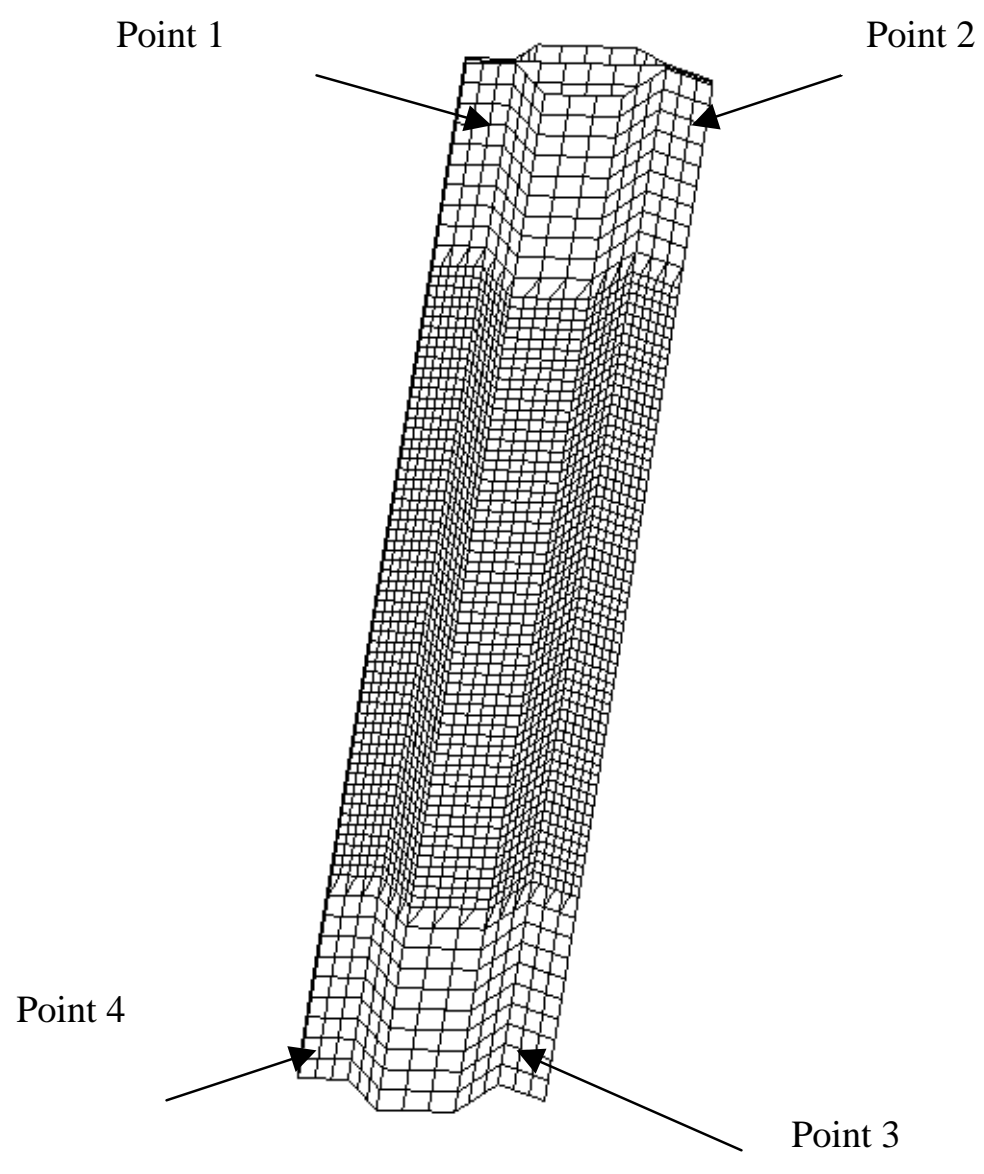

Figure 4.8 BIW boundary conditions 


\subsection{TREATMENT OF CONTACT}

Contact treatment between headform and the upper interior components during impact is one of the most important factors influencing the acceleration response of the headform. Choosing the appropriate contact algorithm and other contact parameters such as friction can cause significant differences obtained in the acceleration pulse. In the following sections, the treatment of contact between different components is discussed.

\subsubsection{FMH AND PANELS}

During impact, the exterior rubber skin of FMH undergoes compression upon contact with the interior trim and/or BIW, absorbing a small magnitude of impact energy. Numerical simulations of contact behavior involve application of spring elements between the nodes of impacting bodies and calculating the forces needed to avoid penetration between the two bodies. The stiffness of the spring elements is derived from the material properties and element size information of the bodies coming in contact. Large differences in material properties between the trim and the rubber skin, leads to insufficient spring stiffness leading to penetration problems resulting in non-physical behavior. This is overcome by modeling a null layer of shell elements with a small thickness over the solid elements of rubber skin and assigning material properties of impacting bodies such as trim and BIW. These elements are used only in contact treatment of impacting bodies.

Selection and evaluation of different contact algorithms in any finite element code is important to understand their influence of the resulting acceleration response of FMH. In this work two different types of contact algorithms are investigated, viz., 
*CONTACT_SURFACE_2_SURFACE and *CONTACT_AUTOMATIC_GENERAL. In *CONTACT_SURACE_2_SURFACE, only the nodes of each elements are checked for penetration against the impact body. This interface type does not consider the shell edges of the impacting body and becomes very important when a sharp edge of BIW such as a flange comes in contact with the FMH. The *CONTACT_AUTOMATIC_GENERAL was developed to account for contact between nodes and elements as well as between shell edge and element. Since only the mid plane is considered in representing thin structural members, such as BIW panels, it becomes meaningful to study the effects of thickness consideration in contact algorithms on the resulting peak acceleration of FMH. Therefore the above two contact algorithms were analyzed with and without the consideration of thickness offsets.

\subsubsection{BIW PANELS}

To account for the interaction between the panels, *CONTACT_SINGLE_SURFACE with a frictional value of 0.2 was defined. In this interface type all the nodes defined in the contact are checked for penetration with the elements and then appropriate force is applied to these nodes to account for load transfer. By default, this interface type considers thickness of the elements included in the contact definition and projects the mid plane surface to half its thickness. 


\subsection{SUMMARY OF ANALYSIS SET UP}

A total of more than 40 analyses involving different material properties, angle of impact, trim designs, and rib designs were performed in this research. Figure 4.9 shows the flow chart of the different analysis performed for both steel and aluminum as BIW material.

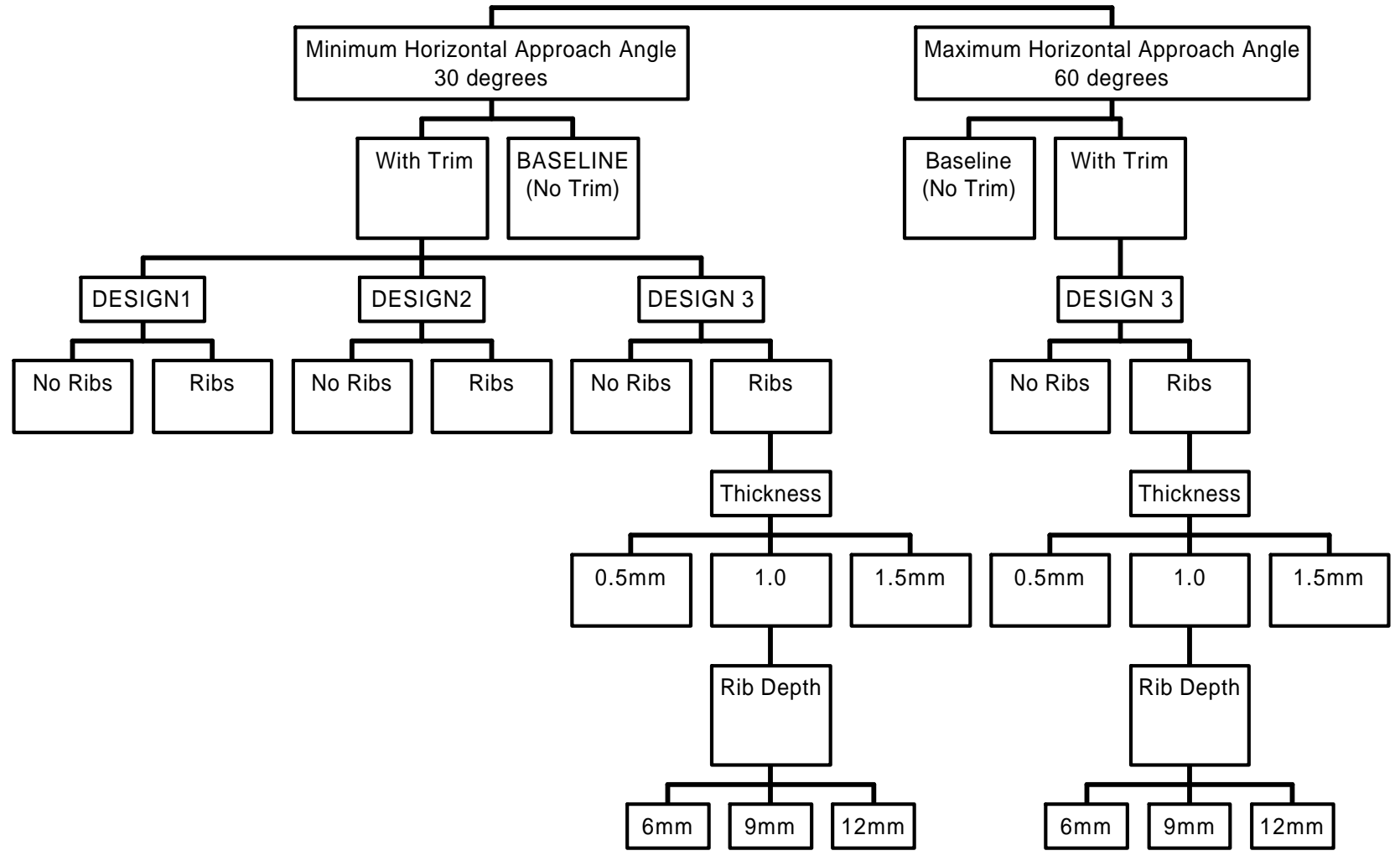

Figure 4.9 Flow chart of analysis setup for both steel and aluminum 


\section{CHAPTER 5 RESULTS AND DISCUSSIONS}

\subsection{FMH CALIBRATION DROP TEST}

In the calibration drop test, the head form is dropped on its forehead impact zone from a height of 14.8 inches in a free fall on to a rigid surface. To eliminate the computational time during the free fall, the FMH is moved close to the rigid surface in the vertical direction as shown in Figure 5.1 and an initial velocity equal to $\sqrt{2 g h}$, where $h=14.8$ inches, is applied to the headform. The current calibration drop test corridor for FMH, recommended by NHTSA, is to be between 225 and 275 g's.

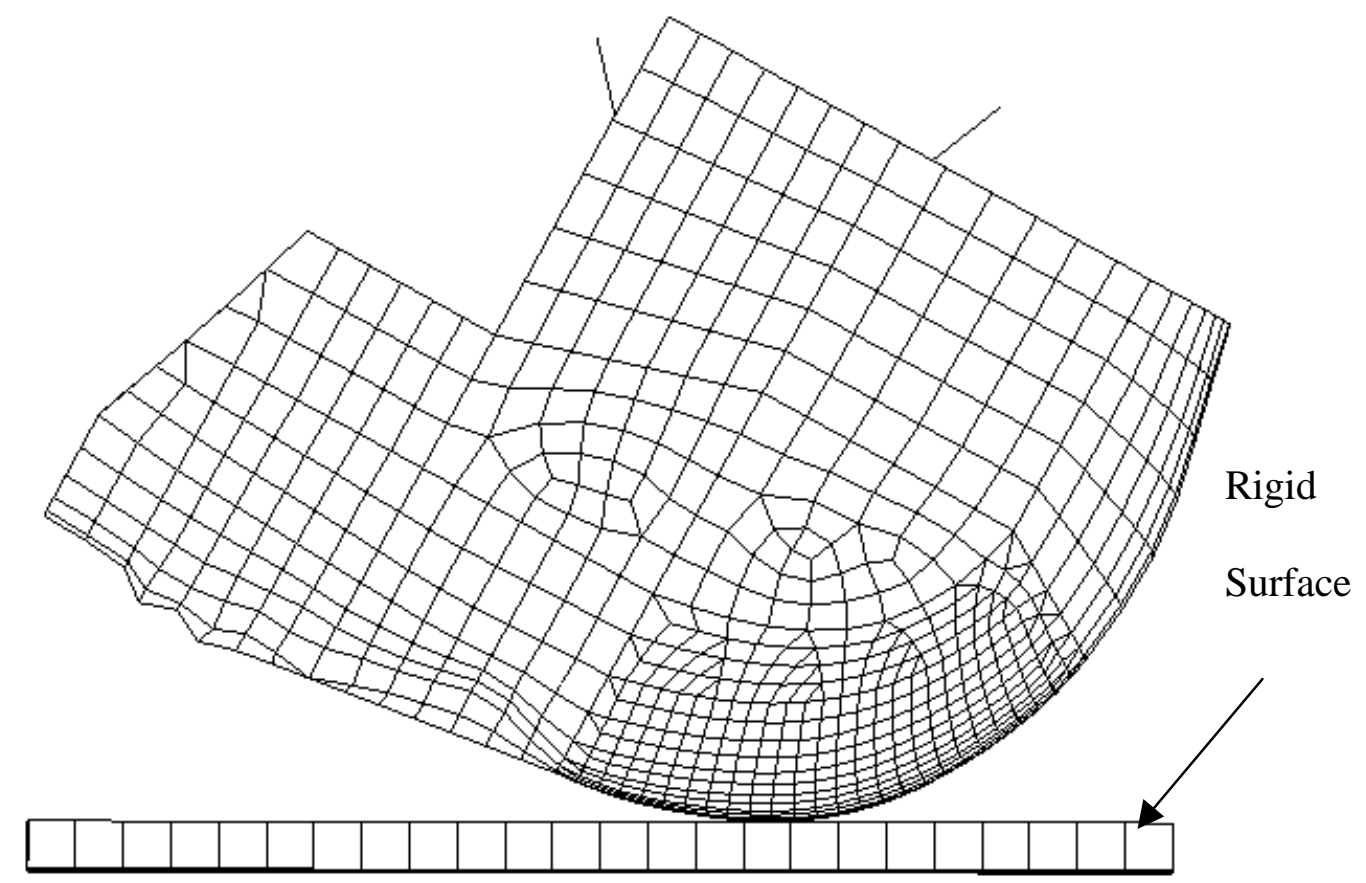

Figure 5.1 FMH calibration drop test set-up 
Figure 5.2 shows the peak resultant acceleration of the finite element head form and the upper and lower corridors as specified by NHTSA. Here, the upper and lower corridors are obtained by simply scaling the finite element model FMH's acceleration response to achieve the minimum and maximum resultant values of 225 g's and 275 g's respectively. It can be observed from the figure, that the peak resultant acceleration of FMH lies between the upper and lower corridor and is approximately equal to $250 \mathrm{~g}$ 's. It can therefore be concluded that the finite element model of the head form can be used to evaluate the head impact protection of interior trim components.

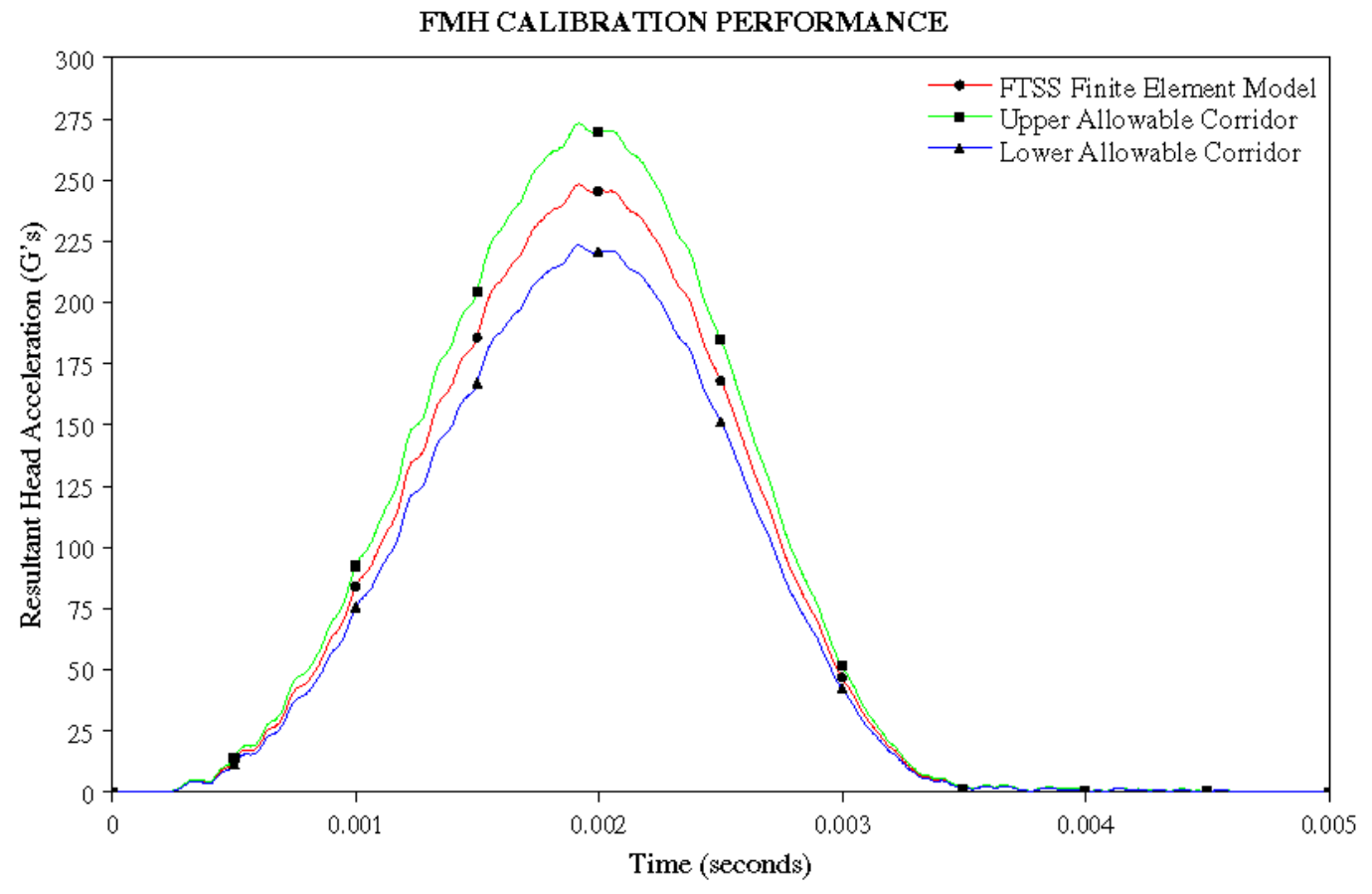




\section{Figure 5.2 Peak resultant acceleration of FMH for calibration drop test}

The peak value of the resultant acceleration has a significant importance while performing correlation between the finite element analysis results and the physical testing. This is because, in finite element models, the peak resultant acceleration of the FMH obtained in calibration drop test is fixed and does not vary for different simulations. During physical testing, NHTSA recommends that the head form be calibrated before every test. The peak resultant acceleration of the physical head form model could vary between these tests and still meet the NHTSA recommendation. This leads to a basic difference in peak value between the physical and finite element model of the head form. Therefore it is recommended to take into account the peak resultant acceleration of the head form in the calibration drop test, before every physical testing of interior trim components. 


\subsection{EFFECTS OF INNER PANEL MESH DENSITY ON HIC(d)}

In a $30^{\circ}$ horizontal approach angle impact condition, the headform comes in direct contact with the flange edge of the inner panel. Although the mesh density of the inner panel could be sufficient to provide a smooth stress distribution, it was found important to study the effects of mesh density on contact forces and resulting head acceleration.

The two different mesh densities of the inner panel, analyzed using steel as the BIW material produced different acceleration response as shown in Figure 5.3. As it can be observed from the figure, the initial slope of the two curves is quite similar during the first $2 \mathrm{~ms}$. But after $2 \mathrm{~ms}$, the coarse mesh produces a sharp spike and then the acceleration seems to drop with small oscillations. The fine mesh on the other hand produces a smoother response and shows two peak values instead of one as seen in the coarse mesh. The first peak is due to the initial contact of the FMH on the flange edge and the second peak is due to the contact with the flat portion of the inner panel. As a result of this, the coarse mesh and the fine mesh predicted a HIC(d) of 1258 and 1291, respectively, resulting in a difference of $2.5 \%$.

Closer examination of the animation showed that in the coarse mesh, only a few nodes coming in contact with FMH exerted large impact forces on the rubber solid element causing the solid element to deform non-physically. This phenomenon can be seen in a side view of the model as shown in Figure 5.4a and 5.4b. In the fine mesh, more number of elements near the impact zone helped to distribute the impact forces over larger number of nodes providing a smoother acceleration response. 


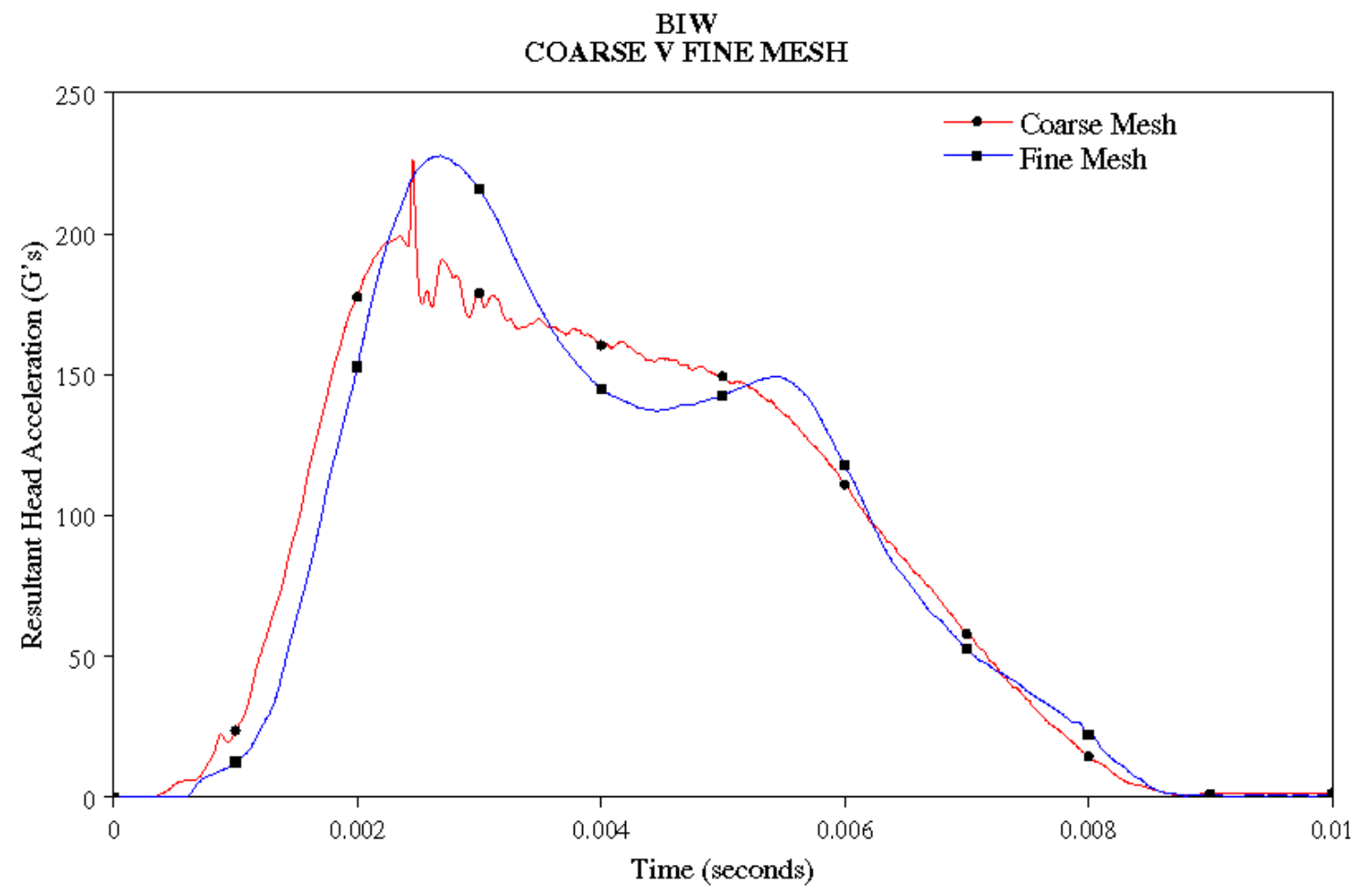

Figure 5.3 Coarse vs fine mesh of inner panel for $30^{\circ}$ horizontal angle 


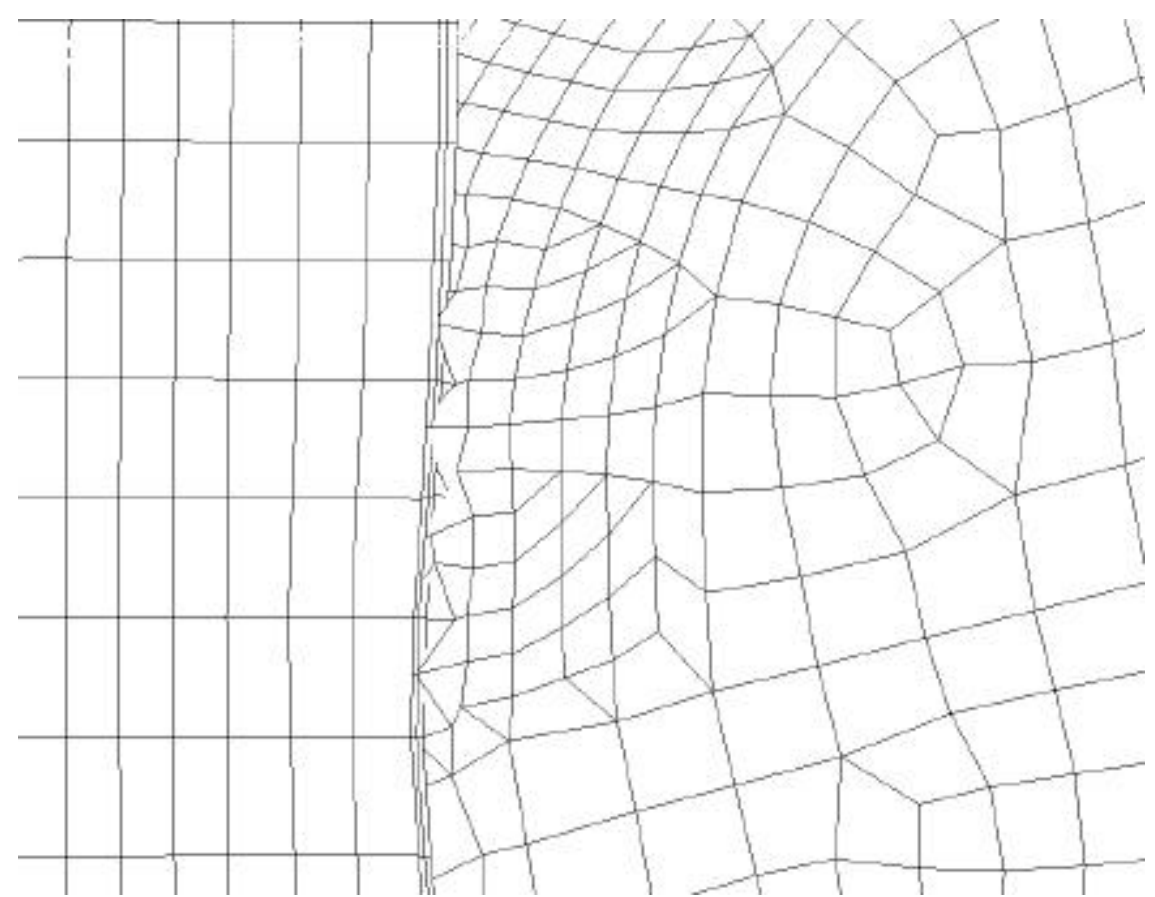

Figure 5.4a Deformation plot at $3.5 \mathrm{~ms}$ using coarse mesh on the inner panel

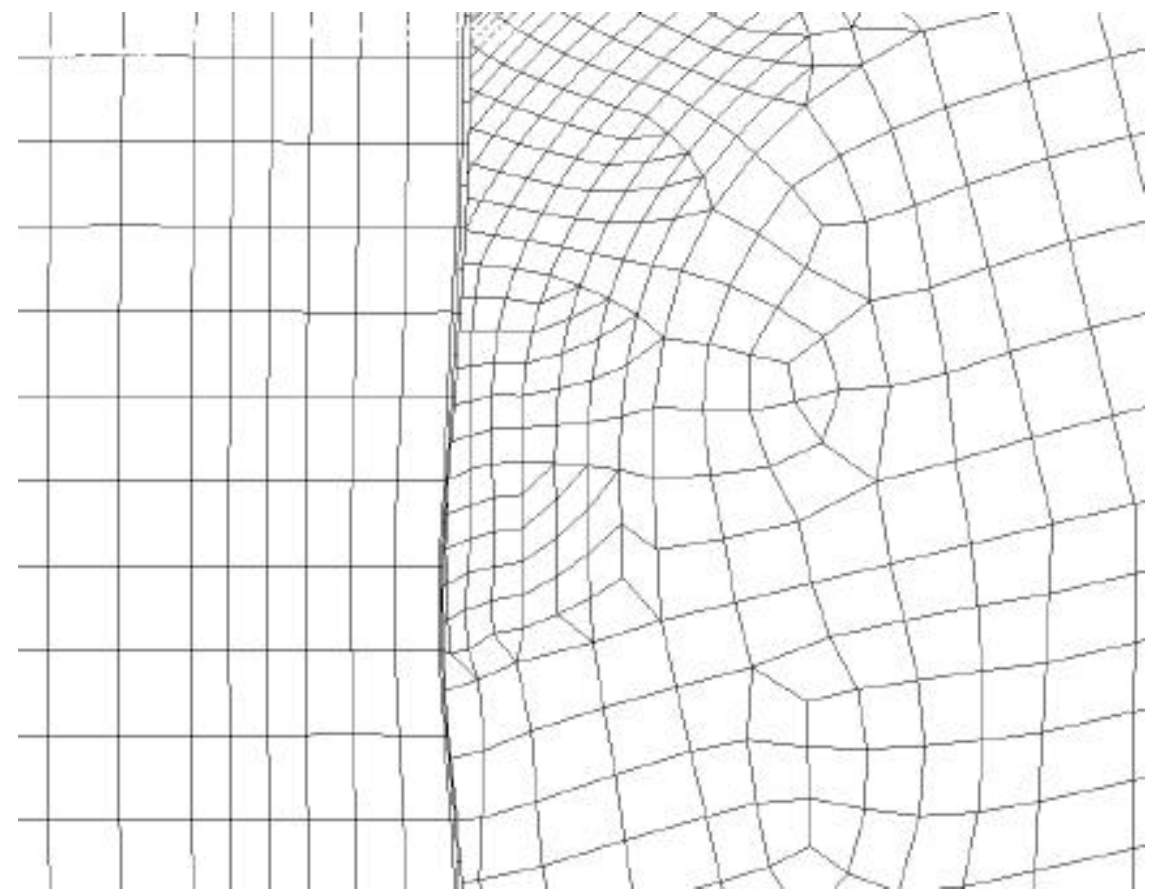

Figure 5.4b Deformation plot at $3.5 \mathrm{~ms}$ using fine mesh on the inner panel 
Though the percentage difference was around 5\%, missing the phenomenon of predicting two peaks in the acceleration response of FMH and providing a smoother response was found critical.

To fully understand the simulation sequence, a section plane A-A, normal to the extruded length of the inner panel was cut at the impact point as shown in Figure 5.5. Top view of the analysis sequence for the finer mesh and at section A-A can be seen at 0 , 4, and $8 \mathrm{~ms}$, in Figure 5.6. The first and second peak in the acceleration response is identified in these sequences.

Based on these results, it was concluded to use the finer mesh density of the inner panel for all the remaining analyses. 


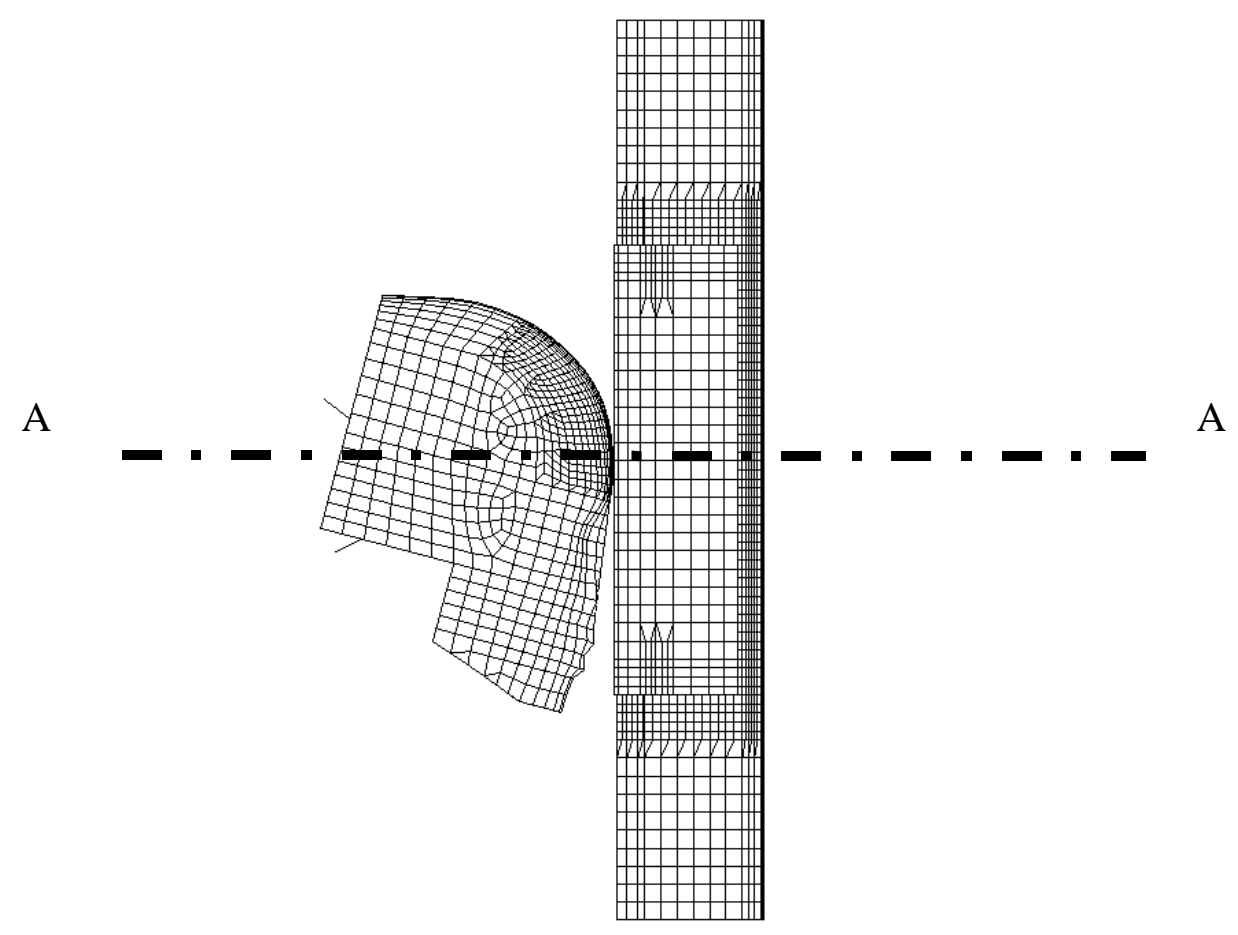

Figure 5.5 Sectional plane at point of first contact 
$0 \mathrm{~ms}$

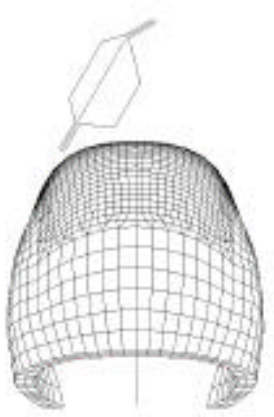

$1 \mathrm{~ms}$
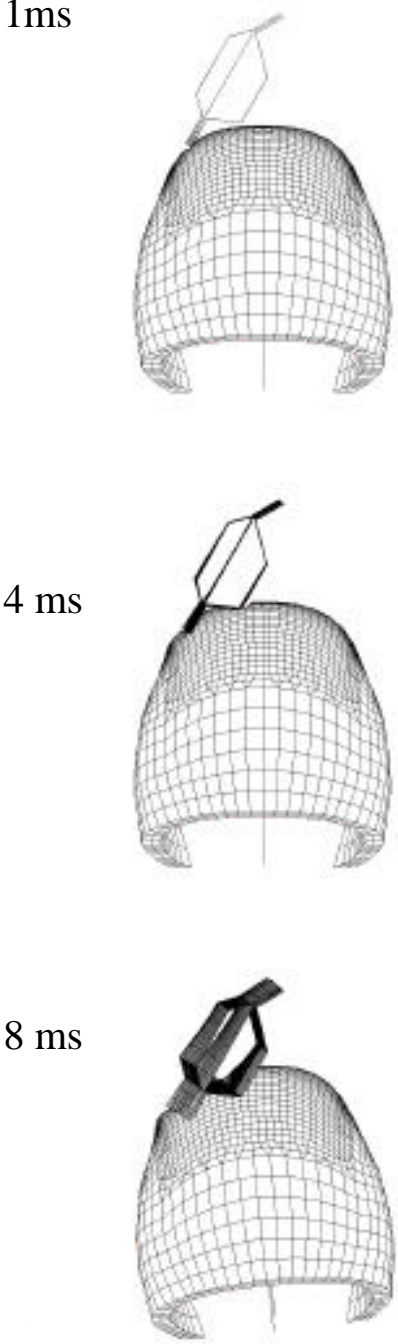

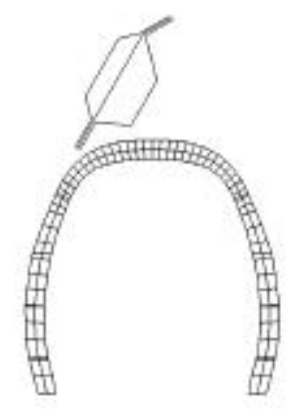

Initial Peak

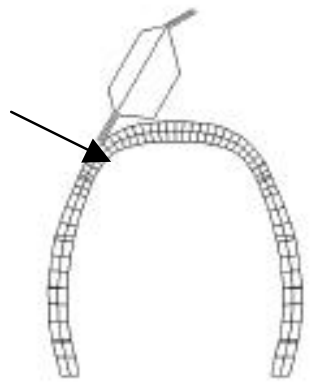

Second Peak
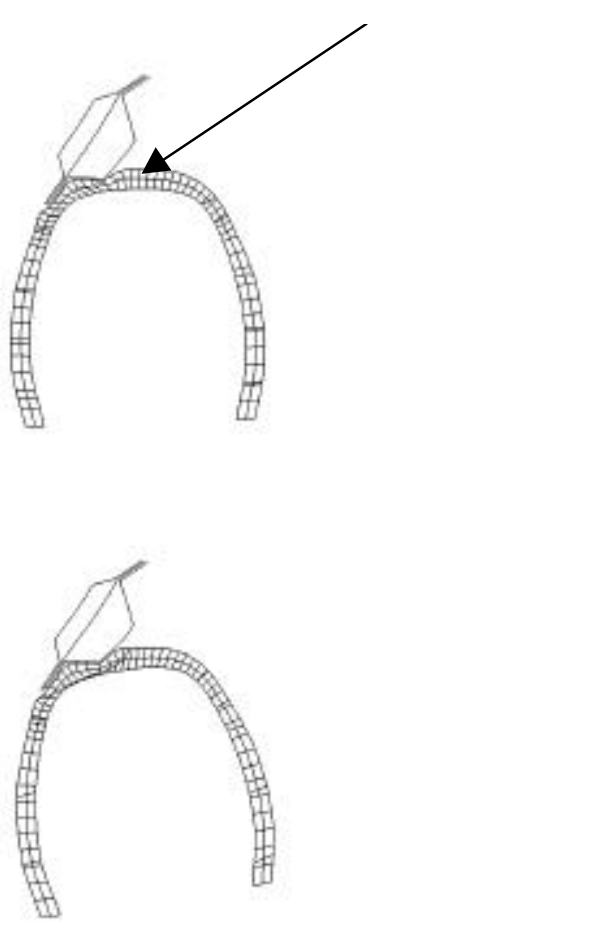

Figure 5.6 Baseline impact at $30^{\circ}$ horizontal approach angle 


\subsection{EVALUATION OF CONTACT ALGORITHMS}

Using fine-mesh model of inner panel, the following three cases involving different contact algorithms were analyzed at $30^{\circ}$ horizontal approach angle.

1. *CONTACT_SURFACE_TO_SURFACE (without thickness offsets)

2. *CONTACT_SURFACE_TO_SURFACE (with thickness offsets)

3. *CONTACT_AUTOMATIC_GENERAL (with thickness offsets)

Figure 5.7 shows the resultant head acceleration obtained using *CONTACT_SURFACE_TO_SURFACE contact type, with and without thickness offsets. Although finer mesh density of the inner panel was used in both the analyses, without considering thickness offsets in the treatment of contact produced oscillatory response around peak acceleration levels. Also the phenomenon of two peaks were missed without taking thickness offset into account resulting in a 5\% decrease in HIC(d).

In Figure 5.8, the acceleration response using *CONTACT_SURFACE_TO_SURFACE and *CONTACT_AUTOMATIC_GENERAL is compared. Though *CONTACT_SURFACE_TO_SURFACE checks only the slave nodes of the FMH for penetration and *CONTACT_AUTOMATIC_GENERAL checks for both slave nodes and edges of elements for penetration, both contact algorithms produced similar acceleration response. Smoother response of the acceleration pulse with two peaks was observed in both the analyses. HIC(d) of 1291 and 1250 was predicted by *CONTACT_SURFACE_TO_SURFACE and *CONTACT_AUTOMATIC_GENERAL 


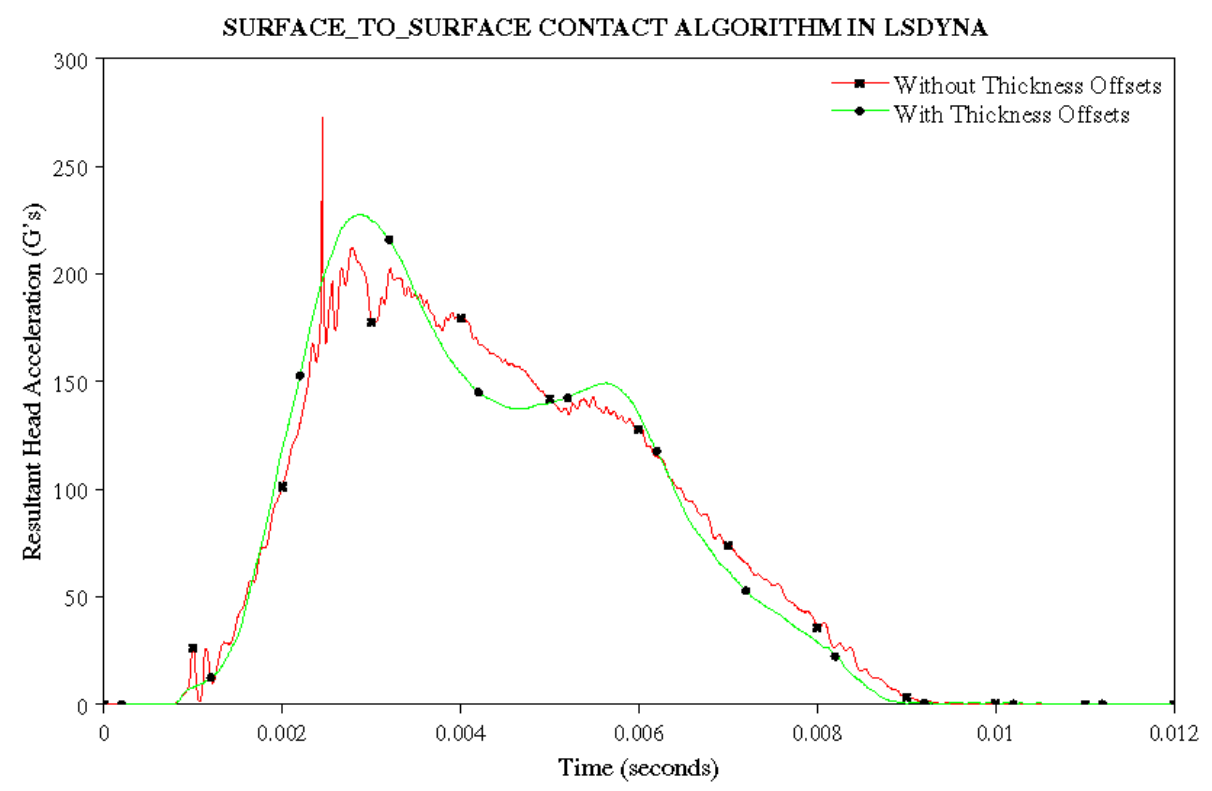

Figure 5.7 Effects of thickness consideration in contact algorithm

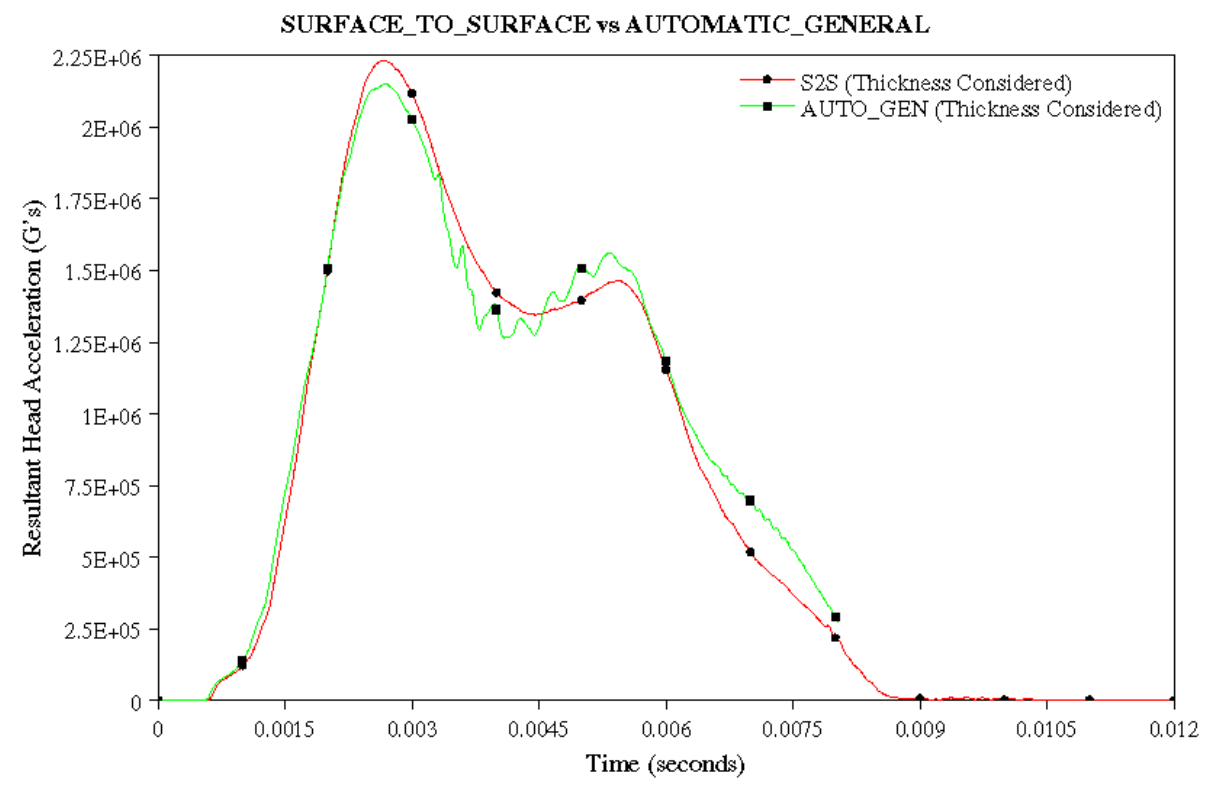

Figure 5.8 Comparison of contact algorithms 
resulting in a $3.1 \%$ difference. This showed that having sufficient number of nodes on the inner panel does not require treatment of element edges in contact algorithms. Based on these results, it was concluded to use *CONTACT_SURFACE_TO_SURFACE with thickness offsets in all the analyses. 


\subsection{BASELINE (NO TRIM) COMPARISON OF STEEL AND}

ALUMINUM FOR 30 ${ }^{\circ}$ AND $60^{\circ}$ HORIZONTAL APPROACH ANGLE

With the conclusions obtained from pervious results, performance between steel and aluminum as a BIW material was investigated at $30^{\circ}$ and $60^{\circ}$ horizontal approach angles and the results are presented in the following sections.

\subsection{1 $30^{\circ}$ HORIZONTAL APPROACH ANGLE}

In this impact condition, both steel and aluminum showed unique energy absorbing characteristics in the acceleration response of FMH as shown in Figure 5.9. As discussed in previous section, the steel BIW showed two peaks in the acceleration pulse and the difference between these two peaks was determined to be around $80 \mathrm{~g}$ 's. The aluminum BIW, on the other had produced a more desirable acceleration response by absorbing the impact energy at almost constant level of acceleration and having a difference of only around $20 \mathrm{~g}$ 's between the two peaks. Also the time duration over which the energy was absorbed in the case of aluminum was an additional $2 \mathrm{~ms}$ compared to steel. Therefore using aluminum as a BIW material resulted in a smaller HIC(d) of 967 while steel produced 1291.

\subsection{2 $60^{\circ}$ HORIZONTAL APPROACH ANGLE}

For the $60^{\circ}$ horizontal approach angle, the acceleration pulse using steel produced an initial peak of around $180 \mathrm{~g}$ 's compared to $230 \mathrm{~g}$ 's in $30^{\circ}$ impact angle as shown in Figure 5.10. The second peak remained at around $160 \mathrm{~g}$ 's thereby indicating a difference of only $20 \mathrm{~g}$ 's compared to $80 \mathrm{~g}$ 's between the first and second peak in $30^{\circ}$ impact angle. 


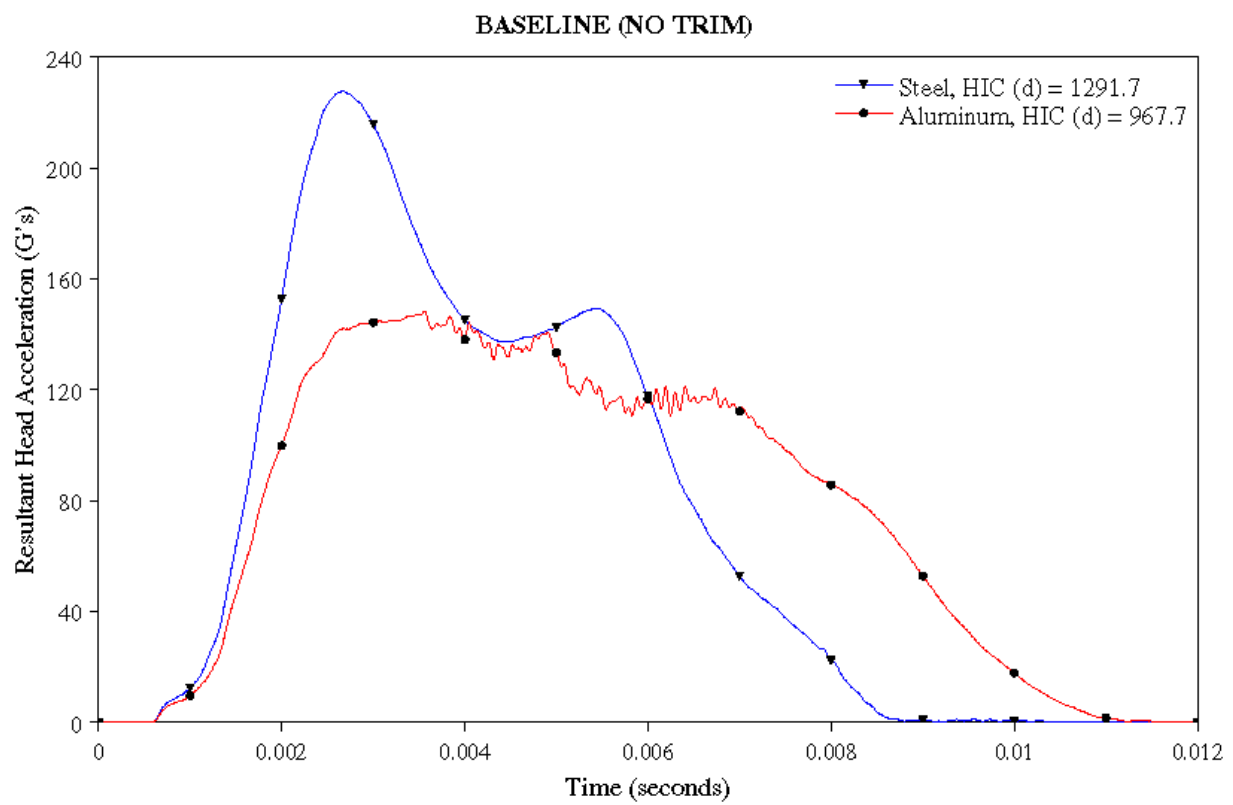

Figure 5.9 Steel vs aluminum for $30^{\circ}$ horizontal approach angle

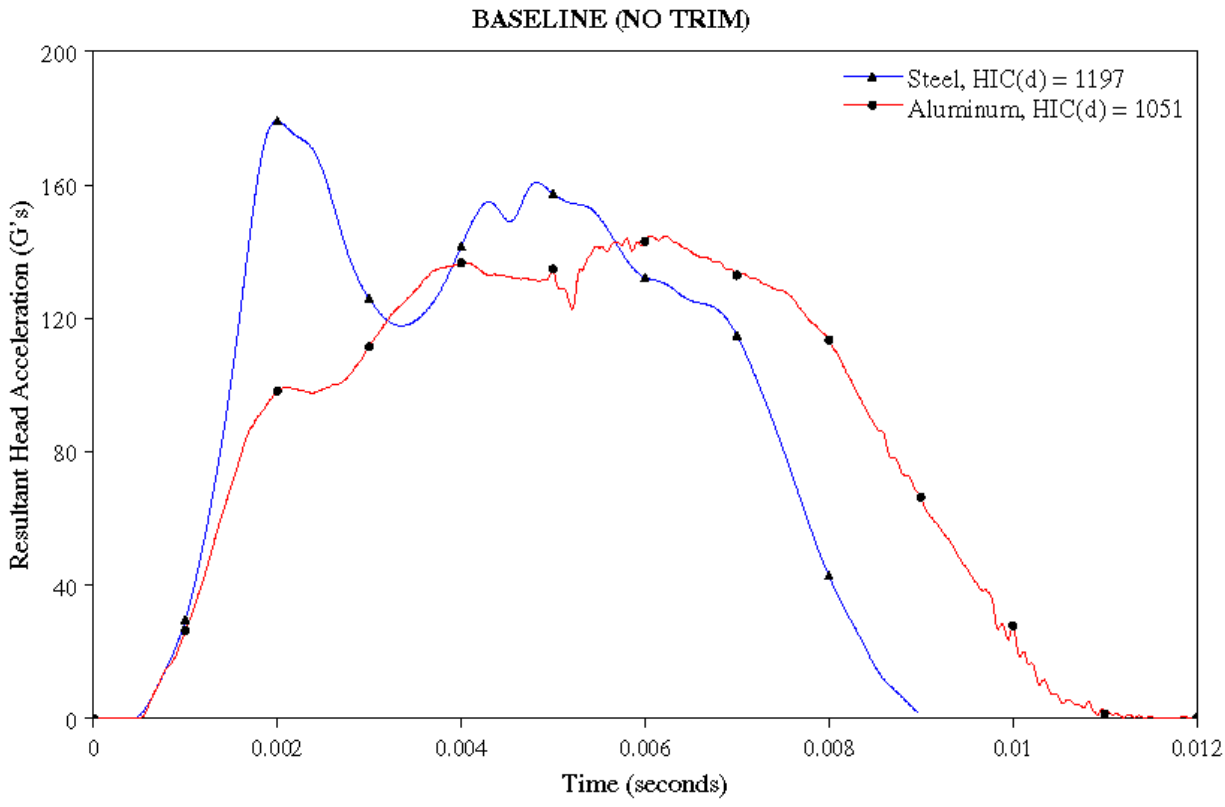

Figure 5.10 Steel vs aluminum for $60^{\circ}$ horizontal approach angle 
In the case of aluminum, a trend of increasing acceleration with an initial peak of $120 \mathrm{~g}$ 's at $2 \mathrm{~ms}$ and a maximum level of around $140 \mathrm{~g}$ 's at $4 \mathrm{~ms}$ is seen. The transient plots, shown in Figure 5.11, indicate the initial contact of FMH to occur at point 'B' on the inner panel rather than the flange edge as seen in $30^{\circ}$ horizontal impact angle. This resulted in a lesser initial peak and due to the deformation at point ' $\mathrm{B}$ ' acceleration seems to drop but increases quickly after contacting the flange edge. As in $30^{\circ}$ impact angle, the aluminum BIW produced a lesser HIC(d), 1051, as opposed to 1197 for steel BIW. 
$0 \mathrm{~ms}$

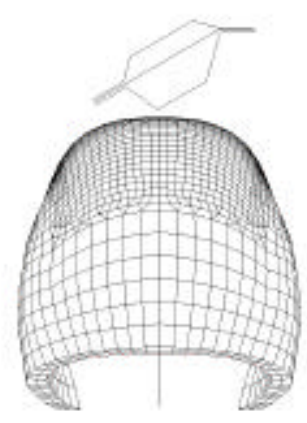

$2 \mathrm{~ms}$

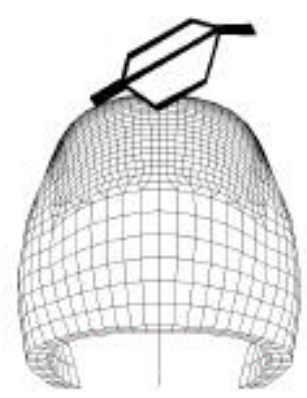

$4 \mathrm{~ms}$

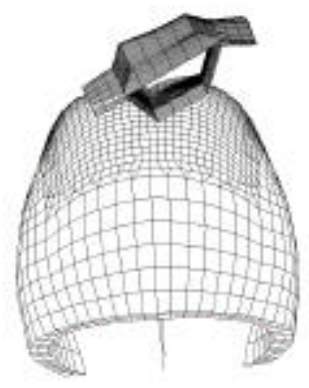

$8 \mathrm{~ms}$

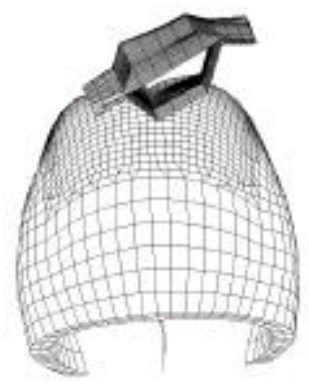

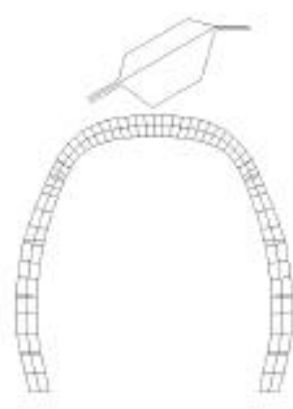

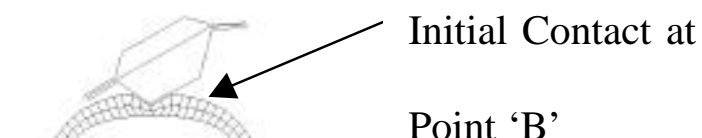

Second Contact

with Flange

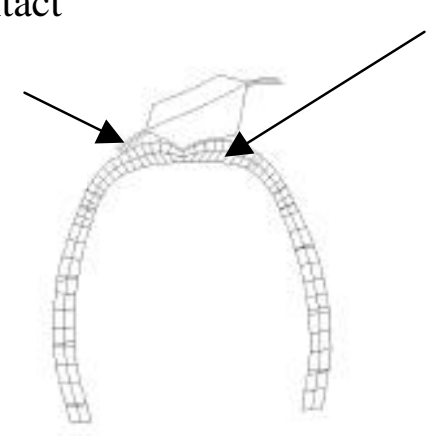

Deformation at

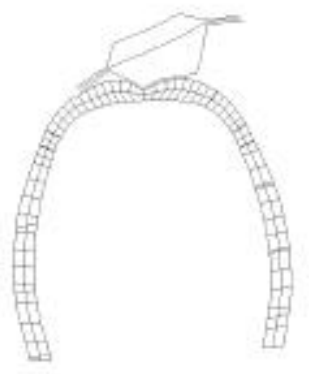

Figure 5.11 Transient plot for $60^{\circ}$ horizontal approach angle 


\subsection{STEEL AND ALUMINUM USING TRIM DESIGN-1 (WITH}

AND WITHOUT RIBS) AT $30^{\circ}$ HORIZONTAL APPROACH ANGLE

To compare the performance of steel and aluminum, Trim Design-1, with a semicircular cross section, was used, with and without ribs. Using the baseline model (no trim), the trim was added and attached to the slot provided in the inner panel at the two clip locations. The FMH was then moved along the impact vector to accommodate the

trim. As shown in Chapter 4, six layers of ribs with a constant thickness of $1 \mathrm{~mm}$ and a rib depth of $6 \mathrm{~mm}$ was used for the analysis involving Trim Design-1 with ribs. The rib was attached to the trim by using *CONTACT_TIED_SHELL_EDGE-TO_SURFACE. The results of Trim Design-1, with and without ribs, are discussed in the following sections.

\subsubsection{TRIM DESIGN-1 WITHOUT RIBS}

In the cases of both steel and aluminum, using Trim Design-1 without ribs, actually caused an increase in $\mathrm{HIC}(\mathrm{d})$ compared to baseline (no trim) analyses. By using Trim Design-1 without ribs, steel and aluminum produced a HIC(d) of 1404 and 1139 respectively as shown in Figure 5.12. The baseline HIC(d) using steel and aluminum was 1291 and 967. Studying the acceleration pulse of steel, Trim Design-1 without ribs, indeed eliminates the second peak in the acceleration pulse, but still resulted in an increase in $\mathrm{HIC}(\mathrm{d})$. This was because more energy was absorbed by the inner panel at the flange rather than by the trim, which seems to absorb energy only during initial $2 \mathrm{~ms}$ of impact. Also less rotation of the FMH about the extruded length axis was observed 
compared to the baseline analysis. The FMH then transfers the kinetic energy to the BIW, starting at around $4 \mathrm{~ms}$ as shown in the transient plots in Figure 5.13.

TRIM DESIGN 1 (NO RIBS)

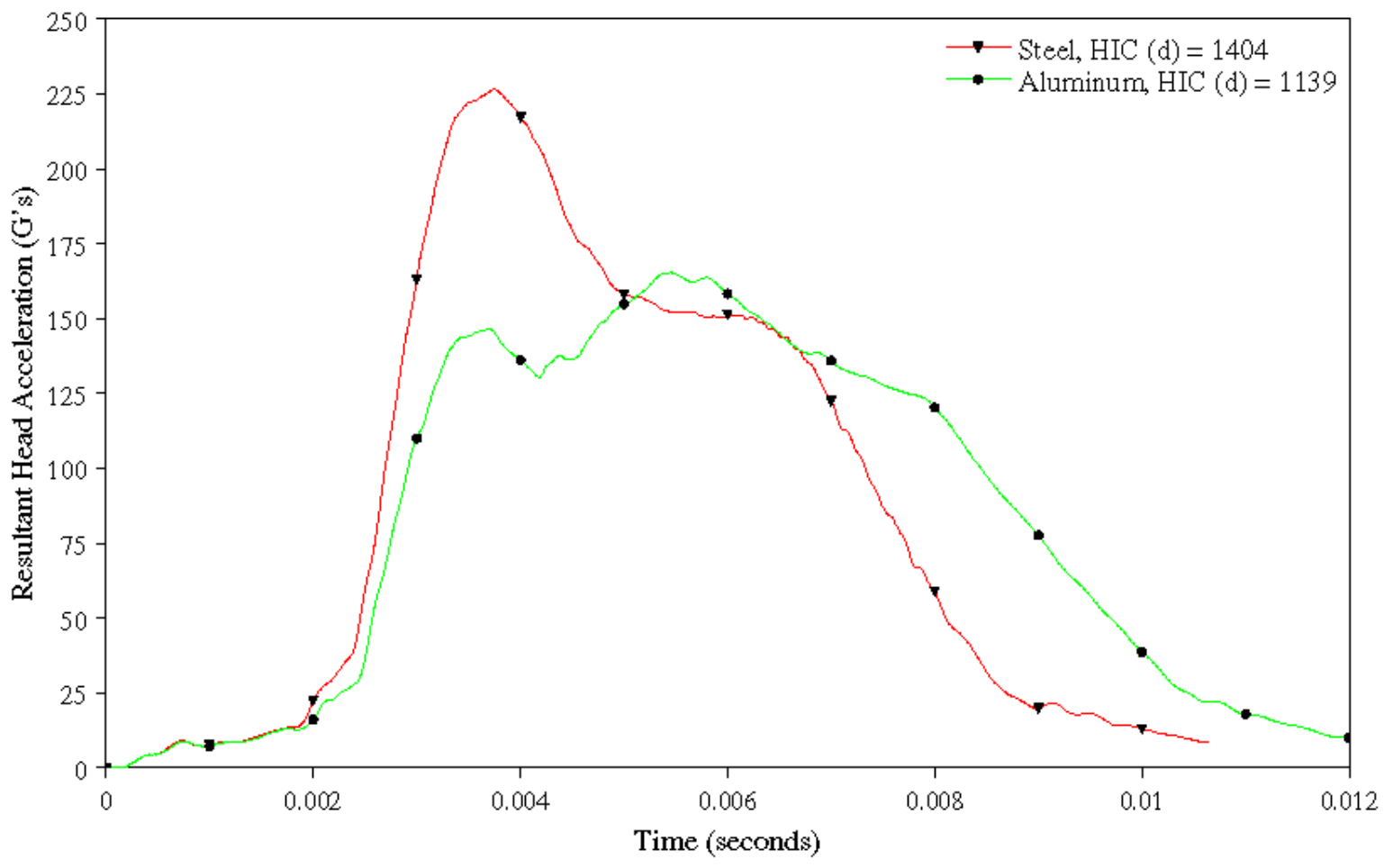

Figure 5.12 Steel and aluminum using Trim Design-1 (without ribs) at $30^{\circ}$ horizontal Angle 
$0 \mathrm{~ms}$
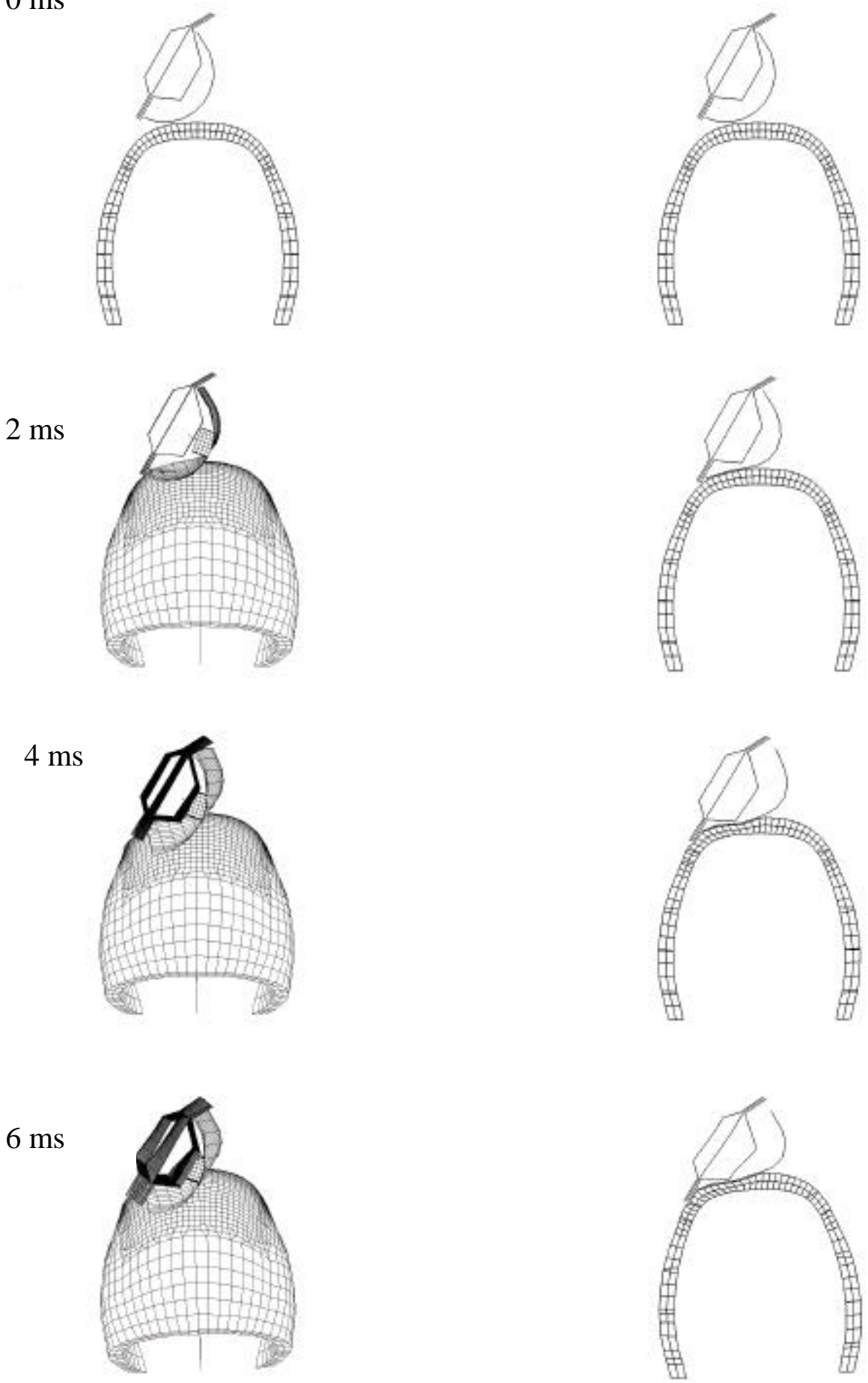

Figure 5.13 Transient plots of steel using Trim Design-1 (without ribs) at $30^{\circ}$ horizontal approach angle 
In the instance of aluminum, with Trim Design-1without ribs, the same phenomenon is observed where the trim absorbs energy only during first couple of milliseconds after contact. After the FMH impacts the flange, the peak acceleration appears to be the same as seen in the baseline analysis at around $150 \mathrm{~g}$ 's. However a higher second peak at $175 \mathrm{~g}$ 's is seen compared to $120 \mathrm{~g}$ 's in the baseline (no trim) model.

\subsubsection{TRIM DESIGN-1 WITH RIBS}

Adding ribs to Trim Design-1 resulted in an increase in $\mathrm{HIC}(\mathrm{d})$ for both steel and aluminum indicating a stiffer response. In the case of steel, the second peak in the acceleration curves reappears as shown in Figure 5.14 due to the impact of ribs on the BIW. Steel and aluminum using trim design, with ribs, produced a HIC(d) of 1416 and

1174, respectively, which is higher, compared to both the baseline and Trim Design-1 with ribs. 
TRIM DESIGN 1 (WITH RIBS)

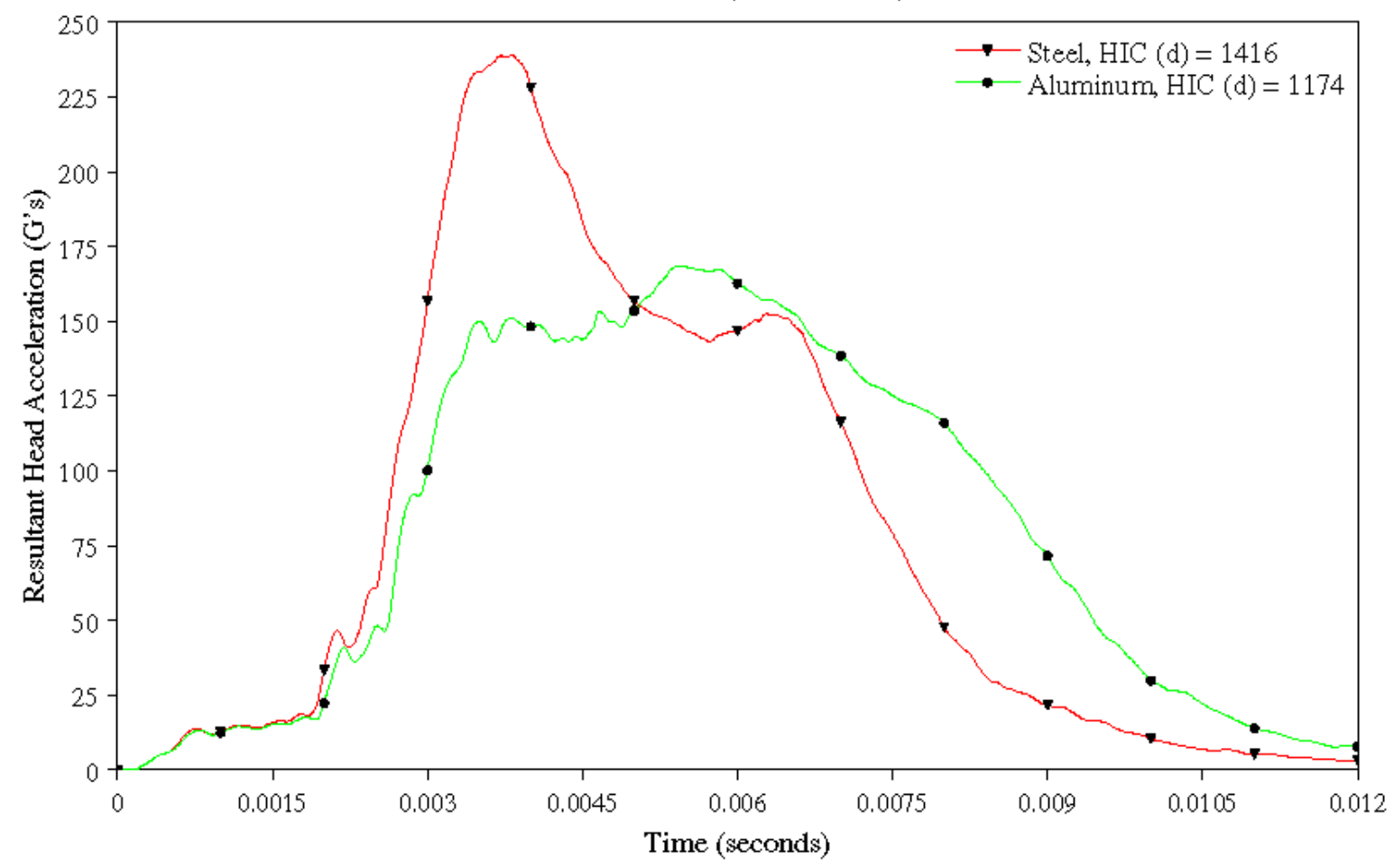

Figure 5.14 Steel and aluminum using Trim Design-1 (with Ribs) at $30^{\circ}$ horizontal approach angle 


\subsection{STEEL AND ALUMINUM USING TRIM DESIGN-2 (WITH}

AND WITHOUT RIBS) AT 30 HORIZONTAL APPROACH ANGLE

In Trim Design-2, the clearance between the inner panel and the trim was increased in an effort to reduce the HIC(d). And accordingly, the FMH was translated back along the impact vector to accommodate the increase in the trim clearance with the inner panel. As in Trim Design-1with ribs, 6 layers of ribs with $1 \mathrm{~mm}$ thickness and 6 mm of rib depth was attached to the inner surface of the trim. Results of Trim Design-2, with and without ribs are presented in the following section.

\subsubsection{TRIM DESIGN-2 WITHOUT RIBS}

By increasing the trim clearance in Trim Design-2, both steel and aluminum produced HIC(d) values of 1318 and 1090, respectively, when compared with Trim Design-1 value of 1404 and 1139, respectively as shown in Figure 5.15. This was however, higher compared to the baseline (no trim) value of 1291 and 967.

In the case of steel, the peak value is slightly smaller compared to Trim Design-1 and the initial peak occurs at around $5 \mathrm{~ms}$ compared to $4 \mathrm{~ms}$. In the transient plots shown in Figure 5.16, the trims slips off the windshield flange at around $8 \mathrm{~ms}$. However less deformation of the inner panel is seen compared to Trim Design-1 at $8 \mathrm{~ms}$ indicating an increase in the energy absorption by the trim.

Aluminum shows similar behavior as seen in Trim Design-1 except for the offsets seen in the initial and second peaks of the acceleration pulse. 
TRIM DESIGN 2 (NO RIBS)

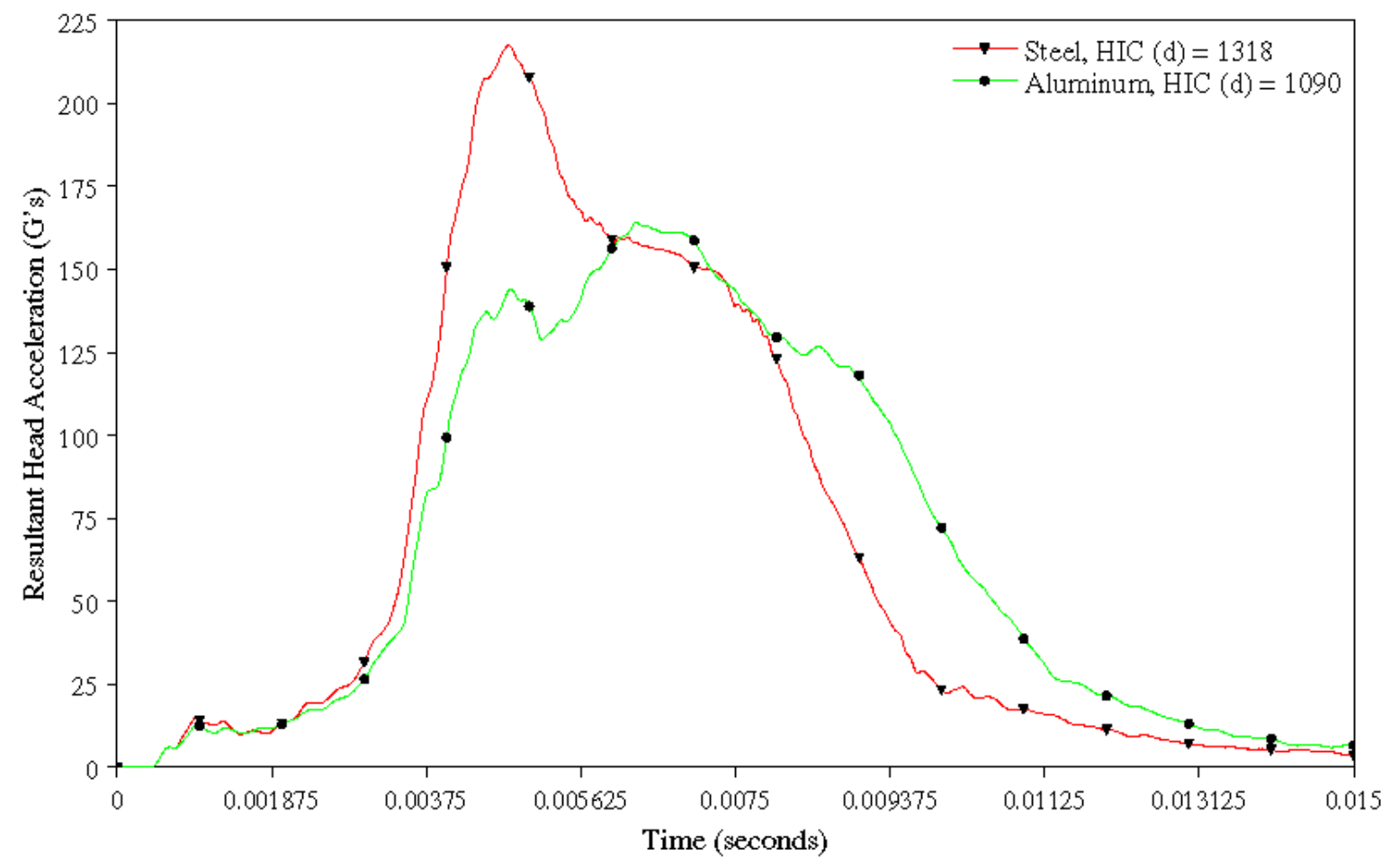

Figure 5.15 Steel and aluminum using Trim Design-2 (without ribs) at $30^{\circ}$ horizontal approach angle 
$0 \mathrm{~ms}$
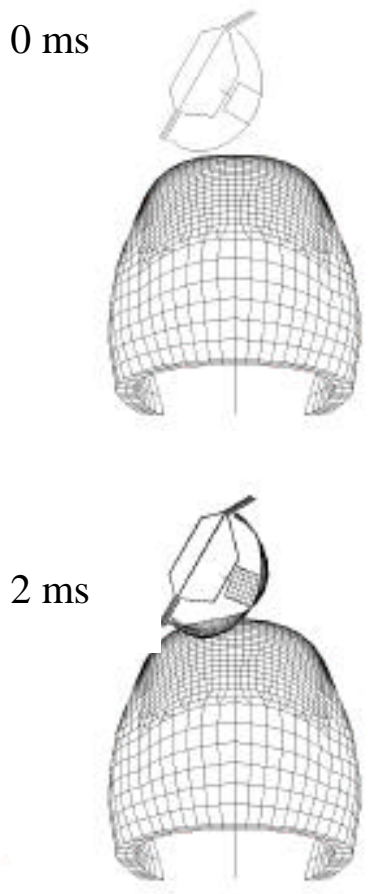

$4 \mathrm{~ms}$
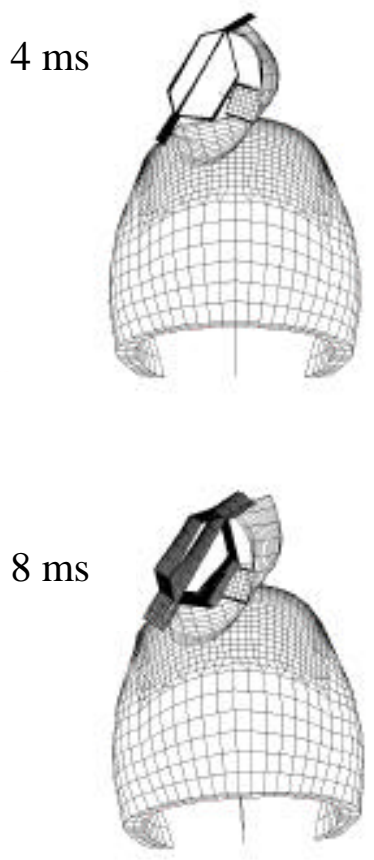
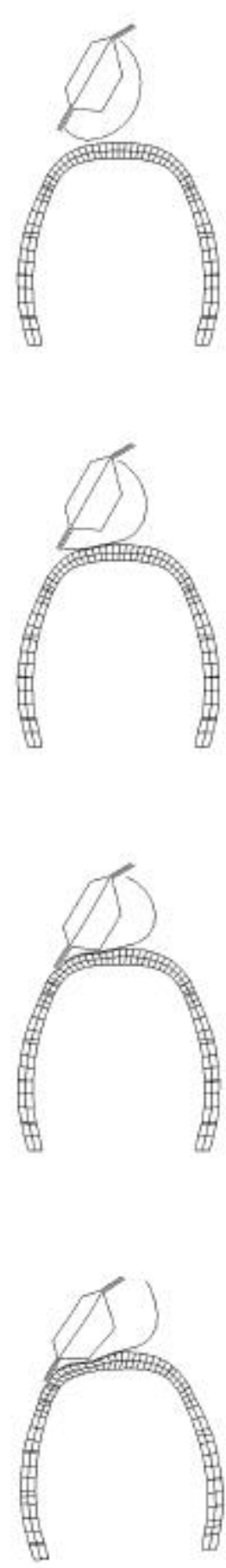

Figure 5.16 Transient plots of steel using Trim Design-2 (without ribs) at $30^{\circ}$ horizontal approach angle 


\subsubsection{TRIM DESIGN-2 WITH RIBS}

Contrary to Trim Design-1, addition of ribs resulted in a reduction of HIC(d) for both steel and aluminum as seen in Figure 5.17. Trim Design-2 with ribs produced HIC(d) of 1233 and 974, respectively for steel and aluminum compared to 1318 and 1090 as seen in Trim Design-2 without ribs.

In the case of steel, there was a third level in the acceleration response at around 8 ms. This is because the ribs impact the inner panel at around $6 \mathrm{~ms}$ and absorbing energy at constant acceleration until around $7 \mathrm{~ms}$. Later, due to the buckling of the ribs the acceleration starts to drop and finally the FMH bottoms out on the inner panel.

For the aluminum, the second peak in the acceleration pulse disappears and the energy is absorbed at constant acceleration of around 150g's indicating increased level of energy absorption by the addition of ribs. 
TRIM DESIGN 2 (WITH RIBS)

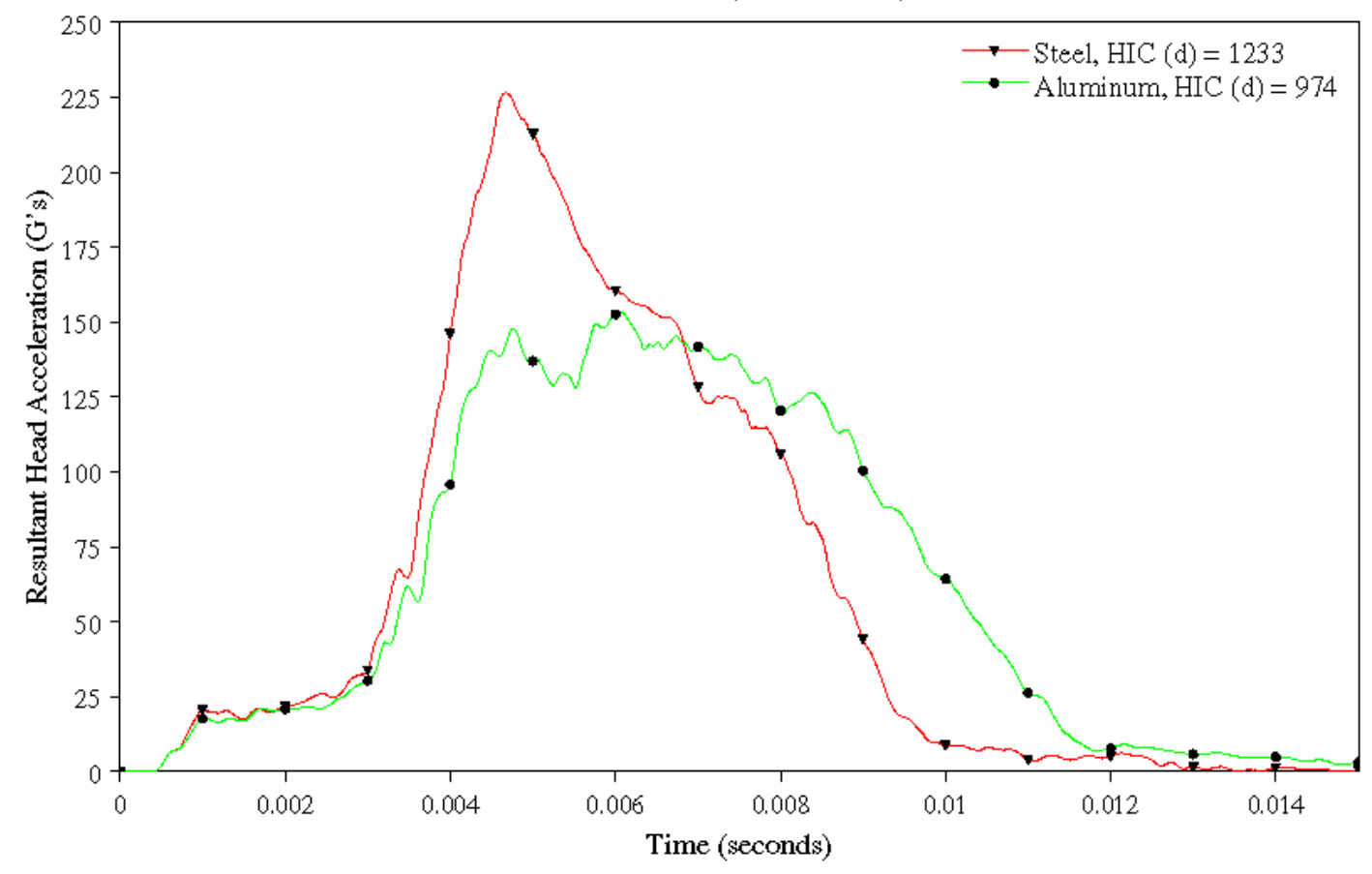

Figure 5.17 Steel and aluminum using Trim Design-2 (with ribs) at $30^{\circ}$ horizontal approach angle 


\subsection{STEEL AND ALUMINUM USING TRIM DESIGN-3 (WITH}

AND WITHOUT RIBS) AT $30^{\circ}$ HORIZONTAL APPROACH ANGLE

Trim Design-3 basically has a larger clearance with the inner panel, both along the impact vector and along the clip axis. Also the trim edge on the windshield flange of the inner panel was more curved to eliminate the edge slipping as seen in Trim Design-2. Results of Trim Design-3, with and without ribs are discussed in the following sections.

\subsubsection{TRIM DESIGN-3 WITHOUT RIBS}

Using Trim Design-3 without ribs, both steel and aluminum produced a lesser HIC(d) values of 1270 and 902, respectively, which are the least among the analyses considered. In the resultant acceleration plot for both steel and aluminum, shown in Figure 5.18, a maximum time duration of around $4 \mathrm{~ms}$ was achieved before the FMH impacted the flange of the inner panel. As a result of this, a lowest initial peak acceleration of around $210 \mathrm{~g}$ 's was obtained in steel. And in the case of aluminum, even without the addition of ribs, the second peak in the acceleration curve disappeared, indicating increased level of energy absorption by the trim before the impact with the flange of the inner panel. However, failure of the lower clip housing just before $8 \mathrm{~ms}$ was seen in both steel and aluminum as shown in Figure 5.19. Failure criterion of the clip housing was based on plastic strain and was set at $50 \%$ of strain in the material model.

Modification to the trim edge on the windshield side of the inner flange resulted in the trim staying on the flange longer than seen in Trim Design-2 resulting in increased 
energy absorption of the trim. However, after $8 \mathrm{~ms}$, slipping of the trim edge was seen in the analysis.

TRIM DESIGN 3 (NO RIBS)

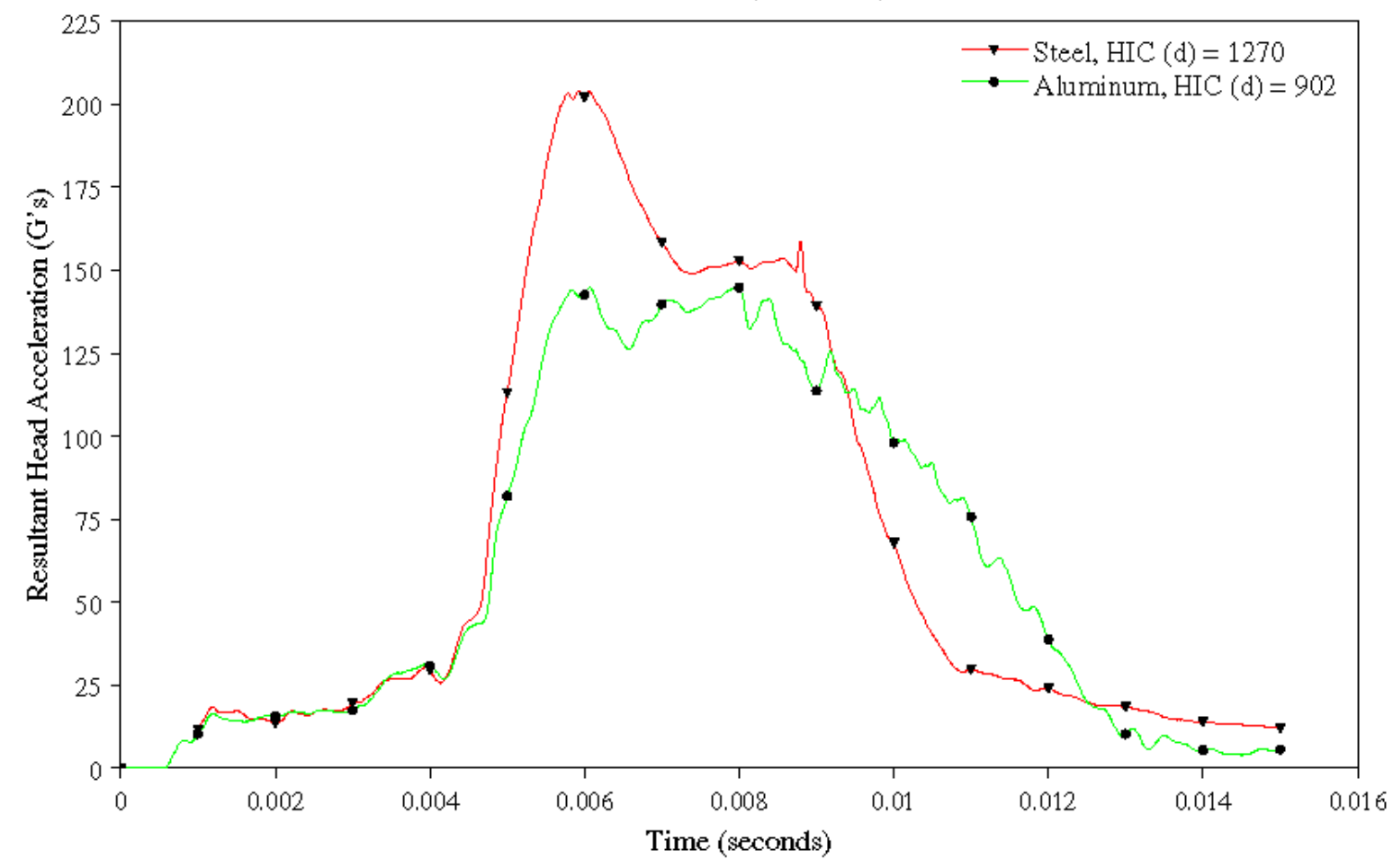

Figure 5.18 Steel and aluminum using Trim Design-3 (without ribs) at $30^{\circ}$ horizontal approach Angle 
$0 \mathrm{~ms}$

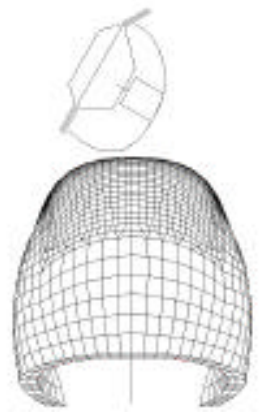

$2 \mathrm{~ms}$

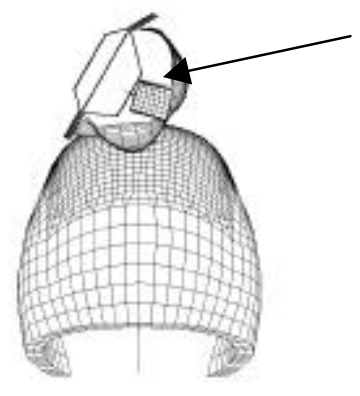

Clip Housing Impacting Inner
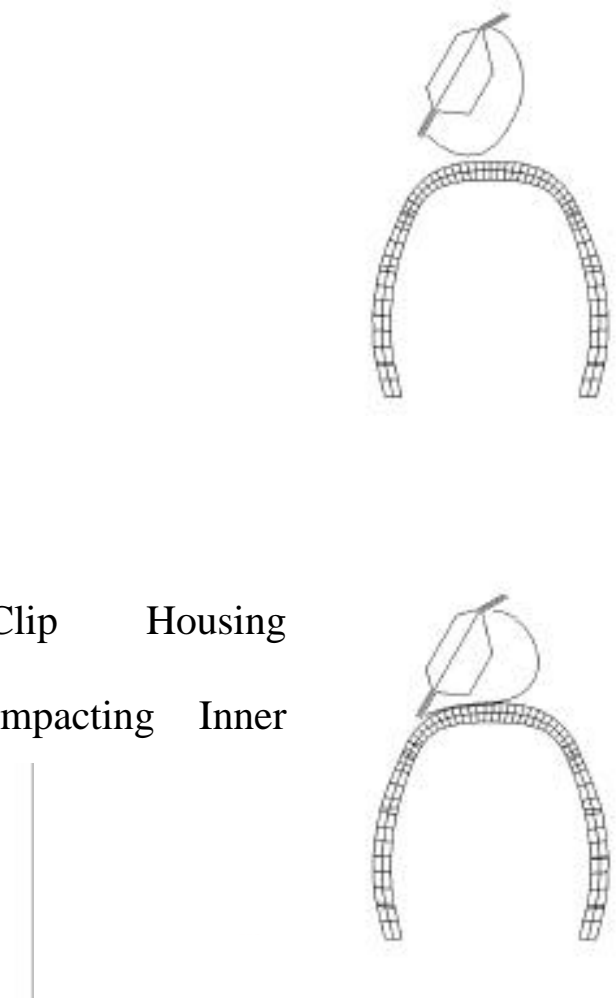

Failing of

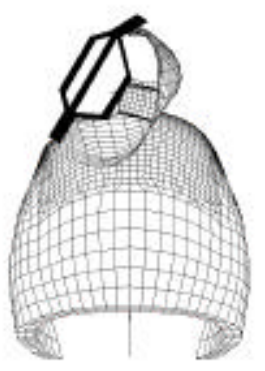

Lower Clip

$8 \mathrm{~ms}$

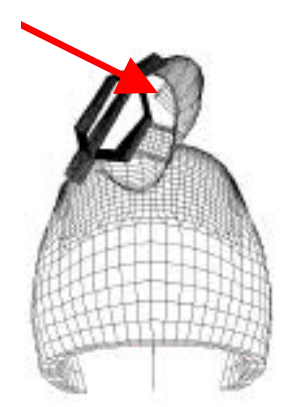

Trim Stays on

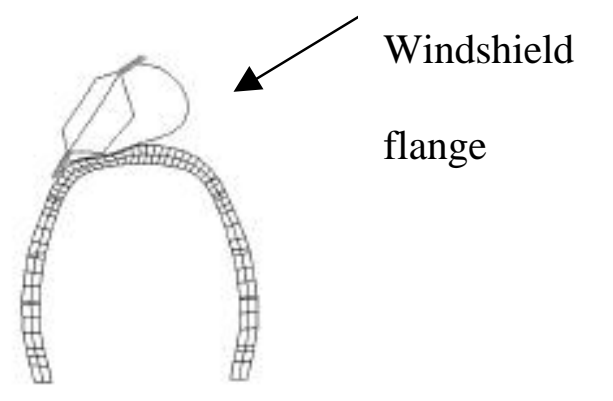

Figure 5.19 Transient plots of steel using Trim Design-3 (without ribs) at $30^{\circ}$ horizontal approach angle 


\subsubsection{TRIM DESIGN-3 WITH RIBS}

Addition of ribs with $1 \mathrm{~mm}$ thickness and $6 \mathrm{~mm}$ depth to Trim Design-3, resulted in a further decrease in $\mathrm{HIC}(\mathrm{d})$ for the steel and aluminum. In both cases, failure of the ribs was also seen. By adding ribs, the resultant acceleration in the case steel decreased from $210 \mathrm{~g}$ 's to $190 \mathrm{~g}$ 's resulting in $\mathrm{HIC}(\mathrm{d})$ of 1163 as seen in Figure 5.20. There was also a second peak due to the impact of ribs on the inner panel.

In the case of aluminum, the acceleration due to the impact of FMH with the inner flange was further reduced to around 140g's resulting in a $\mathrm{HIC(d)}$ of 829 . 


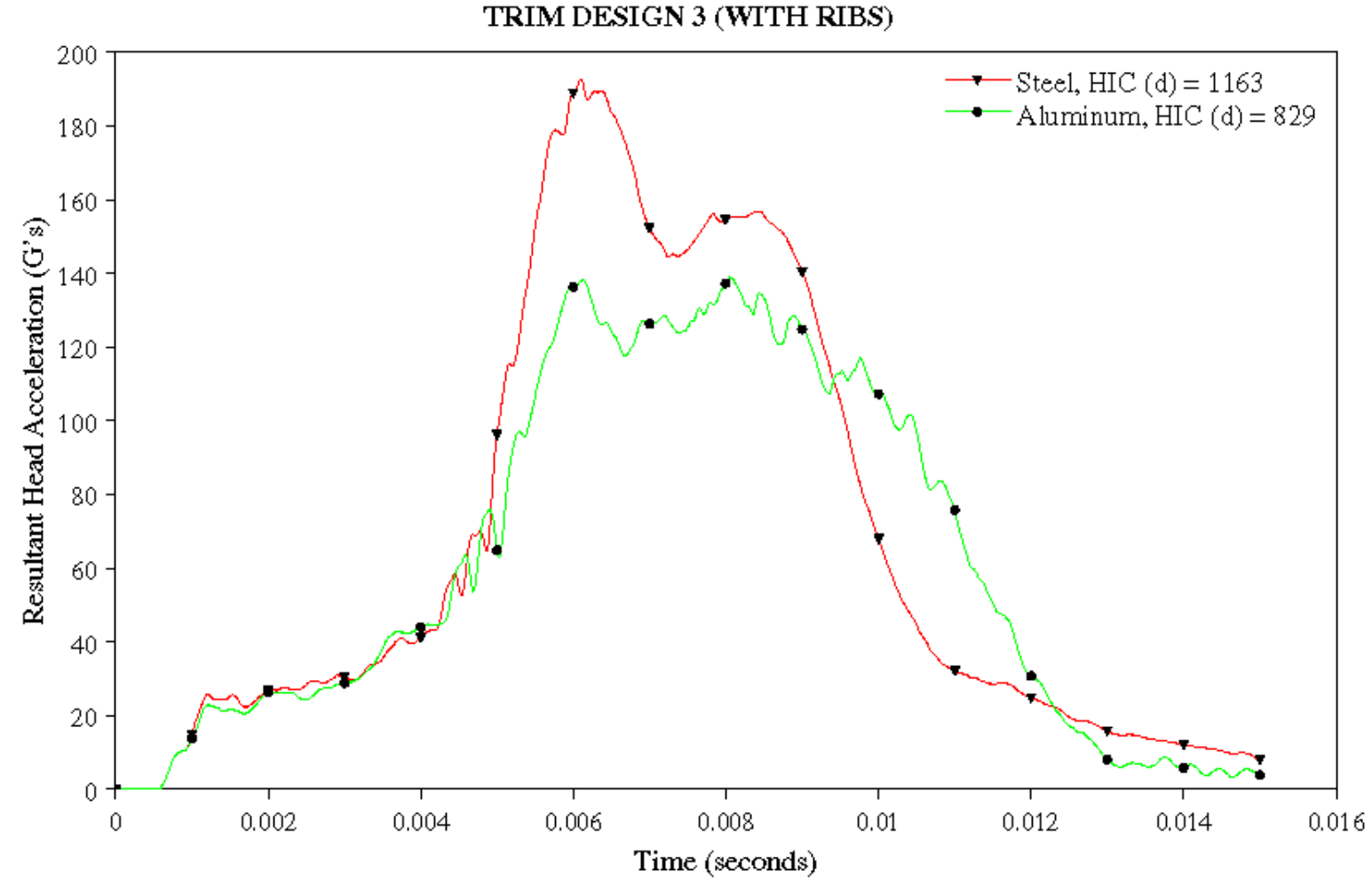

Figure 5.20 Steel and aluminum using Trim Design-3 (with ribs) at $30^{\circ}$ Horizontal approach angle 
Figure 5.21 and 5.22 show the resultant acceleration obtained from Trim Design1, Trim Design-2, and Trim Design-3, without ribs for steel and aluminum.

Figure 5.23 and 5.24 show the resultant acceleration obtained from Trim Design1, Trim Design-2, and Trim Design-3, with ribs for steel and aluminum. 


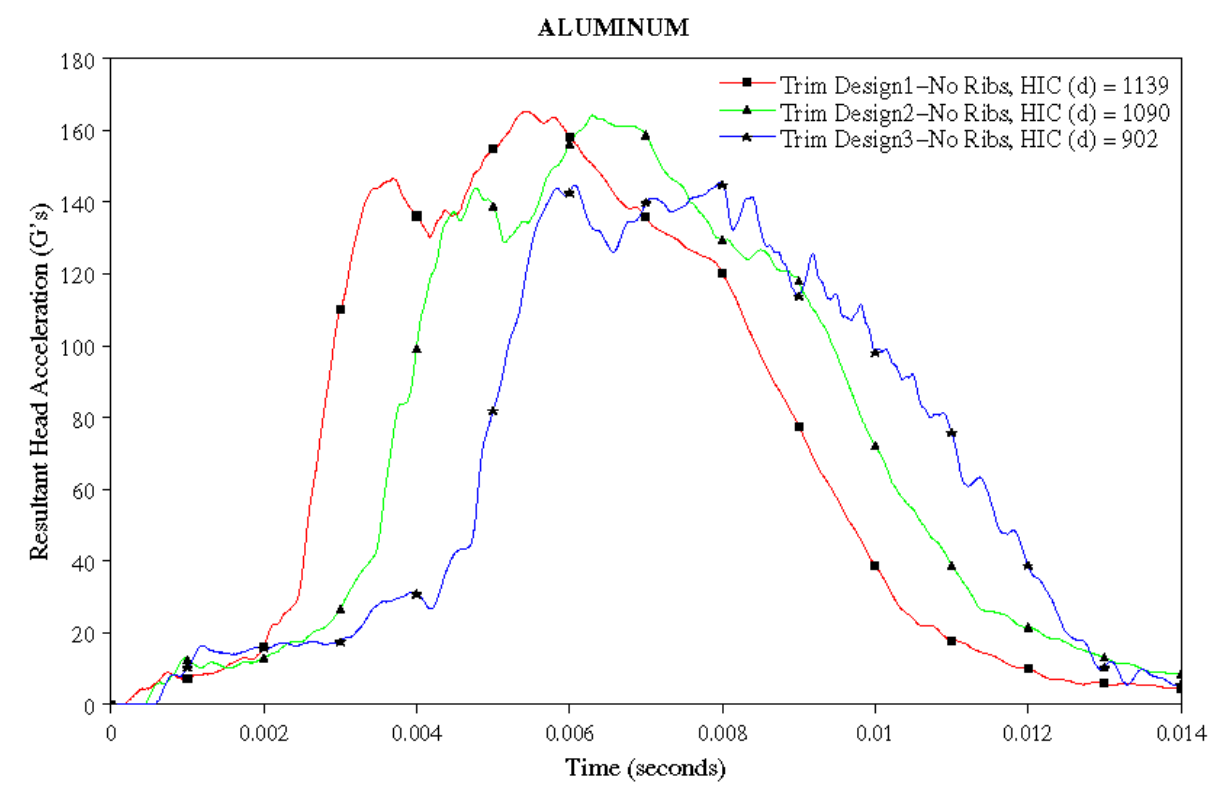

Figure 5.21 Trim Design-1, 2, and 3 (without ribs) using aluminum at $30^{\circ}$ horizontal approach angle

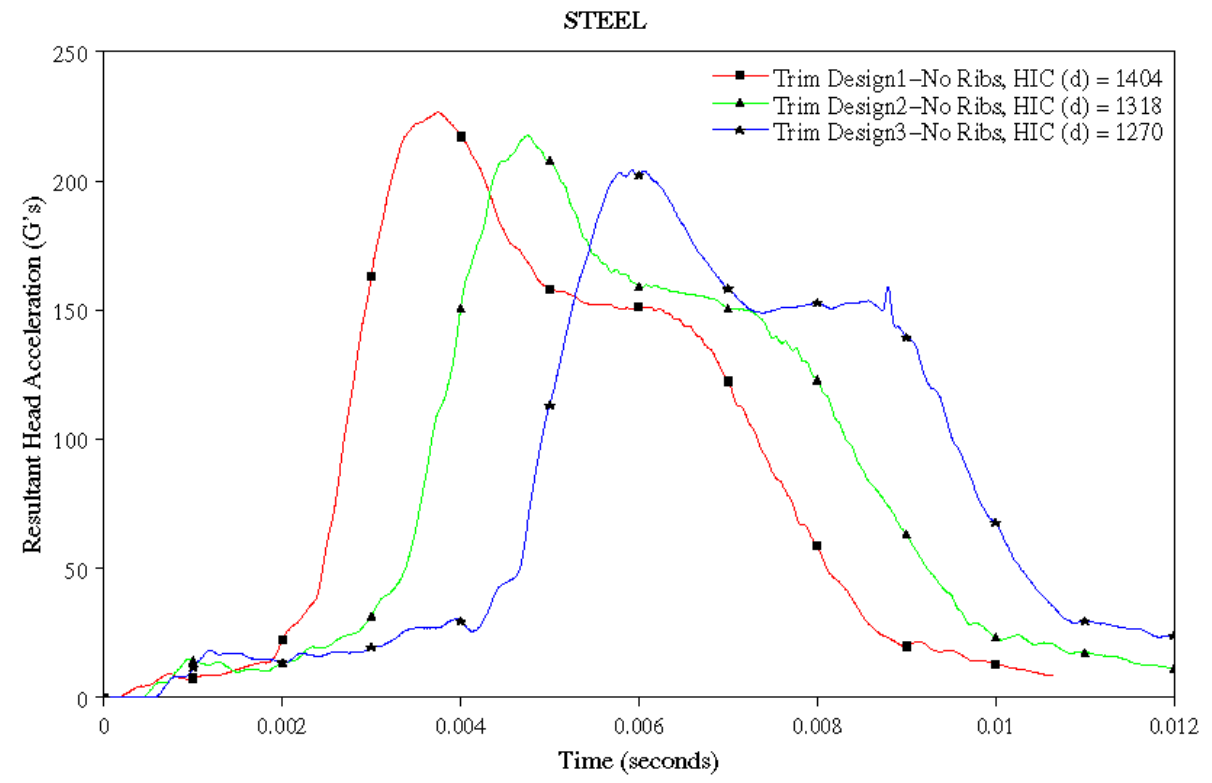

Figure 5.22 Trim Design-1, 2, and 3 (without ribs) using steel at $30^{\circ}$ horizontal approach angle 


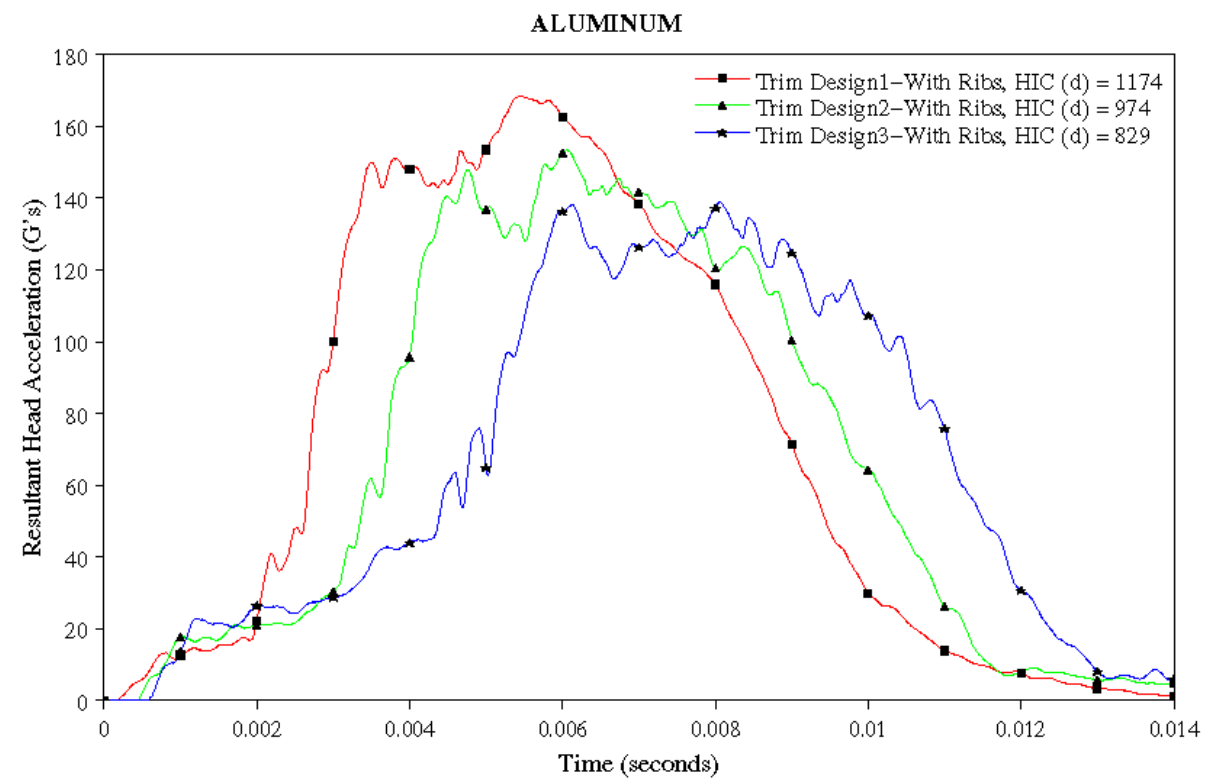

Figure 5.23 Trim Design-1, 2, and 3 (with ribs) using aluminum at $30^{\circ}$ horizontal approach angle

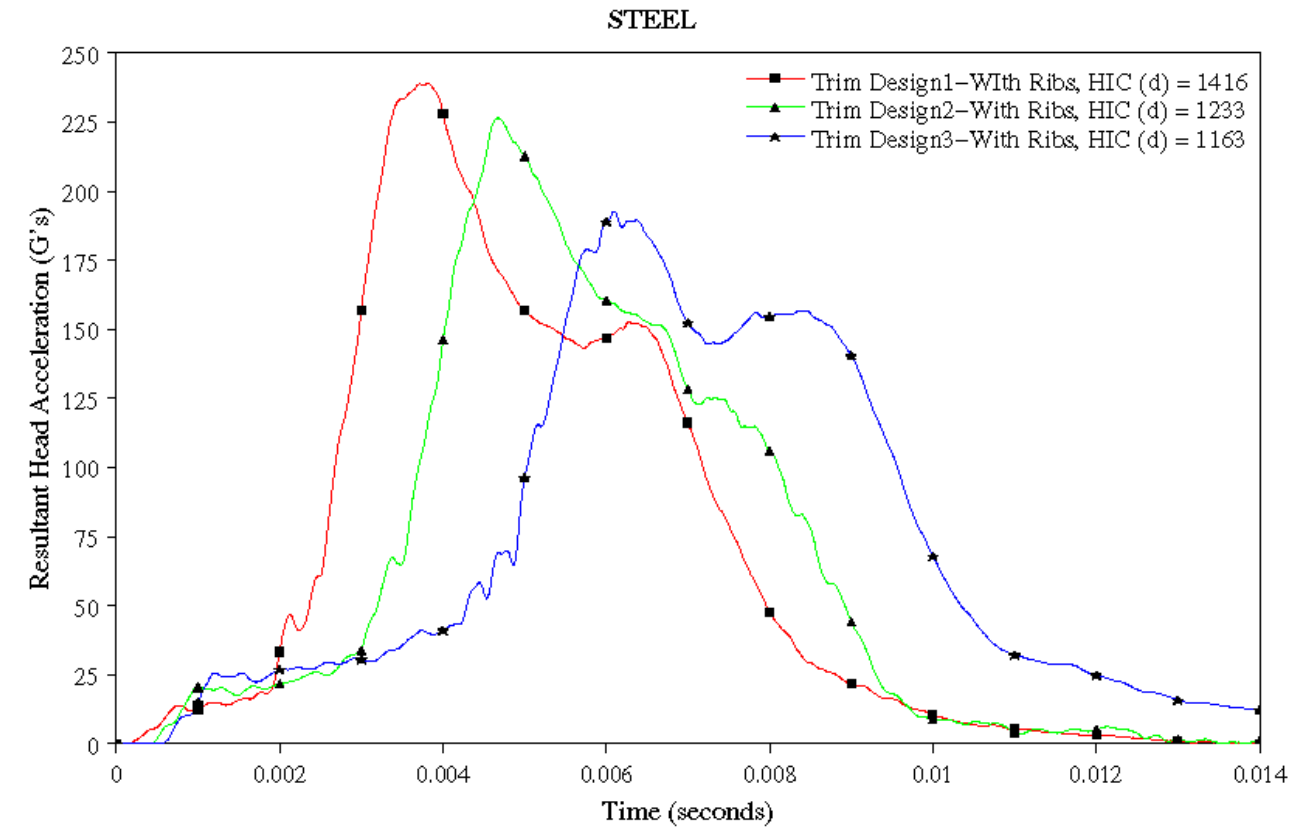

Figure 5.24 Trim Design-1, 2, and 3 (with Ribs) using steel at $30^{\circ}$ horizontal approach angle 


\subsection{TRIM DESIGN-3 WITH AND WITHOUT RIBS USING}

\section{ALUMINUM AT $60^{\circ}$ HORIZONTAL IMPACT ANGLE}

Since Trim Design-3, with and without ribs, produced the best results compared to all the previous analysis, it was then used to determine the effect of $60^{\circ}$ horizontal approach angle. Transient analysis results as seen in Figure 5.25 show that trim slips off the inner flange on the door side at around $3 \mathrm{~ms}$. This was followed by the trim edge slipping from the windshield inner flange at $5 \mathrm{~ms}$. Same phenomenon was observed in both with and without ribs resulting in $\mathrm{HIC}(\mathrm{d})$ of 1119 and 970, respectively. Upon investigation, it was later found that there would be weatherseal covering the inner flange of the door side, which could prevent the trim slipping from the inner flange. On the windshield flange, the windshield itself was not included in the analyses causing the trim

to slip off the flange. Inclusion of both these components could result in higher energy absorption of the trim producing lesser $\mathrm{HIC}(\mathrm{d})$. However to establish a general methodology in the design of A-Pillar trim cross-section, this was considered beyond the scope of the project. 

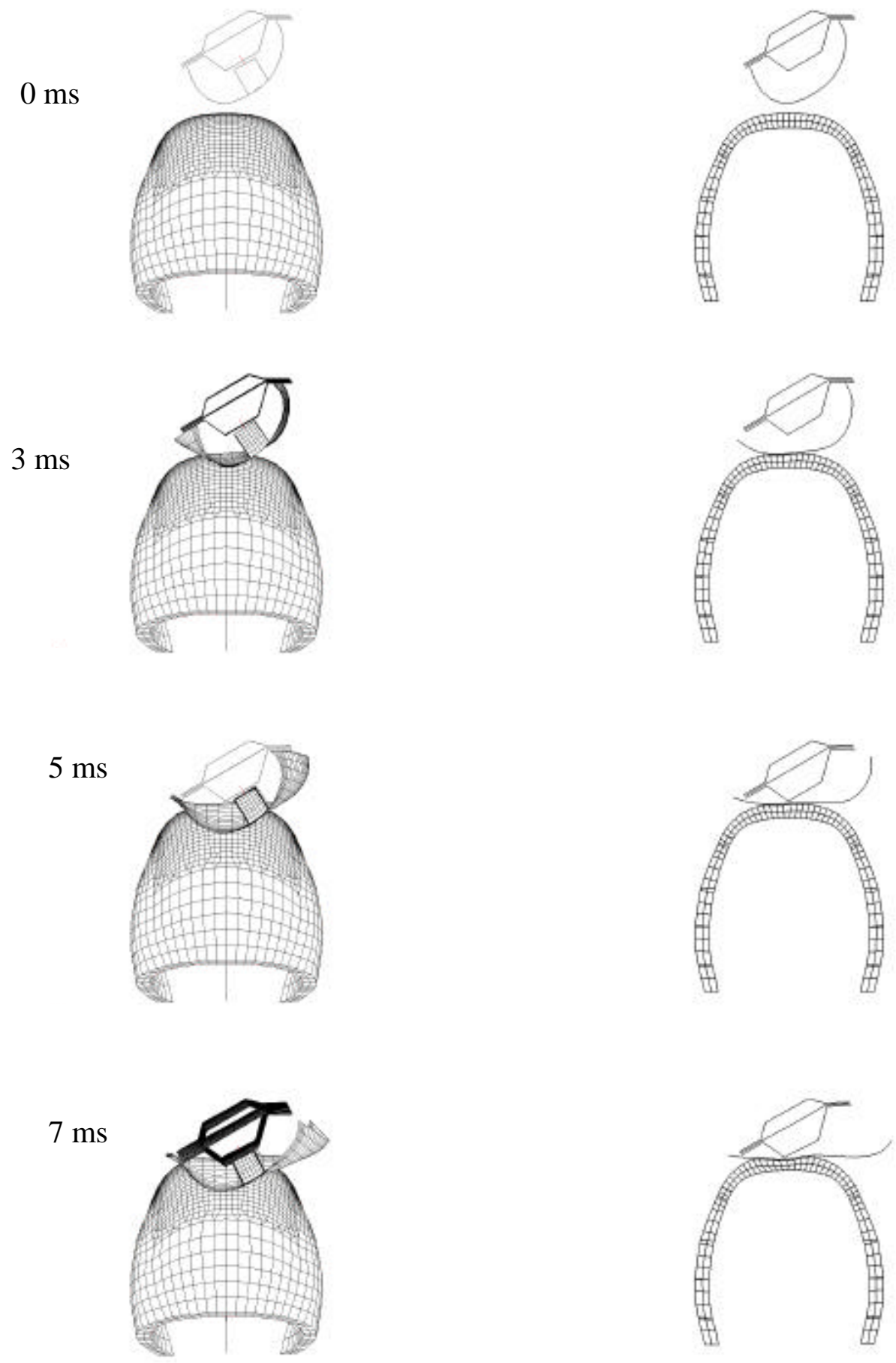

Figure 5.25 Transient plots of Trim Design-3 using aluminum at $60^{\circ}$ horizontal approach angle 


\subsection{OPTIMUM TRIM OFFSET ESTIMATION}

In the previous analyses involving different trim designs, it was seen that Trim Design-3, with the integration of ribs provided the lowest HIC(d) of 829. Increasing the offset helped to lower the HIC(d) level by enabling the trim to absorb more energy before bottoming on the inner panel. However, to determine the optimum trim offset distance, effects of trim clearance with corresponding values of $\mathrm{HIC}(\mathrm{d})$ need to be established.

To achieve this the design of trim surface used in the present analyses is based on three design parameters, viz., A, B, and C. These parameters are characterized relative to BIW geometry and approach angles of the FMH. The definition of the three design parameters based on the $30^{\circ}$ impact angle is shown in Figure 5.26. Parameter ' $A$ ' is defined to be the distance between the target point on the trim and the initial point of contact between the trim and BIW measured along the impact vector. On the other hand, ' $\mathrm{B}$ ' is defined to be the distance between the target point and the trim and the initial point of contact between the trim and BIW measured normal to the inner flange surface. Parameter ' $\mathrm{C}$ ' is the distance between the inner panel and the trim surface along the clip axis.

Tables 5.1 and 5.2 shows the values of the trim design variable ' $\mathrm{A}$ ' for the three trim designs and the corresponding HIC(d) values for both steel and aluminum. 


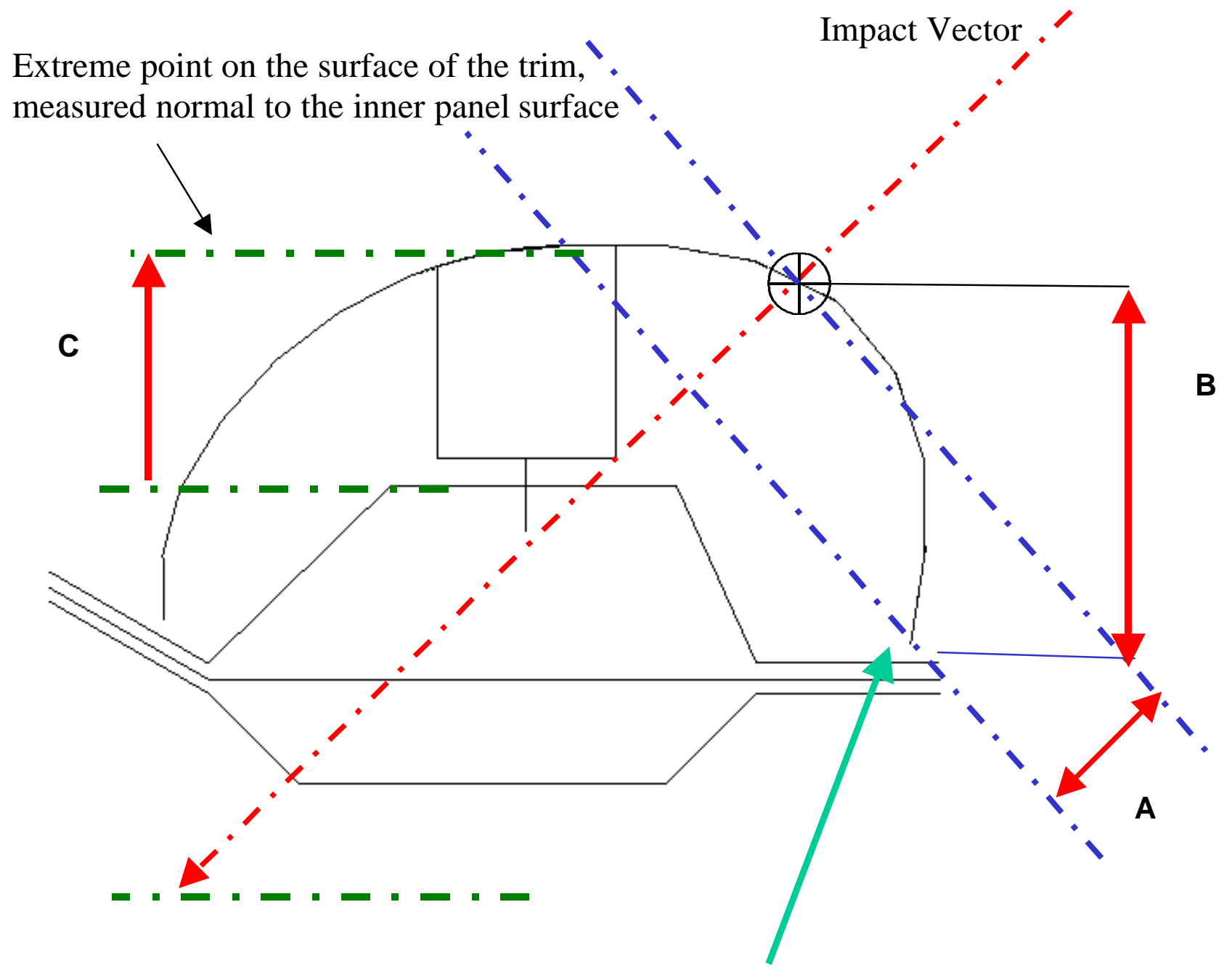

Fist Point Of Contact

Figure 5.26 Trim design variables definitions 


\begin{tabular}{|c|c|c|c|}
\hline \multirow{2}{*}{ TRIM } & \multirow{2}{*}{ DESIGN VARIABLE ‘A’ ’ } & \multicolumn{2}{|c|}{ STEEL } \\
\cline { 3 - 4 } DESIGN & & HIC(d), & HIC(d), \\
& & Without Ribs & With Ribs \\
\hline 1 & -10.6 & 1404 & 1416 \\
\hline 2 & 0.585 & 1318 & 1233 \\
\hline 3 & 7.4 & 1270 & 1163 \\
\hline
\end{tabular}

Table 5.1 Trim design variable ' $A$ ' and corresponding $\mathrm{HIC}(\mathrm{d})$ for steel at $30^{\circ}$ horizontal approach angle

\begin{tabular}{|c|c|c|c|}
\hline \multirow{2}{*}{ TRIM } & \multirow{2}{*}{ DESIGN VARIABLE ‘A’ } & \multicolumn{2}{|c|}{ ALUMINUM } \\
\cline { 3 - 4 } DESIGN & & HIC(d), & HIC(d), \\
& & Without Ribs & With Ribs \\
\hline 1 & & 1139 & 1174 \\
\hline 2 & -10.6 & 1090 & 974 \\
\hline 3 & 0.585 & 902 & 830 \\
\hline
\end{tabular}

Table 5.2 Trim design variable 'A' and corresponding HIC(d) for aluminum at $30^{\circ}$ horizontal approach angle 


\subsubsection{DEPENDENCE OF TRIM DESIGN VARIBLE ‘A’ ON HIC(d)}

To establish the dependence of trim design variable 'A' on the $\mathrm{HIC}(\mathrm{d})$, results obtained from analyzing the three trim designs, with and without ribs, are plotted against the resulting $\mathrm{HIC}(\mathrm{d})$. Since the HIC(d) obtained in these component analyses could be higher than that may actually be seen in the full vehicle analysis, percentage reduction in $\mathrm{HIC}(\mathrm{d})$ for each trim design is plotted against the trim design variables. This can then be used to estimate the trim offset depending on the desired percentage reduction in HIC(d) obtained in the baseline (without trim) analysis of the full vehicle.

Figures 5.27 through 5.32 show the relationship between $\mathrm{HIC}(\mathrm{d})$ and the trim

design variable 'A', with and without ribs, at a $30^{\circ}$ horizontal approach angle for both steel and aluminum. Using these curves, an estimation of trim design variable, with and without curves, can be achieved based on the desired percentage reduction in HIC(d). 


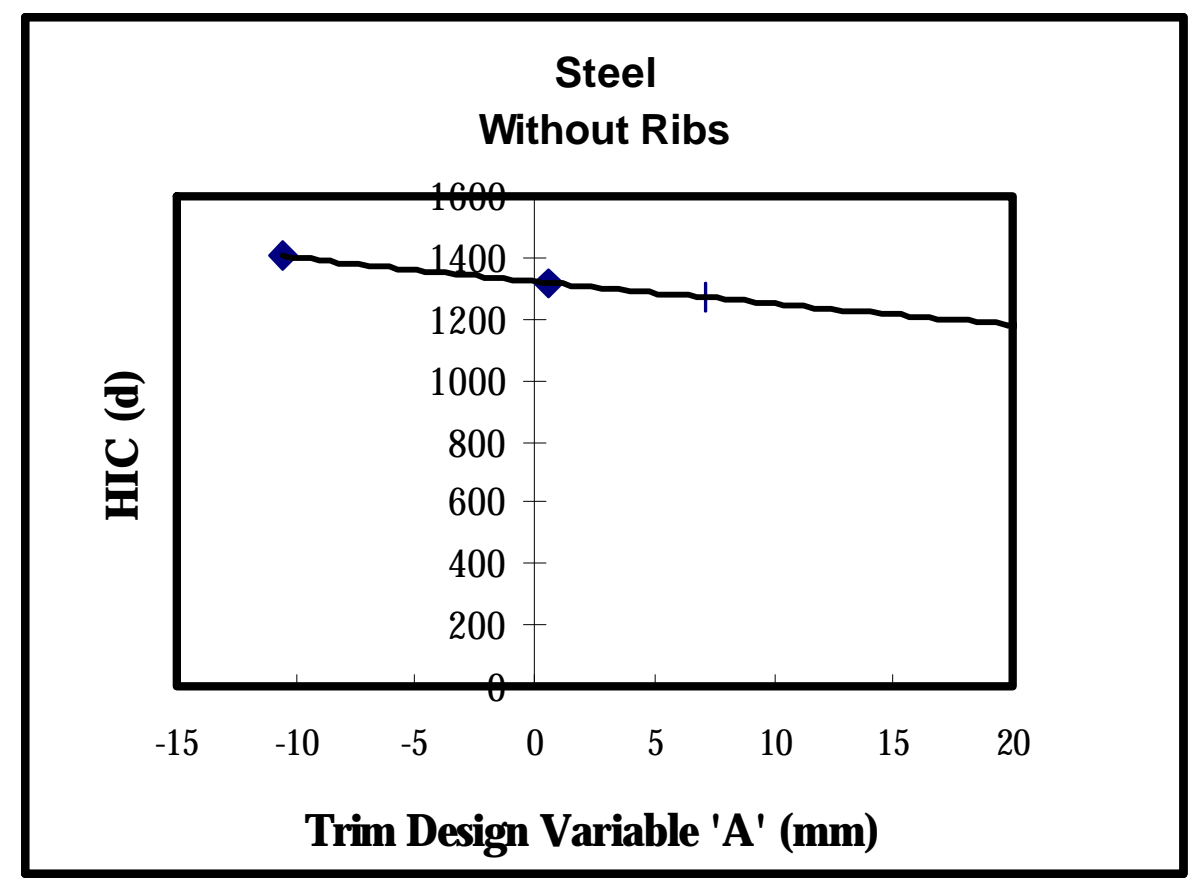

Figure 5.27 $\mathrm{HIC}(\mathrm{d})$ vs design variable ' $\mathrm{A}$ ' using steel at $30^{\circ}$ horizontal approach angle (without ribs) 


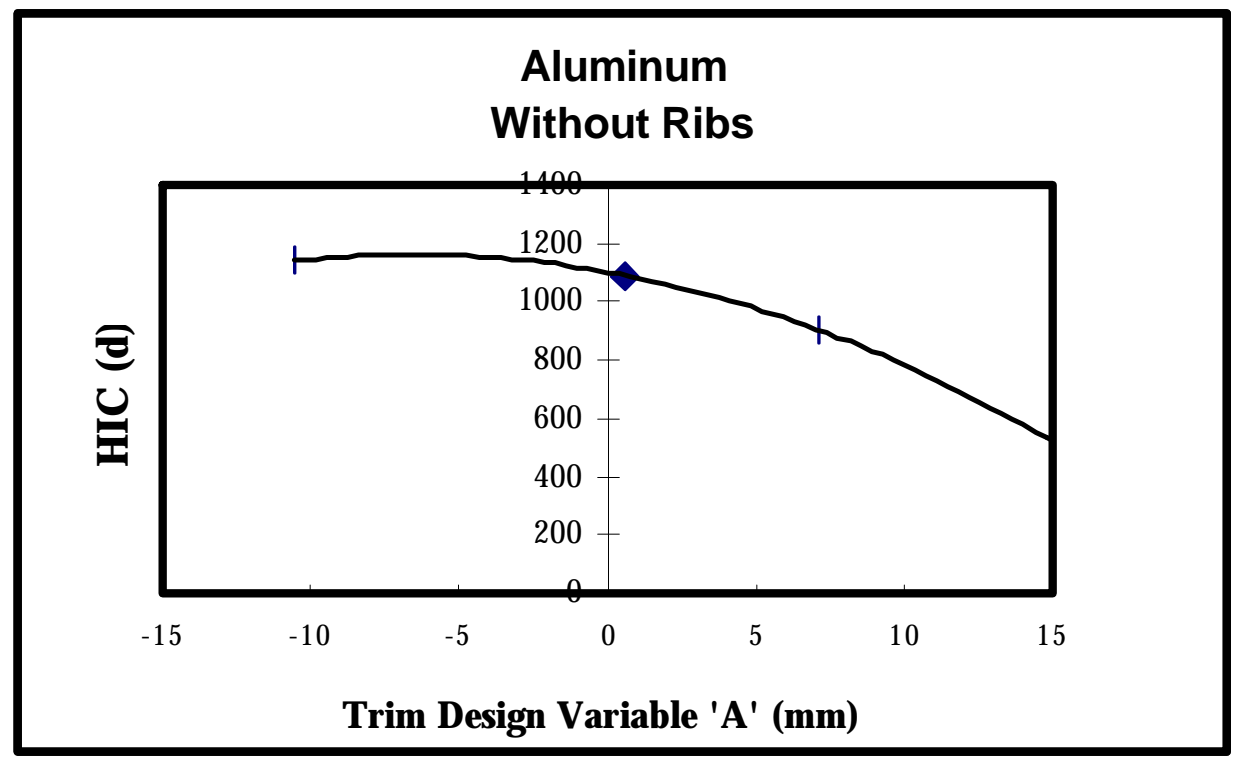

Figure 5.28 $\mathrm{HIC}(\mathrm{d}) \mathrm{vs}$ design variable ' $\mathrm{A}$ ' using aluminum at $30^{\circ}$ horizontal approach angle (without ribs)

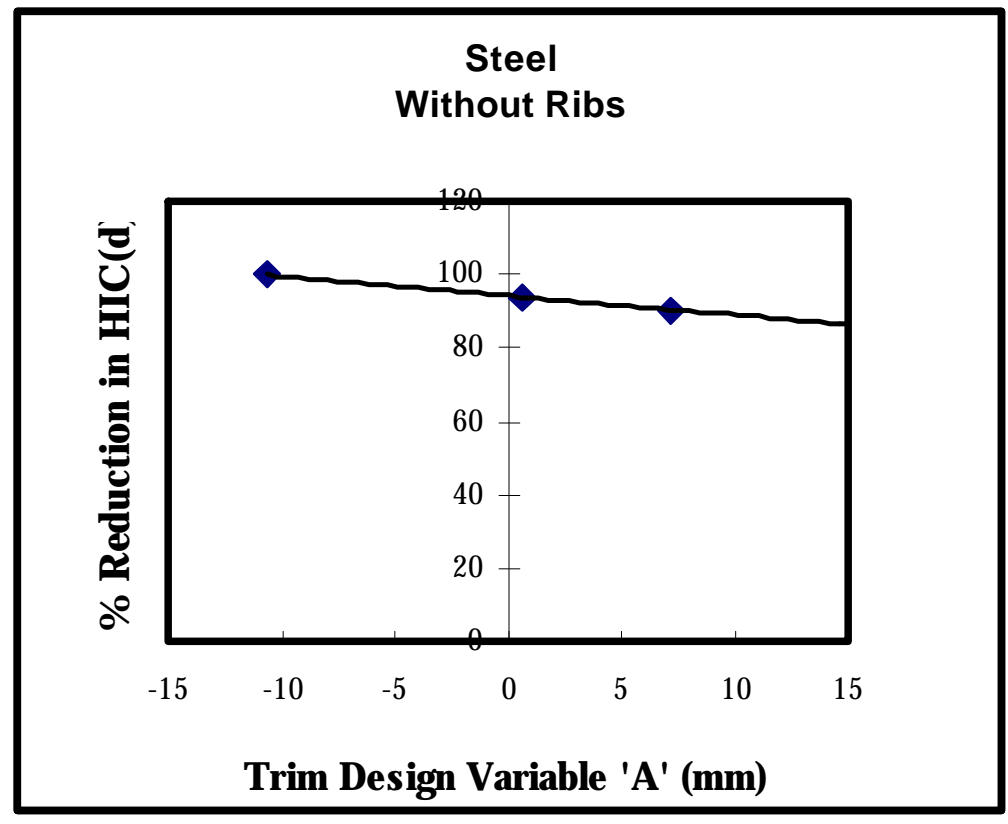

Figure 5.29 Percentage reduction in $\mathrm{HIC}(\mathrm{d})$ vs design variable 'A' using steel at $30^{\circ}$ horizontal approach angle (without ribs) 


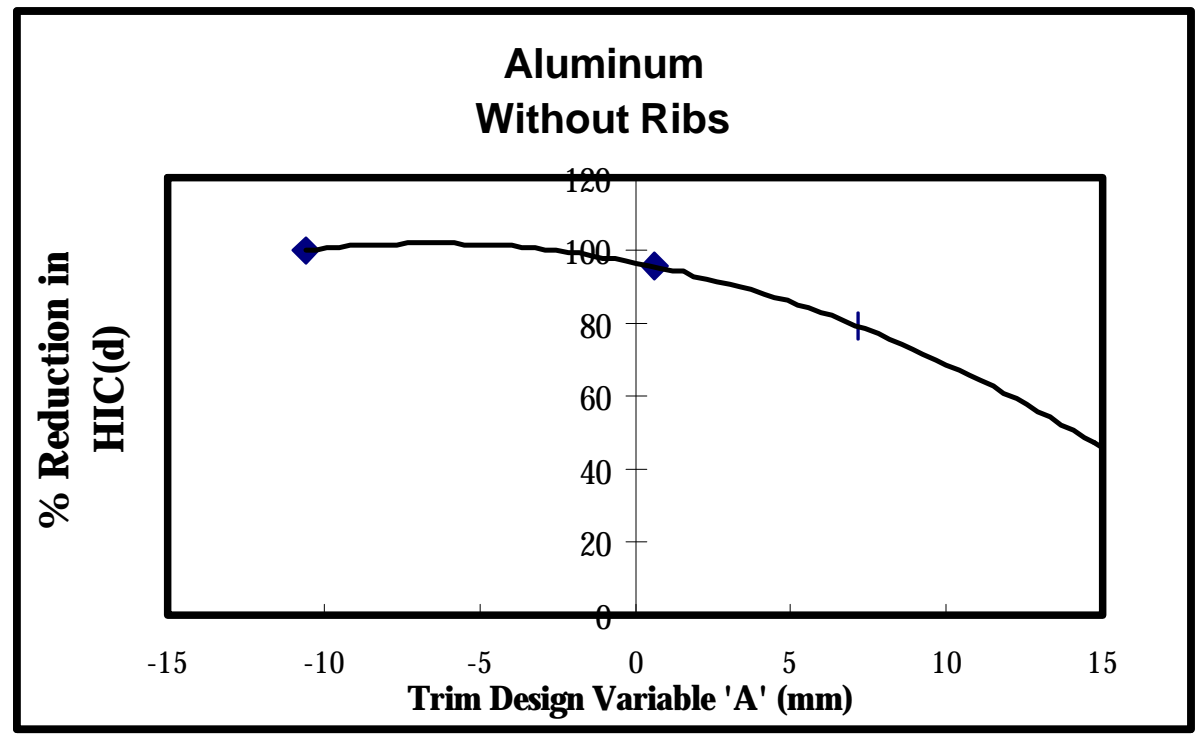

Figure 5.30 Percentage reduction in $\mathrm{HIC}(d)$ vs design variable ' $A$ ' using aluminum at $30^{\circ}$ horizontal approach angle (without ribs) 


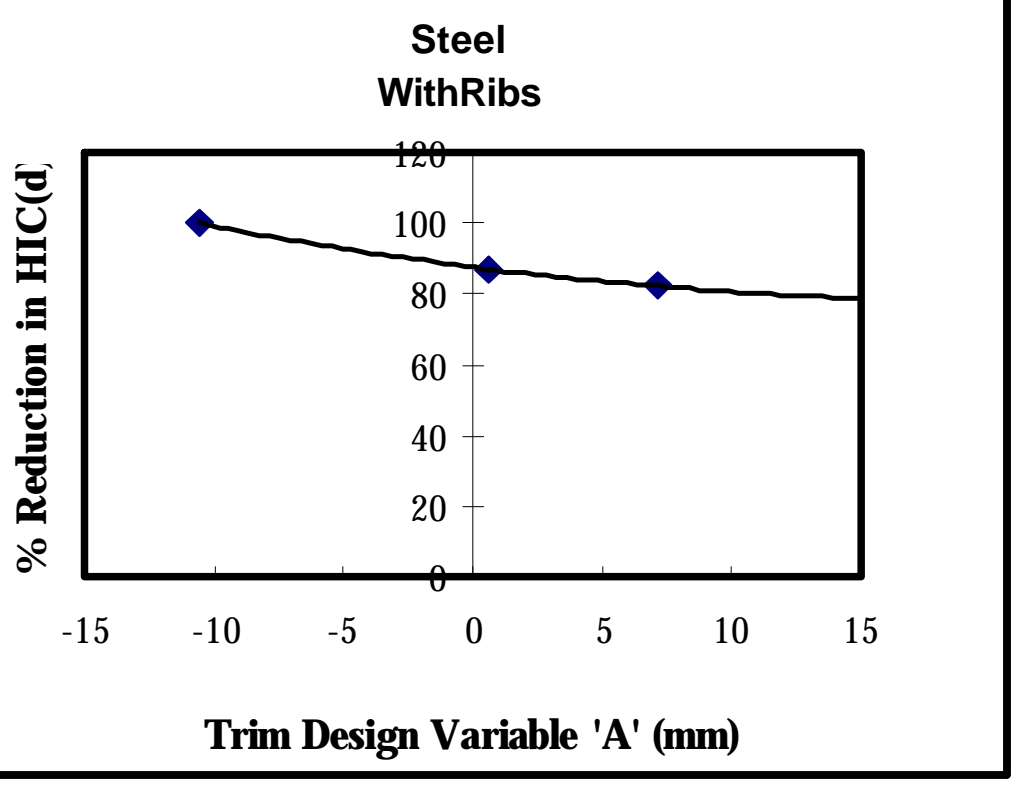

Figure 5.31 Percentage reduction in $\mathrm{HIC}(\mathrm{d})$ vs design variable 'A' using aluminum at $30^{\circ}$ horizontal approach angle (with ribs)

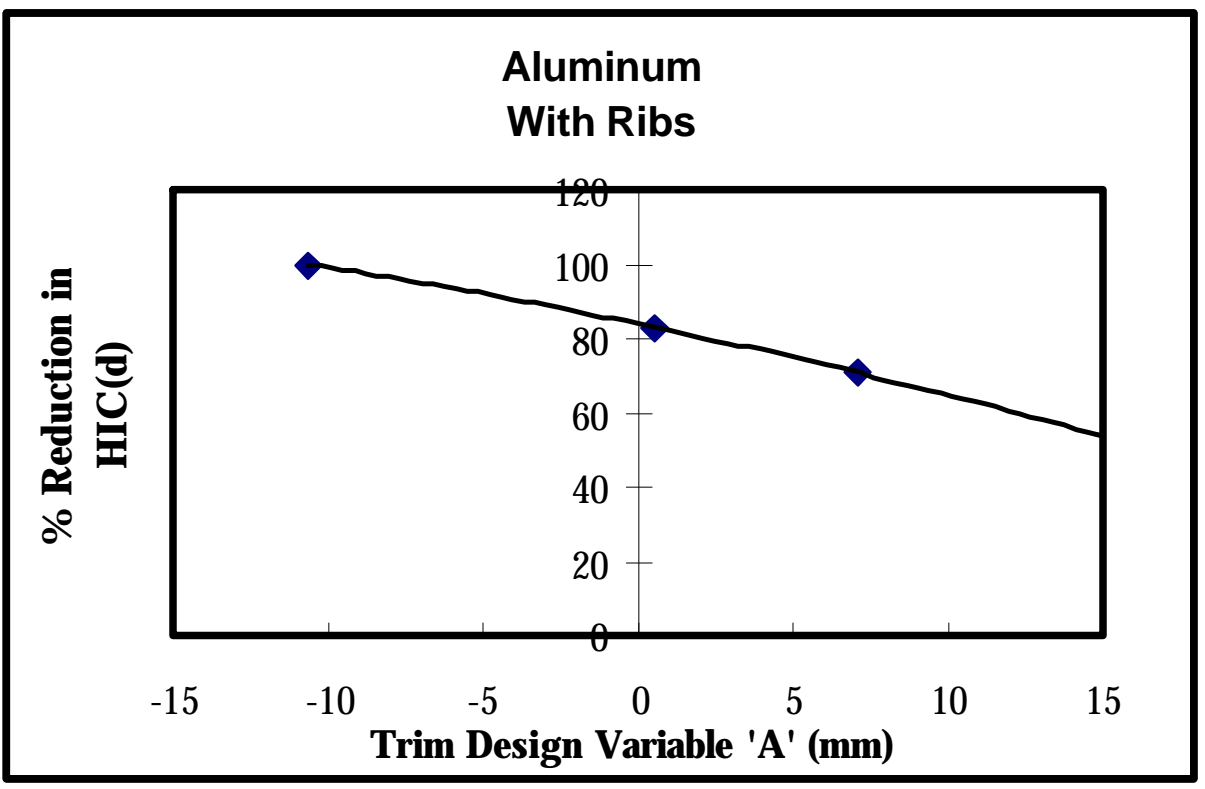

Figure 5.32 Percentage reduction in $\mathrm{HIC}(\mathrm{d})$ vs design variable 'A' using aluminum at $30^{\circ}$ horizontal approach angle (with ribs) 


\subsubsection{DEPENDENCE OF TRIM DESIGN VARIABLE 'B' ON HIC(d)}

In Table 5.3 and Table 5.4, the values of trim design variable ' $\mathrm{B}$ ' for the three trim designs and the corresponding $\mathrm{HIC}(\mathrm{d})$ values are tabulated for both steel and aluminum, with and without ribs as the countermeasure.

Using these values, the trim design variable ' $\mathrm{B}$ ' is plotted against percentage reduction in $\mathrm{HIC}(\mathrm{d})$ in Figures 5.33 through 5. 36. 


\begin{tabular}{|c|c|c|c|}
\hline \multirow{2}{*}{ TRIM } & \multirow{2}{*}{ DESIGN VARIABLE ' $B$ ' } & \multicolumn{2}{|c|}{ STEEL } \\
\cline { 3 - 4 } DESIGN & & HIC(d), & HIC(d), \\
& & Without Ribs & With Ribs \\
\hline 1 & 16 & 1404 & 1416 \\
\hline 2 & 21 & 1318 & 1233 \\
\hline 3 & 26 & 1270 & 1163 \\
\hline
\end{tabular}

Table 5.3 Trim design variable 'B' and corresponding HIC(d) for steel at $30^{\circ}$ horizontal approach angle

\begin{tabular}{|c|c|c|c|}
\hline \multirow{2}{*}{ TRIM } & \multirow{2}{*}{ DESIGN VARIABLE 'B' } & \multicolumn{2}{|c|}{ ALUMINUM } \\
\cline { 3 - 4 } DESIGN & & HIC(d), & HIC(d), \\
& & Without Ribs & With Ribs \\
\hline 1 & 16 & 1139 & 1174 \\
\hline 2 & 21 & 1090 & 974 \\
\hline 3 & 26 & 902 & 830 \\
\hline
\end{tabular}

Table 5.4 Trim design variable ' $B$ ' and corresponding HIC(d) for aluminum at $30^{\circ}$ horizontal approach angle 


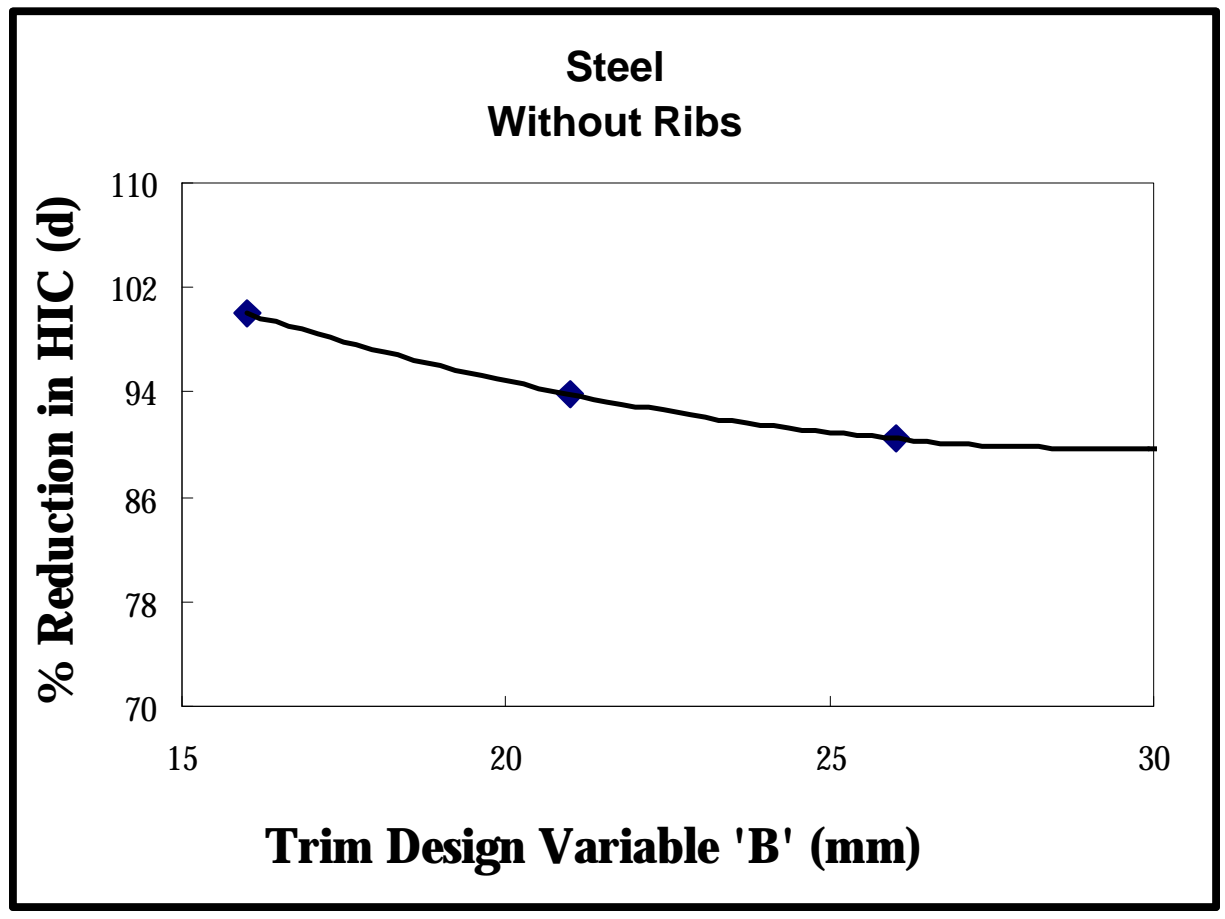

Figure 5.33 Percentage reduction in $\mathrm{HIC}(\mathrm{d})$ vs design variable ' $B$ ' using steel at $30^{\circ}$ horizontal approach angle (without ribs)

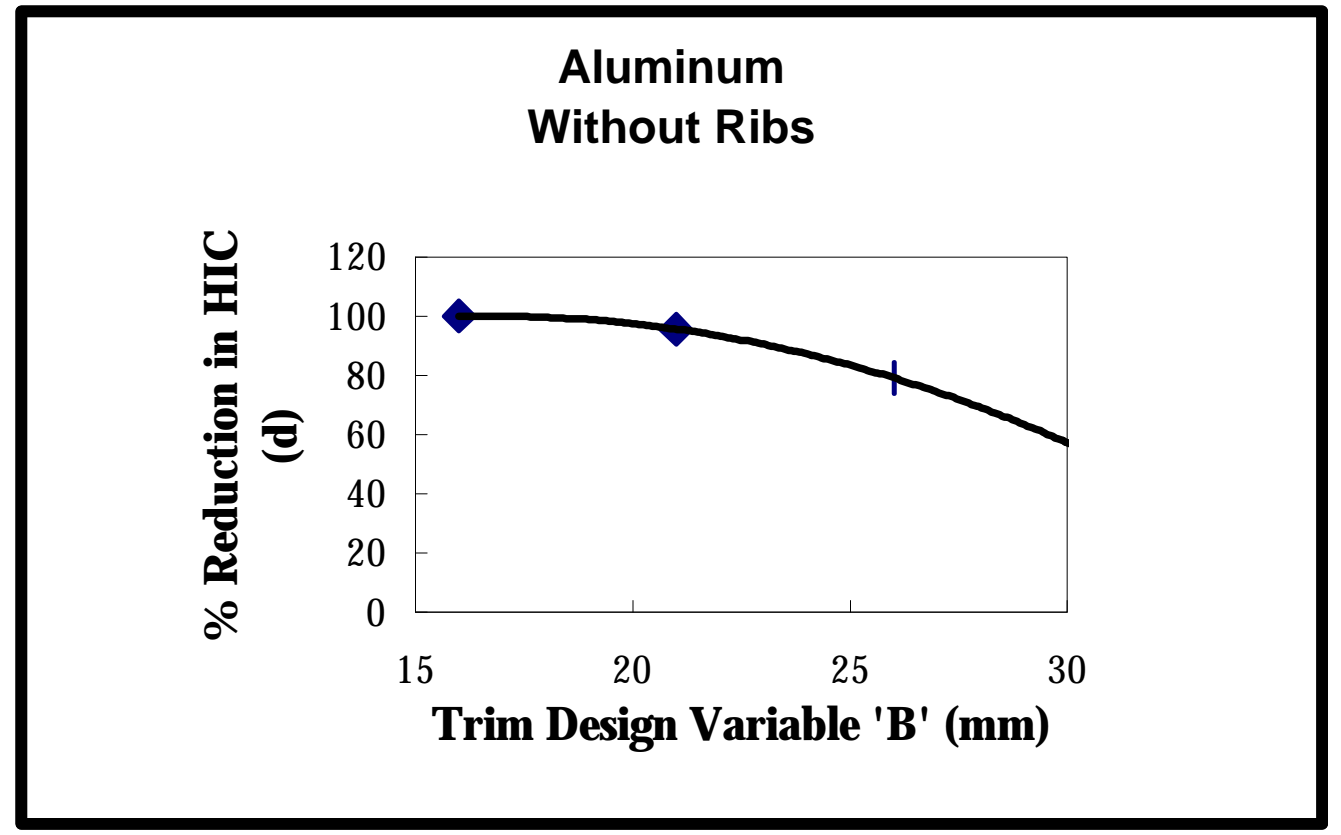

Figure 5.34 Percentage reduction in $\mathrm{HIC}(\mathrm{d})$ vs design variable ' $B$ ' using aluminum at $30^{\circ}$ horizontal approach angle (without ribs) 


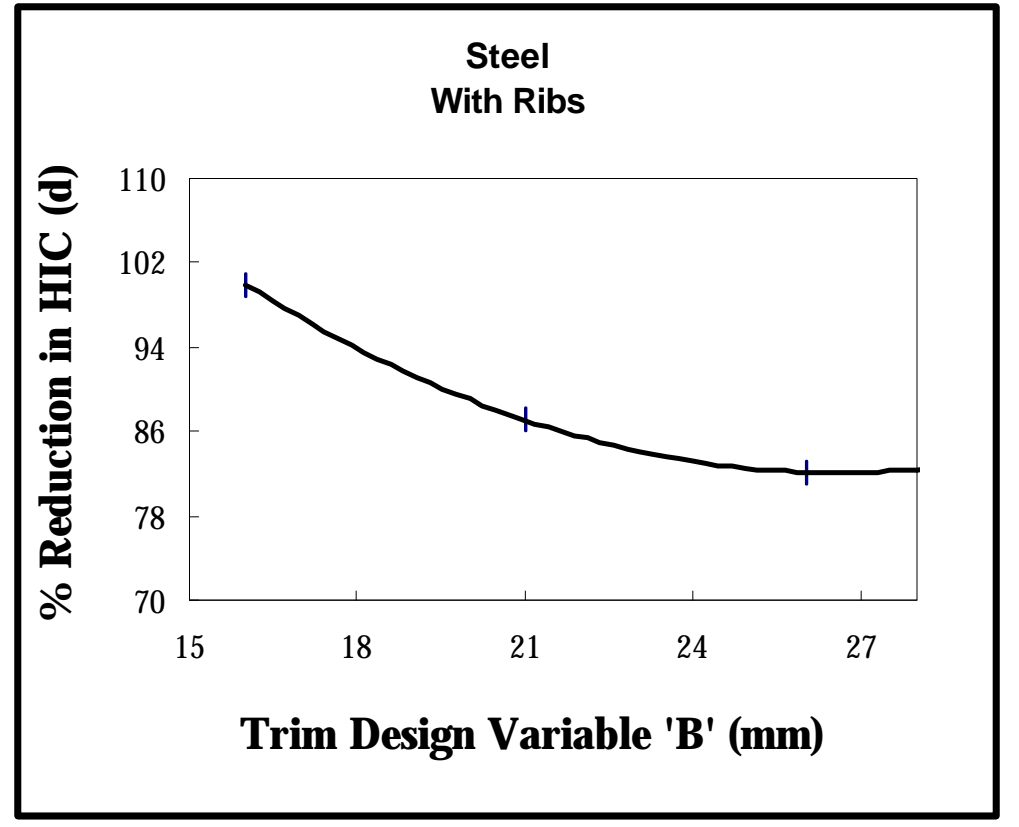

Figure 5.35 Percentage reduction in $\mathrm{HIC}(\mathrm{d})$ vs design variable ' $\mathrm{B}$ ' using steel at $30^{\circ}$ horizontal approach angle (with ribs)

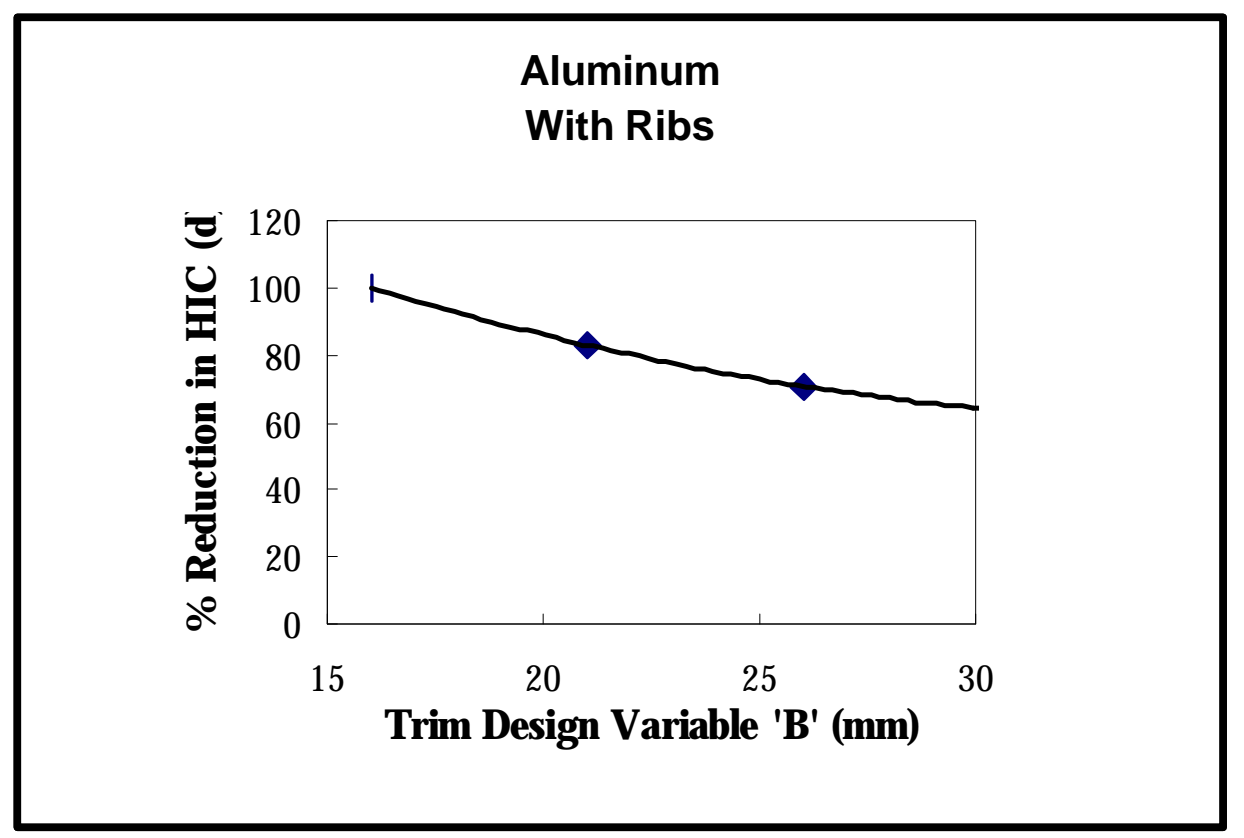

Figure 5.36 Percentage reduction in $\mathrm{HIC}(\mathrm{d})$ vs design variable ' $\mathrm{B}$ ' using aluminum at $30^{\circ}$ horizontal approach angle (with ribs) 


\subsubsection{DEPENDENCE OF TRIM DESIGN VARIABLE ' $C$ ' ON HIC(d)}

In Table 5.5 and 5.6, values of trim design variable ' $C$ ' for the three trim designs and the corresponding $\mathrm{HIC}(\mathrm{d})$, with and without ribs, are tabulated for both steel and aluminum as the BIW material.

Figures 5.37 though 5.39 shows the relationship between trim design variable ' $\mathrm{C}$ ' and the corresponding percentage reduction in $\mathrm{HIC}(\mathrm{d})$. 


\begin{tabular}{|c|c|c|c|}
\hline \multirow{2}{*}{ TRIM } & \multirow{2}{*}{ DESIGN VARIABLE ‘C $’$} & \multicolumn{2}{|c|}{ STEEL } \\
\cline { 3 - 4 } DESIGN & & HIC(d), & HIC(d), \\
& & Without Ribs & With Ribs \\
\hline 1 & 33.8 & 1404 & 1416 \\
\hline 2 & 37.5 & 1318 & 1233 \\
\hline 3 & 42 & 1270 & 1163 \\
\hline
\end{tabular}

Table 5.5 Trim design variable ' $\mathrm{C}$ ' and corresponding $\mathrm{HIC}(\mathrm{d})$ for steel at $30^{\circ}$ horizontal approach angle

\begin{tabular}{|c|c|c|c|}
\hline \multirow{2}{*}{ TRIM } & & \multicolumn{2}{|c|}{ ALUMINUM } \\
DESIGN & DESIGN VARIABLE 'C' $’$ & HIC(d), & HIC(d), \\
\cline { 3 - 4 } & & Without Ribs & With Ribs \\
\hline 1 & & 1139 & 1174 \\
\hline 2 & 33.8 & 1090 & 974 \\
\hline 3 & 37.5 & 902 & 830 \\
\hline
\end{tabular}

Table 5.6 Trim design variable 'C' and corresponding HIC(d) for aluminum at $30^{\circ}$ horizontal approach angle 


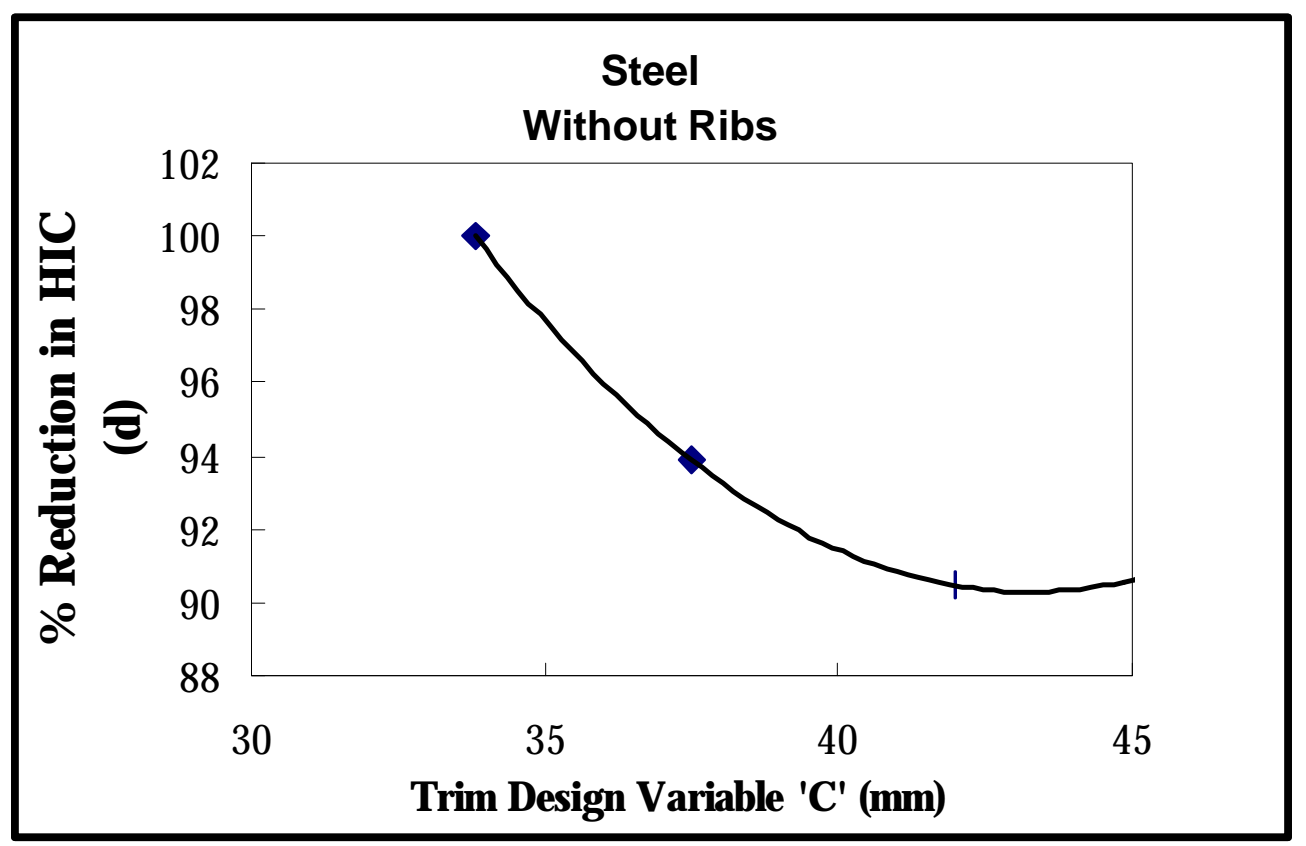

Figure 5.37 Percentage reduction in $\mathrm{HIC}(\mathrm{d})$ vs design variable ' $\mathrm{C}$ ' using steel at $30^{\circ}$ horizontal approach angle (without ribs)

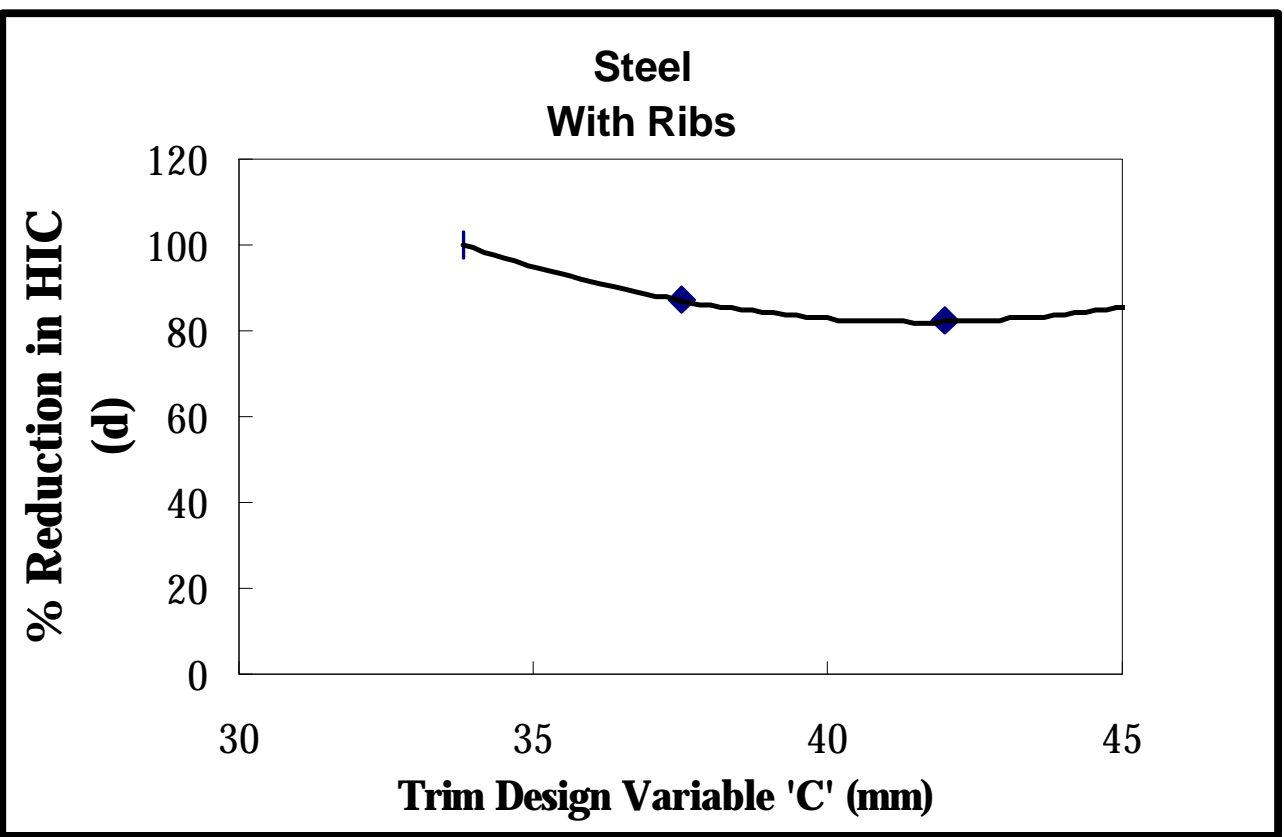

Figure 5.38 Percentage reduction in $\mathrm{HIC}(\mathrm{d})$ vs design variable ' $\mathrm{C}$ ' using steel at $30^{\circ}$ horizontal approach angle (with ribs) 


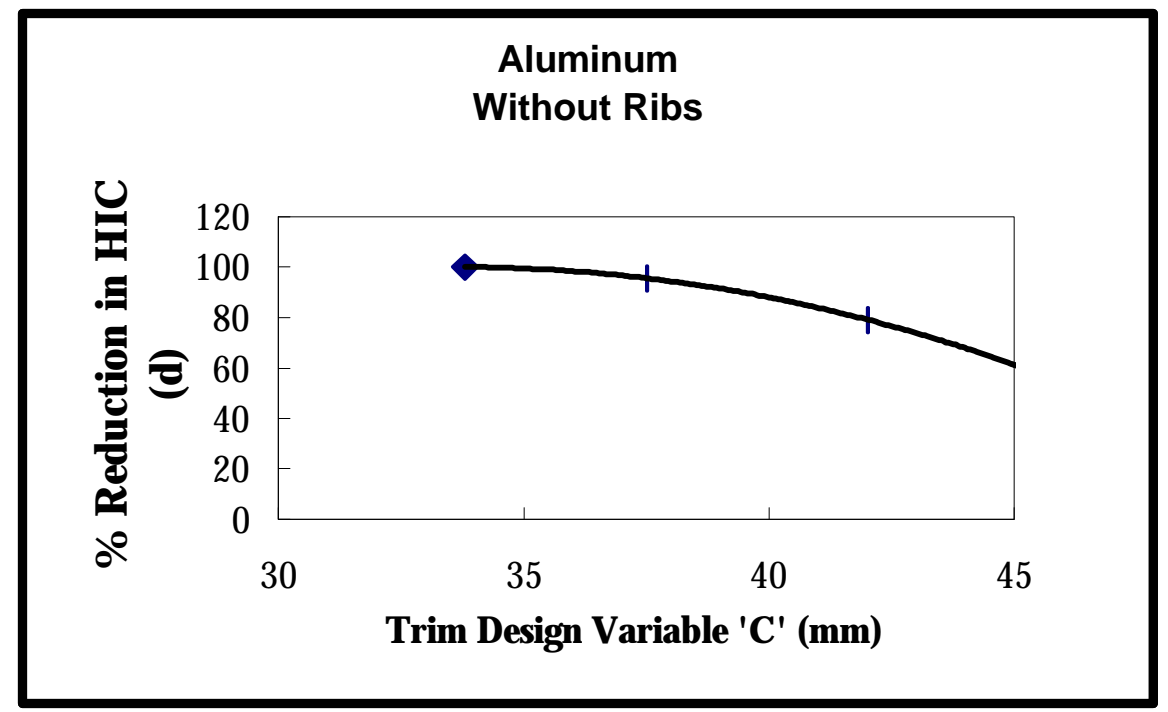

Figure 5.39 Percentage reduction in $\mathrm{HIC}(\mathrm{d})$ vs design variable ' $\mathrm{C}$ ' using aluminum at $30^{\circ}$ horizontal approach angle (without ribs)

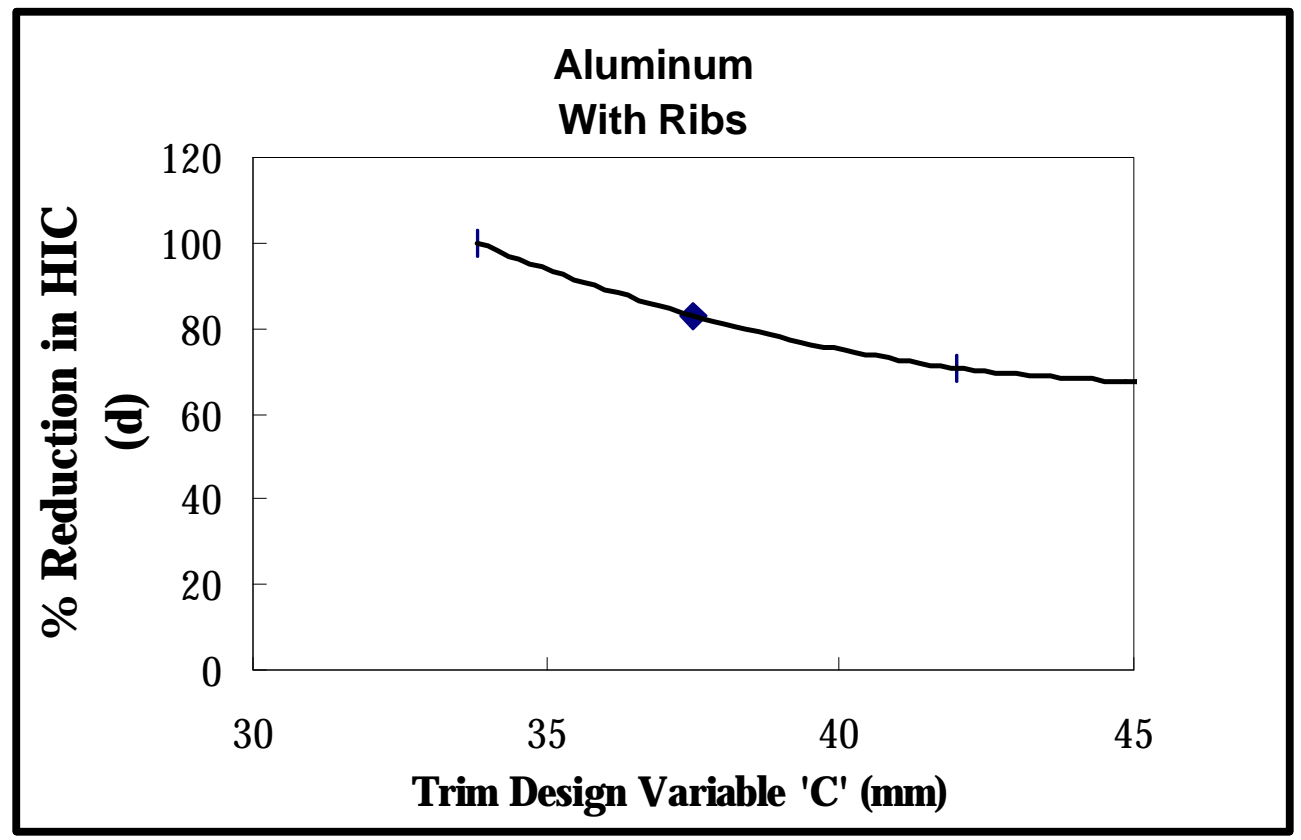

Figure 5.40 Percentage reduction in $\mathrm{HIC}(\mathrm{d})$ vs design variable ' $\mathrm{C}$ ' using aluminum at $30^{\circ}$ horizontal approach angle (without ribs) 


\subsection{DEPENDENCE OF RIB DESIGN VARIABLES ON HIC(d)}

In all the previous analyses, a constant rib thickness of $1 \mathrm{~mm}$ and a constant rib depth of $6 \mathrm{~mm}$ was used to compare the performance of rib as a countermeasure. However, to optimize the rib structure by itself, it was important to study the effects of different rib depths and rib thickness. To study these effects, Trim Design-3 was considered as a basis for the analyses. In this research, three rib thickness of $0.5 \mathrm{~mm}$, $1.0 \mathrm{~mm}$, and $1.5 \mathrm{~mm}$ were studied.

\subsubsection{RIB THICKNESS}

Figure 5.41 shows the $\mathrm{HIC}(\mathrm{d})$ obtained from this three rib thickness for Trim Design-3 at $60^{\circ}$ horizontal approach angle. As it can be seen in the figure, the HIC(d) obtained decreases by increasing the thickness of the ribs. However, at around $1.5 \mathrm{~mm}$, the $\mathrm{HIC}(\mathrm{d})$ seems to reach a plateau indicating no further reduction in $\mathrm{HIC}(\mathrm{d})$.

Figure 5.42 shows the $\mathrm{HIC}(\mathrm{d})$ plotted against the rib depth for a $30^{\circ}$ horizontal approach angle. In this angle of impact, the $\mathrm{HIC}(\mathrm{d})$ decreases initially from $0.5 \mathrm{~mm}$ to $1 \mathrm{~mm}$ and then starts to increase at $1.5 \mathrm{~mm}$ indicating stiffening effect of the ribs. This information would be very useful to prevent over stiffening of the rib structure and to choose the right rib thickness that may result in a reduction in $\mathrm{HIC}(\mathrm{d})$ for any given angle of impact. 


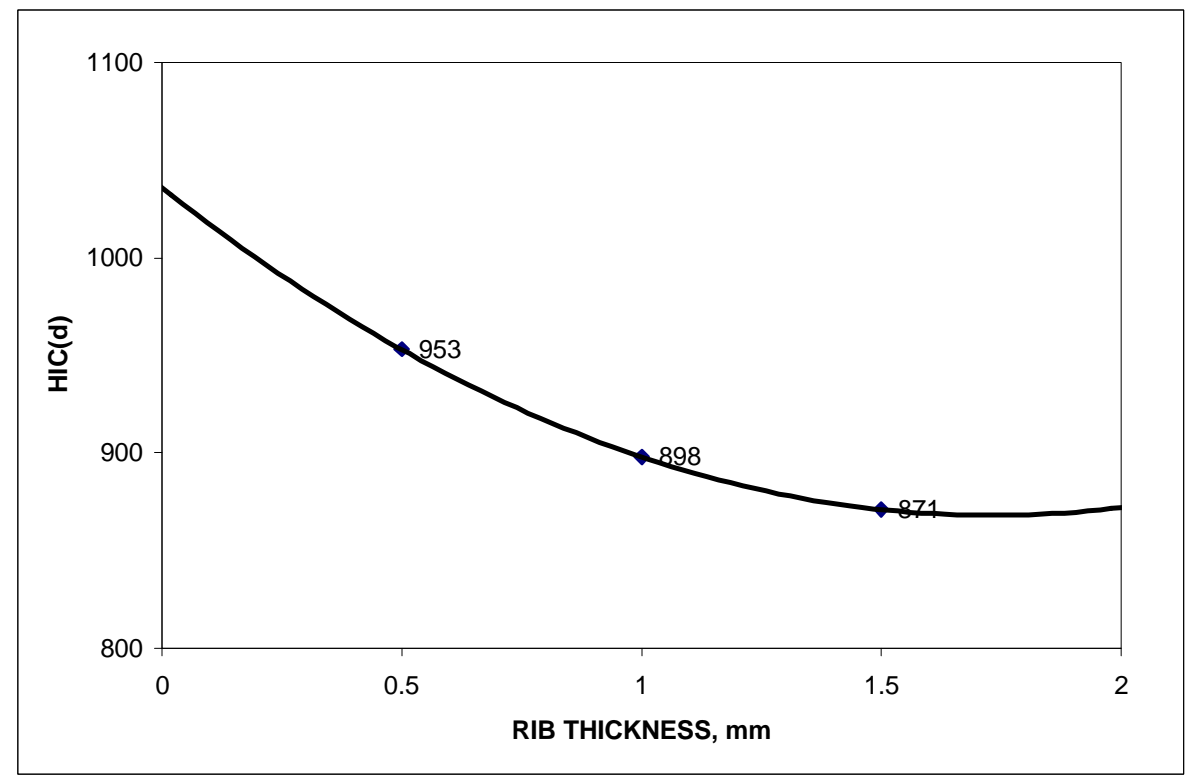

Figure 5.41 Rib thickness vs $\mathrm{HIC}(d)$ for $60^{\circ}$ horizontal approach angle

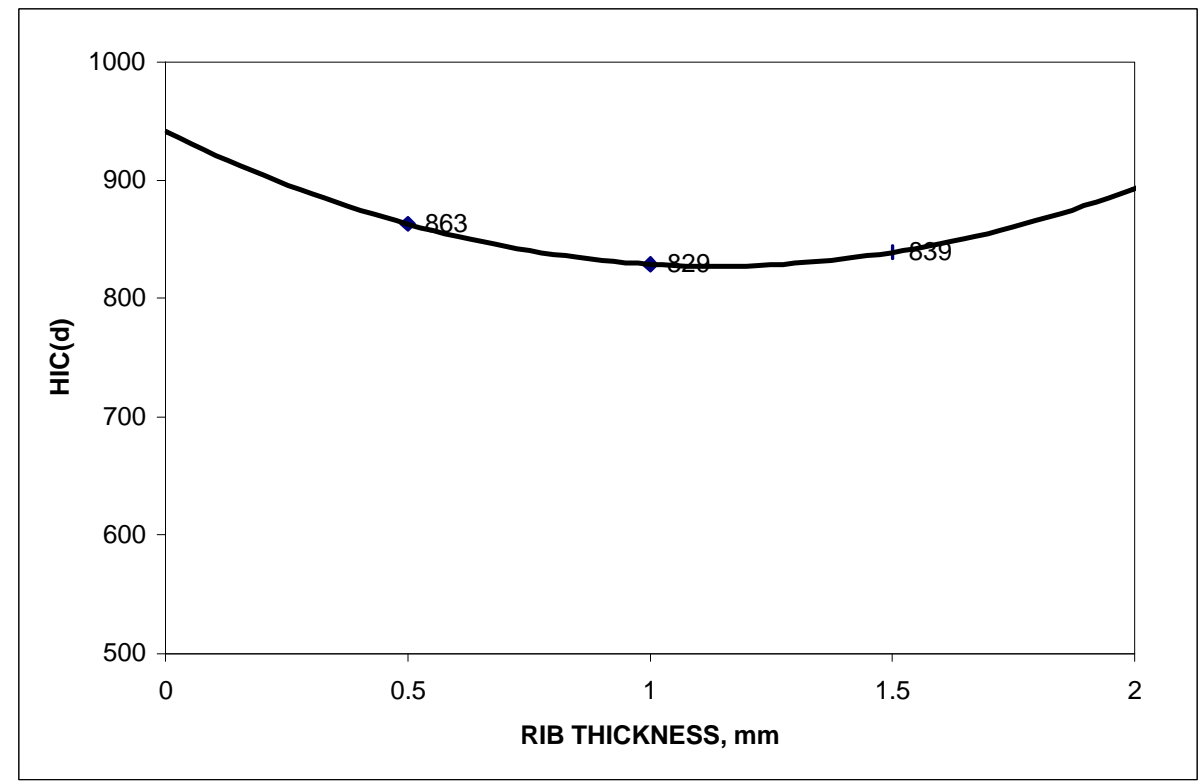

Figure 5.42 Rib thickness vs $\mathrm{HIC}(d)$ for $30^{\circ}$ horizontal approach angle 


\subsubsection{RIB DEPTH}

To determine the effects of rib depth, three depths of $6 \mathrm{~mm}, 9 \mathrm{~mm}$, and $12 \mathrm{~mm}$ were analyzed using Trim Design- 3 at $30^{\circ}$ and $60^{\circ}$ horizontal approach angles using aluminum as BIW material.

Figure 4.43 and Figure 4.44 shows $\mathrm{HIC}(\mathrm{d})$ variation relative to the three rib depths analyzed for both $60^{\circ}$ and $30^{\circ}$ horizontal approach angles respectively. As it can be observed from the figures, for both cases, the HIC(d) decreases with increase in rib depth and reaches a plateau beyond a depth of $12 \mathrm{~mm}$ indication an optimum level. 


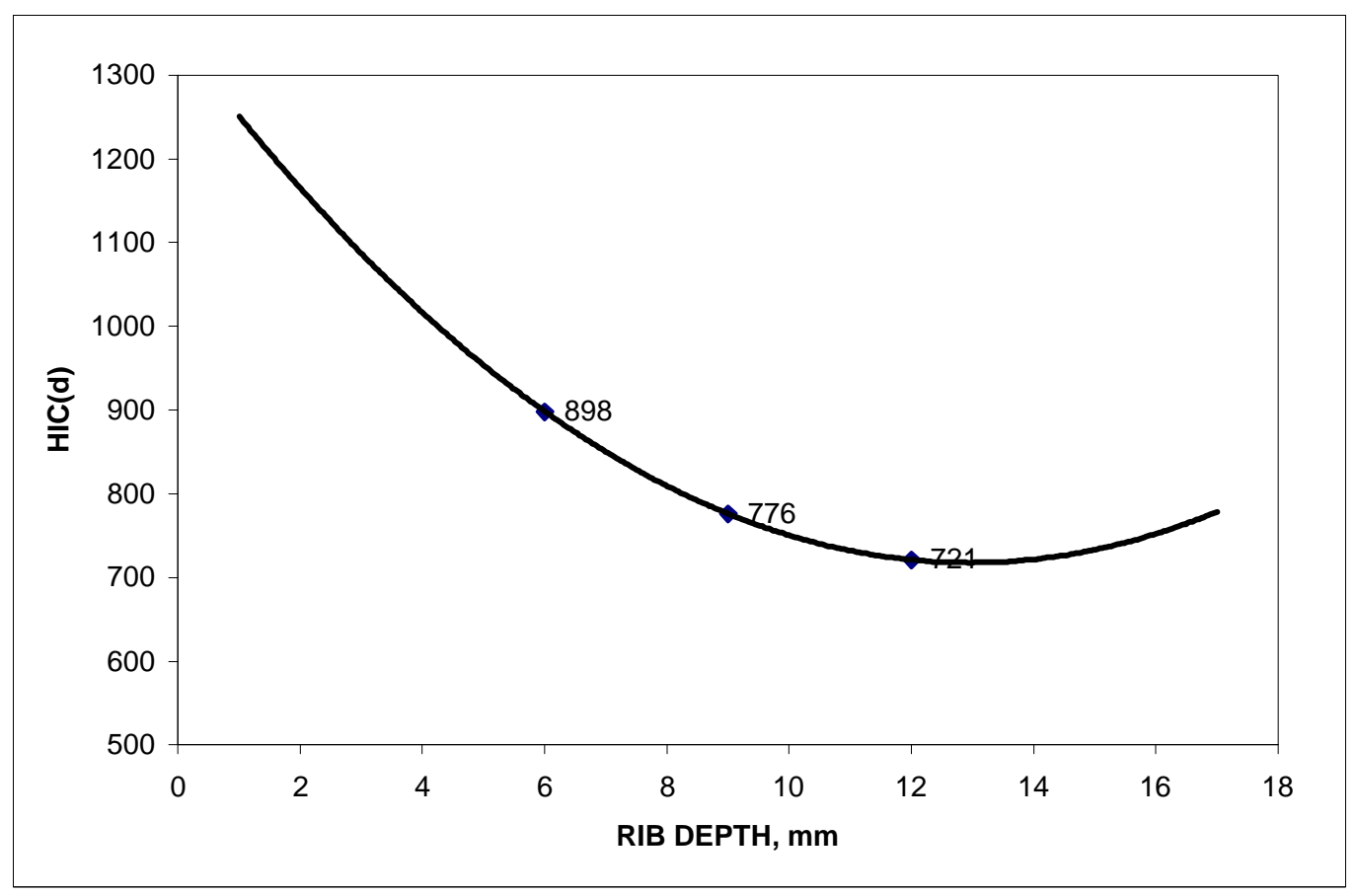

Figure 5.43 Rib depth vs HIC(d) for $60^{\circ}$ horizontal approach angle

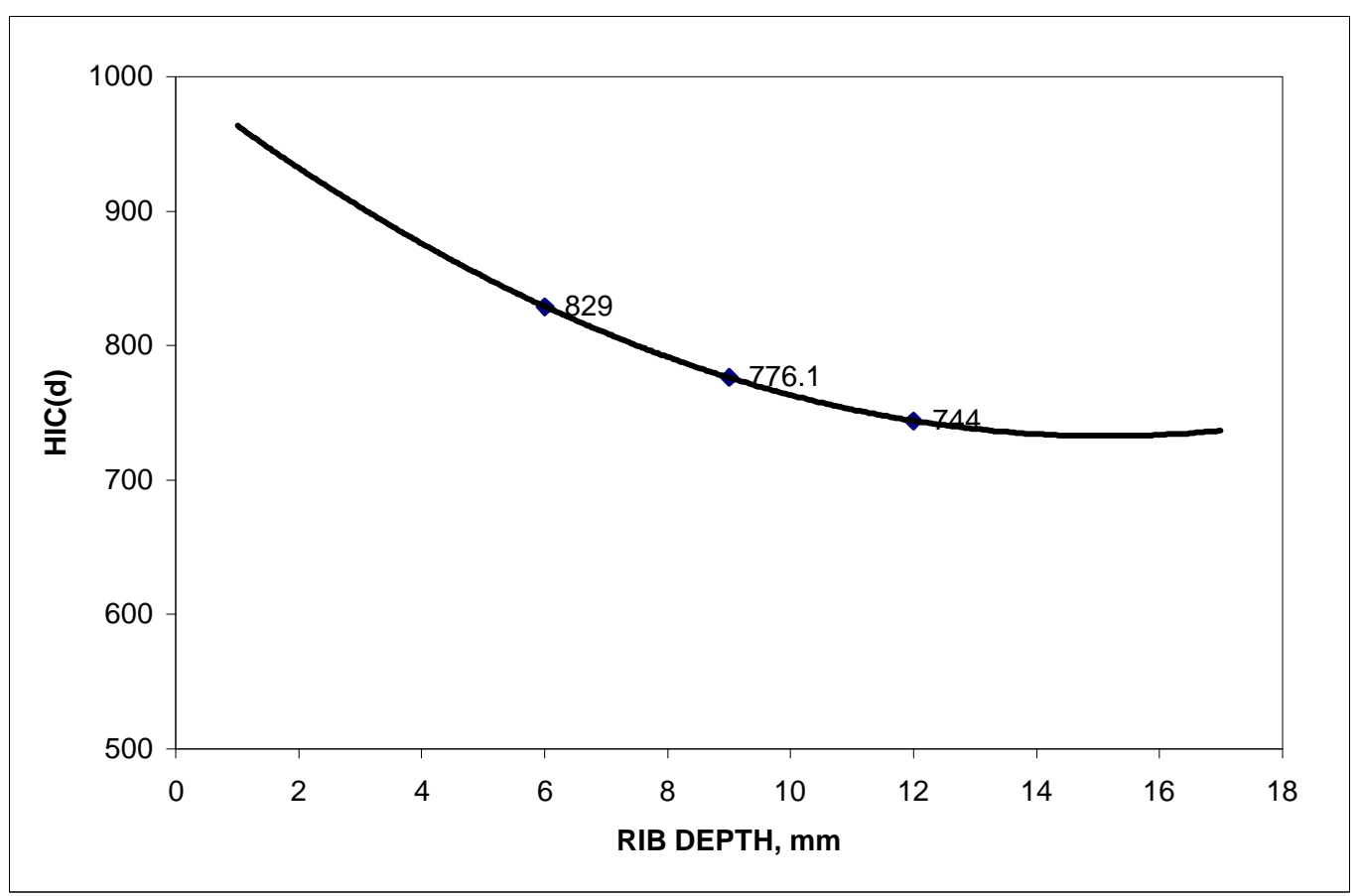

Figure 5.44 Rib depth vs HIC(d) for $30^{\circ}$ horizontal approach angle 


\subsection{MODEL VALIDATION}

In this research, a generic cross-section of an A-Pillar was used to determine the effects of mesh density, contact algorithms and for determining the effects of HIC(d) for various trim designs. Analysis performed on a similar approach for a particular program (name of which cannot be furnished due to proprietary issues), excellent correlation was achieved in acceleration response of the FMH and the HIC(d) was predicted within a tolerance of 5\%. By performing correlation with the physical test data, several contact algorithms, material models, and other parameters were studied that affected the correlation. This was conducted to identify factors that produced good agreement with the experimental data and to use these correlated models to perform design iterations on upper interior components. 


\section{CHAPTER 6 CONCLUSIONS, CONTRIBUTIONS, and FUTURE WORK}

\subsection{CONCLUSIONS}

The following conclusions are drawn from the various finite element analyses performed in this research.

1. Analysis involving different contact algorithms showed a significant dependence of the acceleration response on the type of contact algorithms employed in the simulations. Even though a small change in $\mathrm{HIC}(\mathrm{d})$ was observed between different contact algorithms, there was a considerable difference in the overall acceleration response of the headform. Therefore, choosing the appropriate contact algorithm is found to be very important in performing head impact simulations. In this work, *CONTACT_SURFACE_2_SURFACE proved to be simple and reliable contact algorithm in LSDYNA.

2. Inclusion and exclusion of thickness offsets in contact treatment produced significant difference in the acceleration response for a particular contact algorithm while it produced negligible difference for another contact algorithm. In comparing the time event between the acceleration response and the animation sequence, consideration of thickness offsets in contact algorithms was found to be crucial in achieving the correct acceleration response of FMH.

3. In the comparison involving steel and aluminum as the BIW material, aluminum showed good energy absorbing characteristics for the same A-Pillar cross-section. A 
smoother deceleration history of FMH with reduced HIC(d) was observed in the case of aluminum, which is beneficial. However, the performance of aluminum for a given cross-section needs to be verified for other structural requirements such as side and rollover impact conditions.

4. In analyzing three different trim designs, a greater trim offset was required for steel compared with aluminum as the BIW material.

5. Failure of clips is found to be very crucial in the energy absorbing performance of the trim. In this work, inclusion of failure of clips in the analysis resulted in higher HIC(d) compared to clips that were modeled as a rigid connection. The inclusion of clip failure in finite element modeling is important in predicting the correct energy absorbing capacity.

6. For smaller trim offsets, addition of ribs produced an increase in HIC(d) while for large trim offsets, ribs caused a decrease in $\mathrm{HIC}(\mathrm{d})$.

7. Rib thickness and rib depths for a particular trim can be effectively used to achieve optimum reduction in $\mathrm{HIC}(\mathrm{d})$.

\subsection{CONTRIBUTIONS}

This research has established a direct comparison between steel and aluminum under head impact conditions which is not found in earlier published work relating to aluminum as a possible BIW material to meet head impact requirements. Further, this work establishes a simple and efficient methodology, based on highly nonlinear resultant acceleration response of the free motion headform, that can be applied to provide trim offset recommendations. 


\subsection{FUTURE WORK}

Future work that may be performed to continue the research conducted in this work are listed below:

- Comparison of several types of energy absorbing foams with ribs as a countermeasure.

- Study the effects of adhesive in addition to rivets for the attachment of BIW panels. This can be useful to maintain the structural integrity of aluminum panels for other impact conditions.

- Perform full vehicle analysis and determine the percentage reduction in HIC(d) for different trim offsets to compare with the values obtained in this work.

- Evaluate different trim materials to determine the influence of material properties on $\mathrm{HIC}(\mathrm{d})$.

- Establish similar methodologies for other impact locations on the upper interior components of the vehicle. 


\section{CHAPTER 7 REFERENCES}

1. Arimoto, H., Yasuki, T., Kawamura, K., Kondou, M., A Study on Energy Absorbing Mechanism of Plastic Ribs, SAE Paper Number-982346, 1998.

2. Amori, T. R., Armitage, R. R., Chou, C. C., Lim, G. G., Patel R. N., Shahab S. A., Influence of System Variables on Interior Head Impact Testing, SAE Paper Number-950882, 1995.

3. Bathe, K. J. and Wilson, E. L., Numerical Methods in Finite Element Analysis, Prentice-Hall, 1976.

4. Burton D. E., Physics and Numerics of the TENSOR Code, Lawrence Livermore National Laboratory, Internal Document, UCID-19428, 1982.

5. Chen, W. F. and Han, D. J., Plasticity or Structural Engineers, Springer-Verlag, 1988.

6. Chou, C. C. and Nyquist, G. W., Analytical Studies of the Head Injury Criterion (HIC), SAE Paper Number-740082, 1974.

7. Chou, C. C., Zhao, Y., Lim, G. G., Patel, R. N. , Shahab, S. A., and Patel, P. J. , Comparitive Analysis of Different Energy Absorbing Materials for Interior Head Impact, SAE Paper Number-950332, 1995.

8. Collatz, L., The Numerical Treatment of Differential Equations, 1950.

9. Cook, R. D., Malkus, D S., Plesha, M E., Concepts and Applications of Finite Element Analysis, 1989.

10. Crandall, R.W. and Graham, J. D., The effect of economy standards on automotive safety, The Journal of Law and Economics, 1989. 
11. First Technology Safety Systems (FTSS), Finite Element Model of FMH, 1998.

12. Gadd, C. W., Use of Weighted-Impulse Criterion for Estimating Injury Hazard, Paper 660793-Proceedings of Tenth Stapp Car Crash Conference, P-12, New York: Society of Automotive Engineer, Inc., 1966.

13. Gandhe, G. V., Lorenzo, L, and, Noritake, Y., Design Development of Energy Absorbing Ribs for Meeting FMVSS 201 Extended Head Impact, Dow Chemicals Co., Toyota Motor Corp., SAE Paper Number-970161, 1997.

14. John O. Hallquist, LSDYNA - Users Manual, 1998.

15. Hughes, T. J. R., Taylor, R. L., Sackman, J. L., Curnier, A. C., Kanoknukulchai, W., A Finite Element Method for a Class of Contact-Impact Problems, 1976.

16. Kanianthra, J. N., Upper Head Impact Protection of Occupants in Real World Crashes, 1995.

17. Kenamond, M., Evaluation of Aluminum Hexagonal Honeycomb Structures Under Impact Loading, M. S. Thesis, West Virginia University, 1995.

18. Lim, G. G., Chou, C.C., Patel, R. N., Shahab, S. A., and Patel, P. J., Estimating the Minimum Space to Meet Federal Interior Head Impact Protection, SAE Paper Number-950333, 1995.

19. Lakshminarayan, V., Wang, H., Williams, W. J., Harajli, Y., and Chen, S., Application of CAE Nonlinear Crash Analysis to Aluminum Automotive Crashworthiness Design, SAE Paper Number-951080, 1995.

20. National Highway Traffic Safety Administration, Standard No. 201: Head Impact Protection: Final Rule', 49 CFR, Parts 571, 572 and 589 [Docket No. 92098; Notice 4], RIN 2127-AB85, Federal Motor Vehicle Safety Standards, Department 
of Transportation, 1995.

21. Patrick, L. M., Lissner, H. R., and Gurdjian, E. S., Survival by Design-Head Protection, Proceedings of Seventh Strapp Car Crash Conference, 1963.

22. Sawas, O., Brar, N. S., Dynamic Characterization of Compliant Materials using All Polymeric Split Hopkinson Bar, SAE Paper Number-981138, 1998.

23. Sherman, K. C., Clark, C., Rawson J., Frost, C., Use of High Strain Rate Material Data for Predicting Head Impact Performance of Thermoplastic, SAE Paper Number-950331, 1995.

24. Traugott, T. and Maurer, M., New Ductile, Heat Resistant ABS Resin for Energy Manangement Applications, SAE Paper Number-980969, 1998.

25. Walley, S. M. and Field, J. E., Strain Rate Sensitivity of Polymers, DYMAT Journal, 1, No 3, 211, 1994.

26. Wilkins, M. L., Calculations of Elastic-Plastic Flow, 1964. 